Volume 11, Issue 2 (Summer 2019)

\title{
Rubens's Invention and Evolution: Material Evidence in The Fall of the Phaeton
}

(Republished with additional digital enhancements and text additions, July 2020)

E. Melanie Gifford

m-gifford@nga.gov

Recommended Citation:

E. Melanie Gifford, "Rubens's Invention and Evolution: Material Evidence in The Fall of the Phaeton," Journal of Historians of Netherlandish Art 11:2 (Summer 2019) DOI: 10.5092/ jhna.2019.11.2.1

Available at https://jhna.org/articles/rubens-invention-evolution-fall-of-phaeton/

Published by Historians of Netherlandish Art: https://hnanews.org/

Republication Guidelines: https://jhna.org/republication-guidelines/

Notes: This PDF is provided for reference purposes only and may not contain all the functionality or features of the original, online publication. This PDF provides paragraph numbers as well as page numbers for citation purposes.

ISSN: 1949-9833 


\title{
Rubens's Invention and Evolution: Material Evidence in The Fall of the Phaeton
}

\author{
E. Melanie Gifford
}

An early work by Peter Paul Rubens, The Fall of Phaeton, in the collection of the National Gallery of Art in Washington, $D C$, documents the experimentation that was essential to Rubens's creative process. This article accompanies the reader through direct study of the painting itself, combining a range of technical evidence with formal analysis to pinpoint three distinct stages of the composition: the composition Rubens began during his early years in Italy (Stage 1); his first revisions (Stage 2); and the composition we see today (Stage 3), which reflects the final inventive revisions he made after his return to Antwerp. In tracing Rubens's creative process, the article offers new perspectives on the changing aesthetic goals of his formative years and his extraordinarily fertile mind.

Generous funding by the Samuel H. Kress Foundation supported JHNA's development of enhanced image tools and navigation (click here for the technical project narrative). Clicking on the images in the article identified in the captions by the reference "IIIF multi-mode viewer" allows the user to study The Fall of Phaeton up to a microscopic level using a range of technical images and paint samples. Clicking on any other figure opens the side-by-side viewer, allowing the user to zoom in and compare that image to all the works of art illustrated in the article. Additional grant funding from Association of Research Institutes in Art History (ARIAH) added new functionality to both image viewers. Clicking on detail figures in the article now opens the overall image zoomed in at the corresponding area. Many images also have annotations: hovering over a shaded area will open a window with additional text and/or comparative images.

An additional digital feature, "Exploration and Resources," gives scholars and students direct access to the image tools and technical evidence on The Fall of Phaeton, inviting them to continue researching the painting on their own. With additional guidance on the interpretation of technical information and the use of the image tools, we hope this feature will support classroom use of this article as an example of art historical research that draws on evidence of the artist's techniques. 


\section{Introduction}

1 In 1600, Peter Paul Rubens set out for Italy, where he soon was appointed to the court of Vincenzo Gonzaga, Duke of Mantua. For an ambitious painter not yet twenty-three years old, who had become a master in the Antwerp Guild of Saint Luke just two years earlier, this was a pivotal moment. Over the next eight years Rubens traveled extensively, carrying out commissions not only in Mantua but also in Rome, in Spain (where he traveled as Gonzaga's envoy), and in Genoa. The Fall of Phaeton (fig. 1), in the collection of the National Gallery of Art, ${ }^{1}$ embodies Rubens's restless exploration. He initiated this painting in Italy, but this article will argue that he continued to work on it after his return to Antwerp late in 1608, on receiving news of his mother's final illness. In Italy, Rubens may have painted Phaeton to test the market for smaller-scale mythological works, a complement to the large-scale commissions he secured. But back home in Antwerp, he used the painting itself as a laboratory for experimentation and invention.

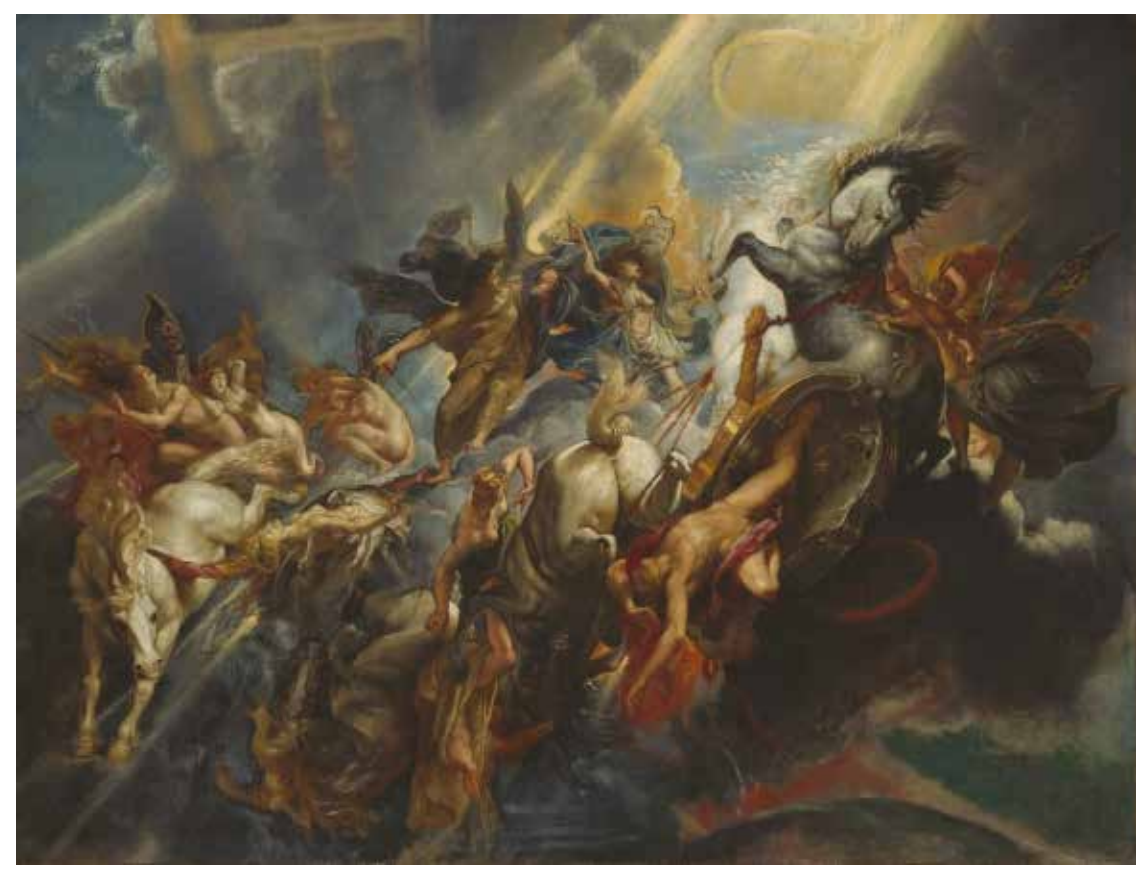

Fig. 1 Peter Paul Rubens, The Fall of Phaeton, begun ca. 1604-1605, completed ca. 16101612 (Stage 3), oil on canvas, $98.4 \times 131.2$ $\mathrm{cm}$. The National Gallery of Art, Washington, DC, photography by Greg Williams (artwork in the public domain) [IIIF curtain and comparison viewer]

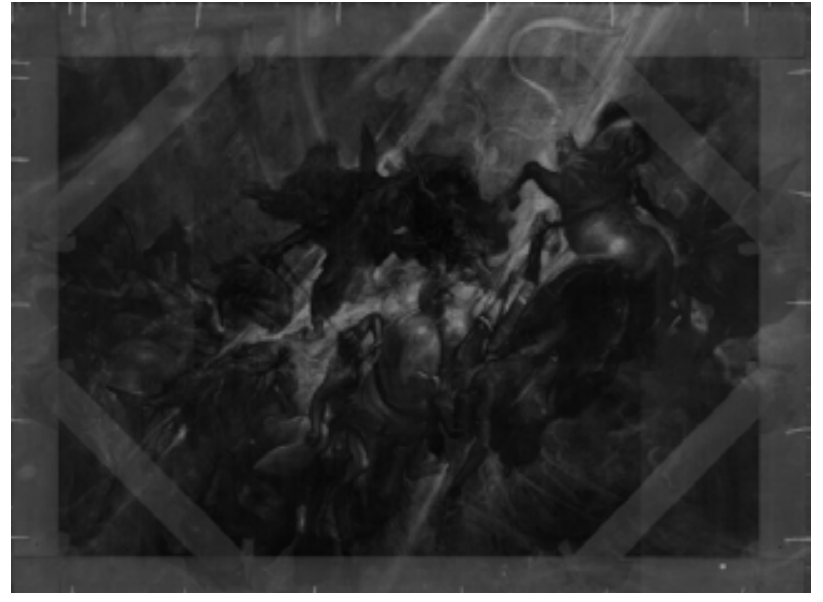

Fig. 1X-radiograph view

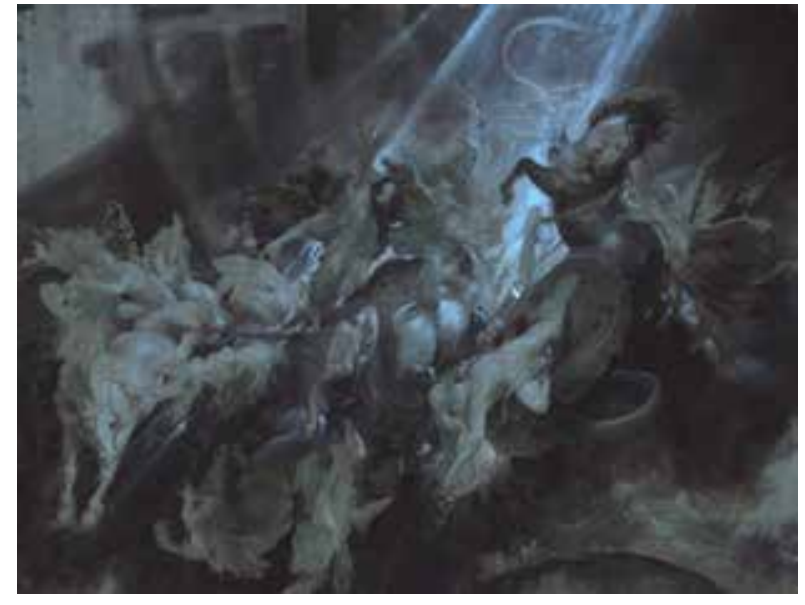

Fig. 1 False-color infrared reflectogram (IRR) view 
The Fall of Phaeton represents the tragic myth of Phaeton recounted by Ovid and other classical writers, ${ }^{2}$ depicting the moment at which the foolhardy youth was cast to his death by Jupiter's thunderbolt. After Phaeton's mother revealed to him that he was the son of Apollo, Apollo agreed (against his better judgment) to allow Phaeton to drive the chariot of the sun across the sky accompanied by the Horae, or Hours-goddesses of time. ${ }^{3}$ The inexperienced driver inevitably lost control, veering from his assigned path along the zodiac and igniting the Earth below. When the Earth beseeched Jupiter's aid, he sacrificed Phaeton, hurling a thunderbolt that destroyed the chariot and sent the youth headlong from the sky. Rubens's image does not show Jupiter himself but instead abstractly evokes both his thunderbolt's force and its impact, depicting a flood of golden light (with just a suggestion of sinuous lightning) as Phaeton falls to his death in a tangle of horses and Horae.

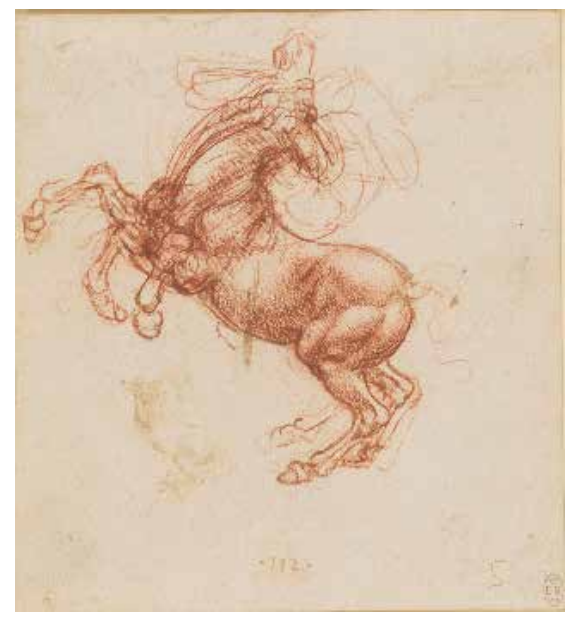

Fig. 2 Leonardo da Vinci, A Rearing Horse, ca. 1503-1504, red chalk, pen, and ink on paper, $15.3 \times 14.2 \mathrm{~cm}$. London, The Royal Collection Trust, RCIN 912336 (artwork in the public domain). Formerly in the collection of Pompeo Leoni [comparison viewer]

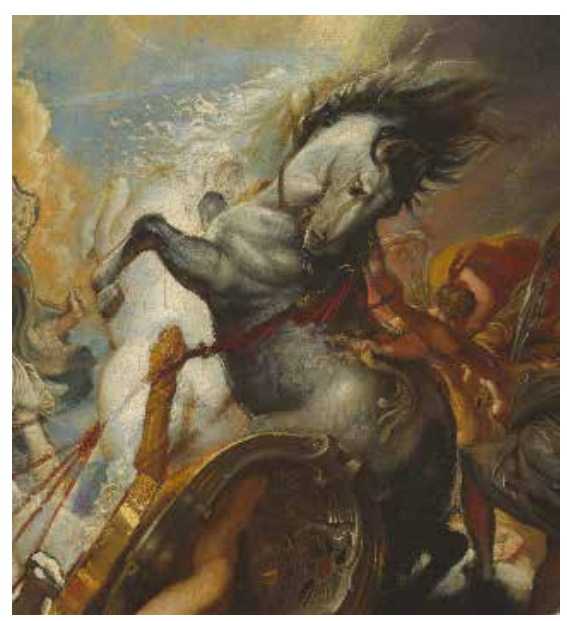

Fig. 3 The Fall of Phaeton, detail of rearing horses [comparison viewer]

On his travels during his years in Italy, Rubens took every opportunity to study works of art, from paintings and drawings by his contemporaries and Renaissance masters to antique sculptures. ${ }^{4}$ Among the many works he studied, Rubens found vigorous, complex compositions particularly compelling. Horses in The Fall of Phaeton reflect his familiarity with the drawings Leonardo had made in preparing the intricate composition of his monumental Battle of Anghiari, studies of battling horses that Rubens pored over in the collection of sculptor Pompeo Leoni in Spain (figs. 2, 3). ${ }^{5}$ Several figures mirror the classical works he studied, including the famous Hellenistic sculpture of the Crouching Venus; he would have been intimately familiar with the version of this work in the Gonzaga collection (figs. 4,5$){ }^{6}$

While based in Mantua he steeped himself in paintings that he saw in nearby Venice, and both The Fall of Phaeton and the large works that he painted for Gonzaga in Mantua, such as the Transfiguration (see fig 21), ${ }^{7}$ reflect the impact of Tintoretto's vivid brushwork and strong colors in works such as The Transportation of the Body of Saint Mark (fig. 6). ${ }^{8}$ 


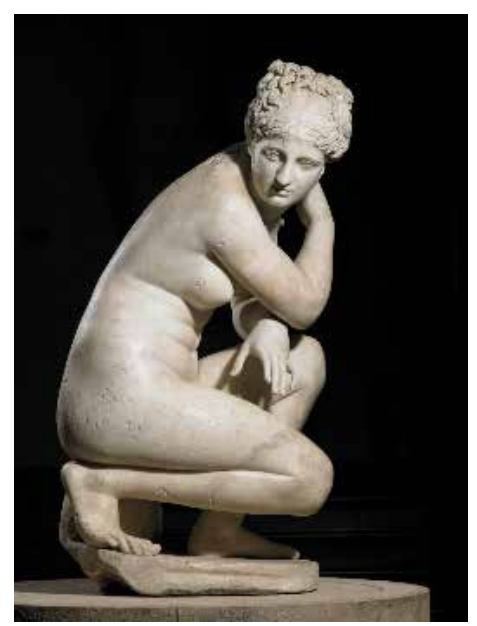

Fig. 4 Roman, Aphrodite or "Crouching Venus," second century AD, marble, 125 $\times 53 \times 65 \mathrm{~cm}$. London, The Royal Collection Trust, RCIN 69746 (artwork in the public domain). Formerly in the Gonzaga Collection, Mantua

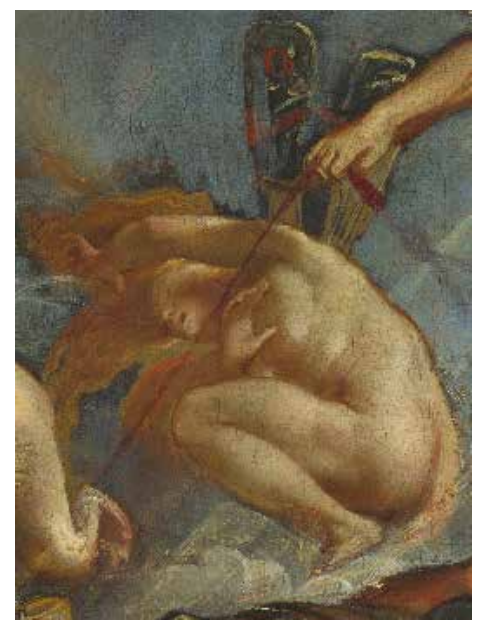

Fig. 5 The Fall of Phaeton, detail of crouching Hora

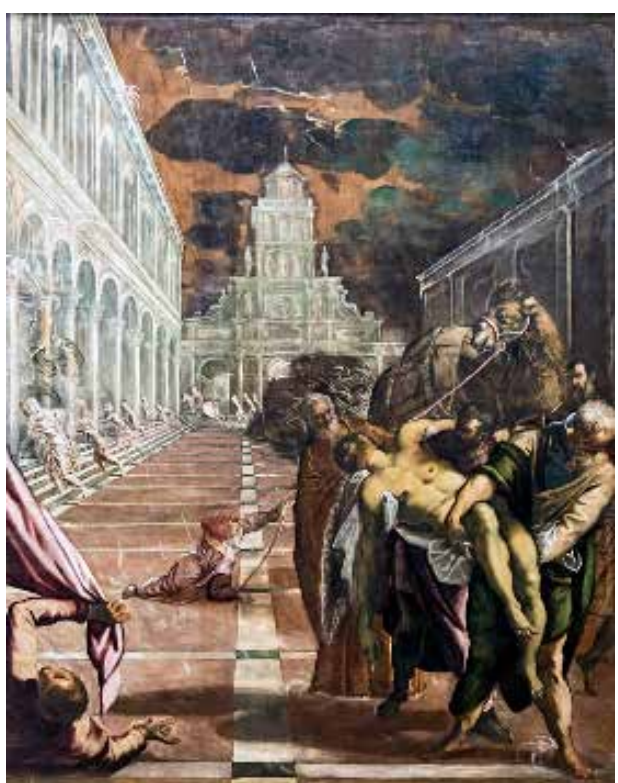

Fig. 6 Jacopo Tintoretto, The Transportation of the Body of Saint Mark, ca. 1562-1566, oil on canvas, $398 \times 315 \mathrm{~cm}$. Galleria dell'Accademia, Venice (artwork in the public domain) [comparison viewer]

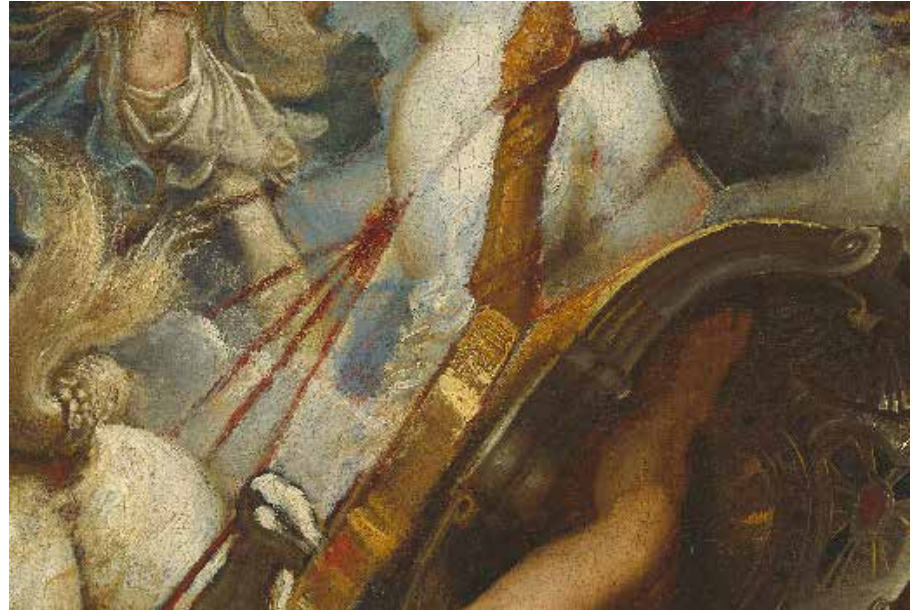

Fig. 7 The Fall of Phaeton, detail showing overpainted reins and traces [comparison viewer]

has since explored how this work reflects Rubens's passionate course of study. ${ }^{9}$ As it now appears, however, The Fall of Phaeton does not reflect Rubens's initial rendering of the scene. Extensive pentimenti, or artist's changes, are readily apparent and hint at his struggle to find a satisfying compositional solution (fig. 7). Scholars have noted that many of the tangled reins and traces from which the horses pull free have been painted over. ${ }^{10}$ Arthur Wheelock, in his catalogue of seventeenth-century Flemish paintings in the collections of the National Gallery of Art in Washington, DC, illustrated an x-radiograph of the painting, documenting the addition of the white horse in the upper right and the removal of a twelfth Hora from the lower right, where only the Hora's foot remains in the x-ray image (fig. 8). He proposed that around 1604 or 1605, Rubens first conceived of the composition as two crossing diagonal elements-the broad beam of light and the curved zodiac, the path of the sun-and that before he returned to Antwerp, he had completed the revisions, emphasizing the diagonal thrust of light and painting the Earth in flames 


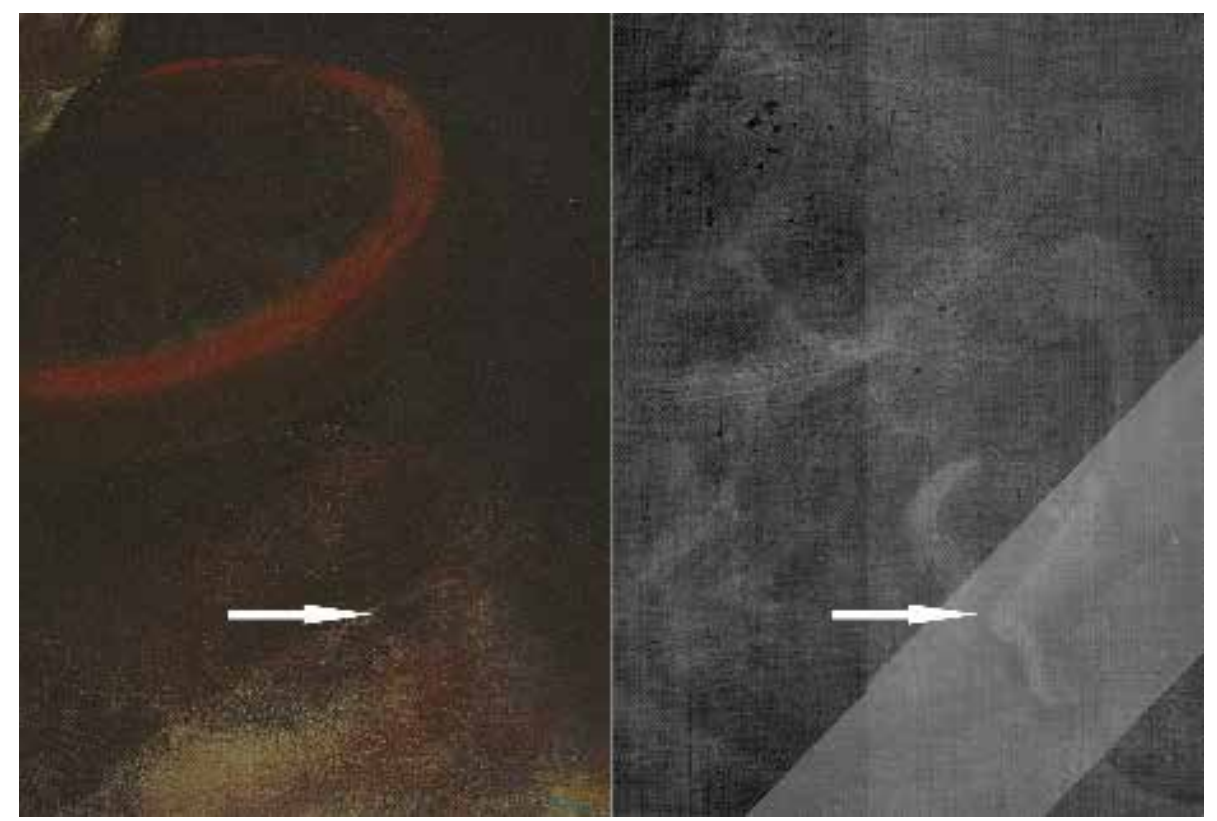

Fig. 8 The Fall of Phaeton, detail of the lower right, in visible light and x-radiograph. An arrow indicates the foot of a Hora that Rubens painted over.

in the lower right in place of the zodiac. ${ }^{11}$ Because projects that Rubens undertook soon after his return (including drawings, oil sketches, and paintings of The Death of Hippolytus and The Conversion of Saint Paul) echo compositional features of The Fall of Phaeton, ${ }^{12}$ and because the painting is probably the one cited in an Antwerp inventory of $1657,{ }^{13}$ scholars have presumed that for unknown reasons Rubens did not sell the completed painting to an Italian buyer but instead brought it with him when he returned to Antwerp, where it inspired his new compositions. ${ }^{14}$

The initial technical study in preparation for Wheelock's 2005 catalogue gave tantalizing hints that the evolution of The Fall of Phaeton was more complex than had previously been recognized. That publication, however, did not offer sufficient scope to explore these complexities. This article expands on the original study with the findings of research that has continued since the publication of the catalogue.

Through the generosity of colleagues, it also has been possible to examine a number of related works by Rubens (along with their available technical documentation) for comparison to The Fall of Phaeton, ${ }^{16}$ including Hero and Leander (c. 1604-1605), ${ }^{17}$ The Death of Hippolytus, ${ }^{18}$ and three versions of The Conversion of Saint Paul (all c. 1610-1612). ${ }^{1}$

This article presents evidence for two sets of revisions to The Fall of Phaeton. Distinct differences between these revisions, both in brushwork and materials, are evidence that Rubens revised his initial composition (which will be referred to as Stage 1) in not one, but two separate campaigns: a first set of revisions (Stage 2) that scholars have until now assumed to be features of the original composition, and a final set of revisions that created the painting we see today (Stage 3). The material evidence suggests that Rubens's original composition was a vivid evocation of the horror of Phaeton's death. Soon after, while still in Italy, he carried out the first revisions, suppressing the more gruesome aspects of the original scene. This evidence suggests that he revised the composition for the last time after his return to Antwerp around 1610-1612. In these final revisions, Rubens used The Fall of Phaeton as a proving ground to test solutions for complex compositions. 
Based on both technical and compositional evidence, this article will argue that as Rubens wrestled with new compositions, such as The Conversion of Saint Paul and The Death of Hippolytus, he did not work in a linear manner, taking inspiration from The Fall of Phaeton well after its completion. Instead, he worked on several of these paintings simultaneously, a practice that was essential to his creative process. It is well known that Rubens often reworked paintings by his students and associates, and he also retouched works in his collection by other artists, bringing an imaginative and expressive perspective that often refocused those paintings and drawings. ${ }^{20}$ This article highlights another context: Rubens transforming his own earlier work. His goal was not to update The Fall of Phaeton for sale but to use it for research as he sought a solution to a specific compositional problem raised by other works.

\section{Overview of the technical evidence}

Before considering the evolution of The Fall of Phaeton, a brief introduction to the types of evidence used to identify each of these stages will be helpful. A range of methods was used to characterize Rubens's handling of paint and the sequence of his compositional changes. The paint surface was examined under high magnification and imaged with $\mathrm{x}$-radiography and false-color infrared reflectography (an adaptation of traditional infrared reflectography, or IRR, that combines images in different wavelengths to highlight material differences). ${ }^{21}$ The paint materials were analyzed in a limited number of minute paint samples (always taken from the edges of existing paint losses) using light microscopy and scanning electron microscopy with energy dispersive spectroscopy (SEM-EDS). ${ }^{22}$ Throughout the examination process, however, close visual examination has also been an essential method of study: informative in its own right and crucial when evaluating Rubens's aesthetic goals in light of varied technical analyses. The results of all these research methods are available to the reader for further investigation by accessing image tools, visible by selecting (clicking) images in this article, as well as in the related article, Exploration and Resources. Clicking on the images in the article identified in the captions by the reference "IIIF multi-mode viewer" allows the user to study The Fall of Phaeton up to a microscopic level using $\mathrm{x}$-radiograph and IRR images and paint cross-section samples. Clicking on any other figure opens the "side-by-side viewer," allowing the user to zoom in and compare that image to all the works of art illustrated in the article.

The primary discussion of this article considers the evolution of The Fall of Phaeton in chronological order, from the original composition through successive revisions. But because technical study begins with close visual examination of the painting's surface, the first approach to a painting necessarily works backward through the artist's process. When studying the painting as it appears today (Stage 3), examination with the naked eye reveals the first evidence of Rubens's thinking: intriguing anomalies in the handling of paint. At the top of the figure group, two Horae are silhouetted against clouds illuminated by golden light (fig. 9) and look in horror beyond the composition's border toward the unseen Jupiter, who is the source of the abstract wash of light that floods from the upper right. In the spaces between their cloaks is a ruddy color that at first glance could be interpreted as the same warm light. Closer looking, however, reveals brushstrokes of brilliant scarlet and yellow that seem different from the golden light. Other methods of technical investigation go below the surface for further clues to Rubens's earlier revisions (Stage 2) and his original composition (Stage 1). 


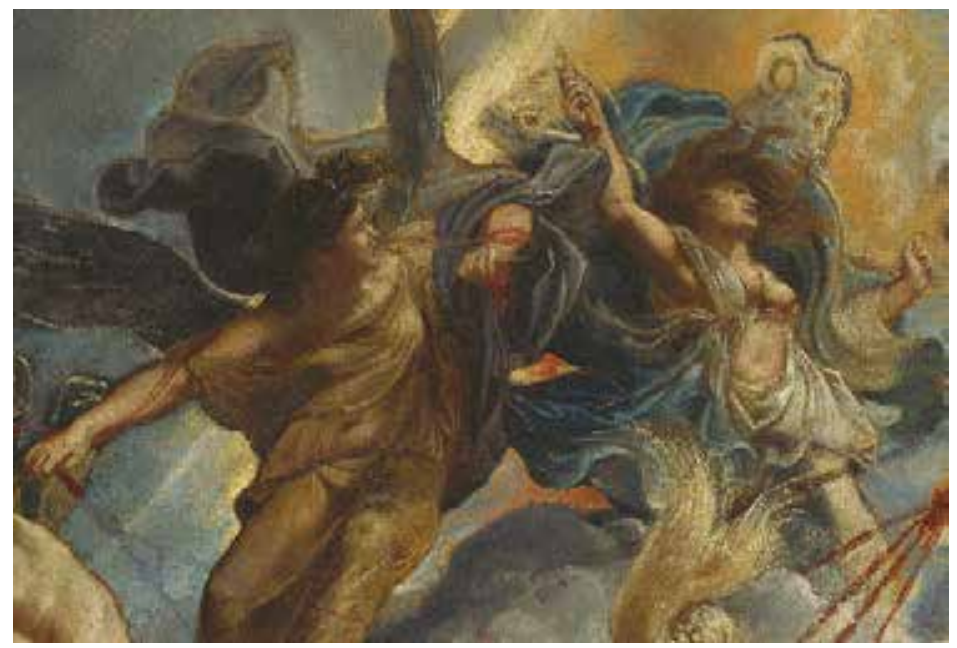

Fig. 9 The Fall of Phaeton, detail of upper Horae. Flickering red and orange brushstrokes between the figures are inconsistent with the golden light behind them.

When we magnify the area between the two Horae (fig. 10a), it becomes clear that some of the red-orange strokes visible on the surface are partially covered by paint depicting warm golden light, and that other traces of red can be glimpsed beneath surface paint corresponding to blue sky and gray clouds. Technical images expand on this evidence (figs. 10a, b, c). Although now largely hidden by the overlying paint layers, the flickering brushwork of these strokes stands out clearly in the $\mathbf{x}$-radiograph because of the density of the pigments used, vermilion and lead-tin yellow. In the false-color IRR the margins around the spaces between the Horae's robes are dark black (an indication of carbon black paint), which suggests Rubens might have depicted a black background behind the red-orange strokes.

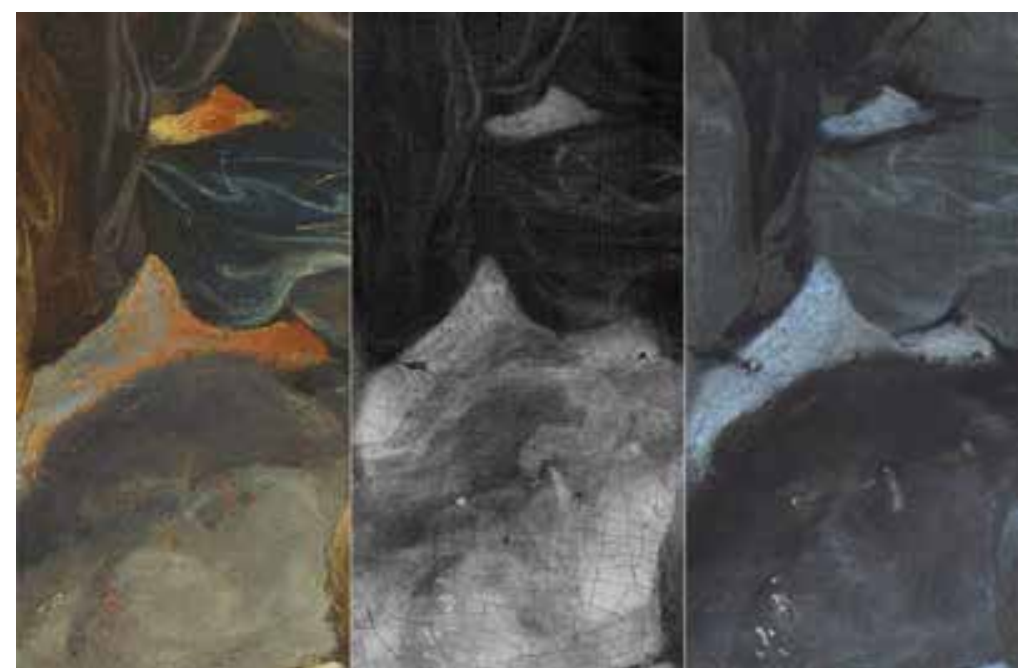

Fig. 10 Left to Right: 10a-The Fall of Phaeton, detail from the center of fig. 9; 10b - X-radiograph of The Fall of Phaeton, the area shown in fig. 10a reveals flickering brushwork below the surface; 10c-False-color infrared reflectogram (IRR) of The Fall of Phaeton, detail of the area shown in fig. 10a reveals black sky hidden by later paint

Finally, a microscopic cross-section sample taken from a paint loss in the blue sky to the left of these Horae (fig. 11) identifies the pigments Rubens selected and the order in which he applied his paints at that exact point, detailed information that can be correlated to the more general 
information in technical images. The sample shows that at this point on the painting, the paleblue paint of the sky hides a thin layer of yellow-white paint (perhaps from a streak of light) and, below that, a thick layer of black paint that may correspond to the black background inferred from the false-color IRR image.

\section{Stage 1: first composition}

13 The previous discussion illustrates the examination process-touching on a few of the observations that can be derived from a range of examination methods-to go progressively deeper into the painting's structure and back in time. Research is never linear, and interpreting technical research on paintings with as complex a history as The Fall of Phaeton is a particular challenge. Nonetheless, when we step back to look over the sum of the evidence gathered, patterns emerge. The process of characterizing the painting's appearance at crucial points in its history, and considering how and why Rubens made specific choices, offers new perspectives on his creative experience and his evolving goals for the painting. The following discussion undertakes to trace the history of The Fall of Phaeton, selecting from all the evidence gathered to date to document the evolution proposed here. Readers who use the tools available in the "Exploration and Resources" feature will almost certainly make new observations.

\section{Painting materials \& structure}

14 The fundamental structure of The Fall of Phaeton - a fine-weave canvas prepared with a single-layer, a yellow-tan ground based on ochre and clay minerals ${ }^{23}$ - shows that in Italy Rubens adjusted his practice to use locally available supplies. In Antwerp, both before and after his time in Italy, he often painted even large paintings on oak panels prepared with a double ground, a structure widely used in the north, typically choosing a mid-toned upper ground. ${ }^{24}$ After his return from Italy he often painted onto a streaky upper ground (or imprimatura). ${ }^{25}$ In Italy at this time, however, canvas was the typical support for easel paintings, and grounds based on earth pigments, like this one, would have been routinely available. ${ }^{26}$ It seems plausible that in both Flanders and Italy Rubens did not prepare his painting supports himself but purchased commercially prepared panels or canvases, choosing a mid-toned ground color that was consistent with his visual aims. ${ }^{27}$

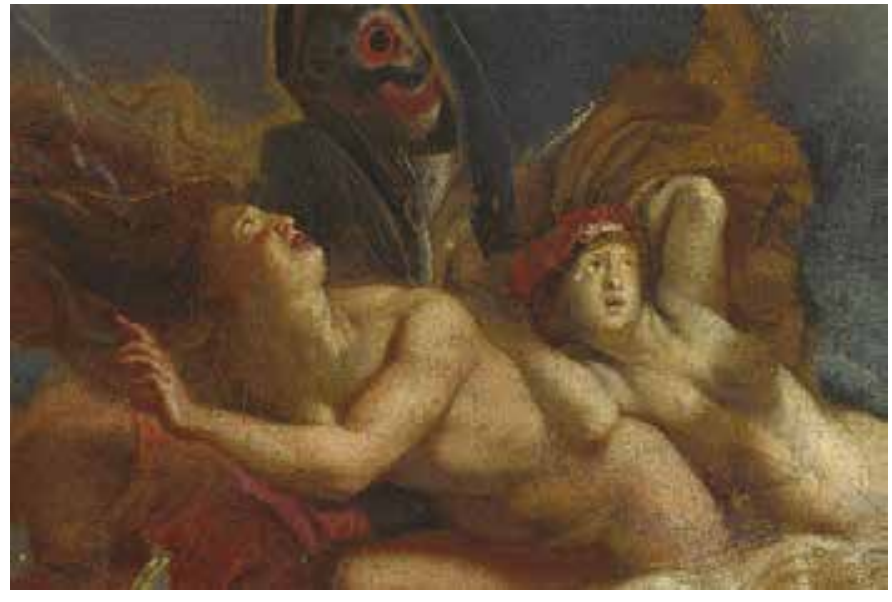

Fig. 12 The Fall of Phaeton, detail of Horae on left ] 
Though he may have adapted to local supplies, Rubens did not abandon his personal painting practices. At this early stage of his career, the visual qualities of the ground and painted sketch were already integral to his aesthetic. His choice of a mid-toned ground, rather than the darker red or orange grounds also common in Italy, was probably deliberate, as he left it visible in many areas (fig. 12). He laid out the design for his composition directly on the ground with a painted sketch, just as he did throughout his career in preparatory oil sketches such as A Lion Hunt of 1614-1615, where this design stage is the dominant image (figs. 13, 14) ${ }^{28}$ He used golden-brown paint to sketch the central mass of figures in The Fall of Phaeton, occasionally reinforced with a few strokes of a blackish sketch paint that he also used to lay out some aspects of the setting (with a few dark lines, for example, he roughly anticipated the placement of streaks of light in the sky). ${ }^{29}$ Following the sketched design with almost no changes, he worked his final paint rapidly and confidently.

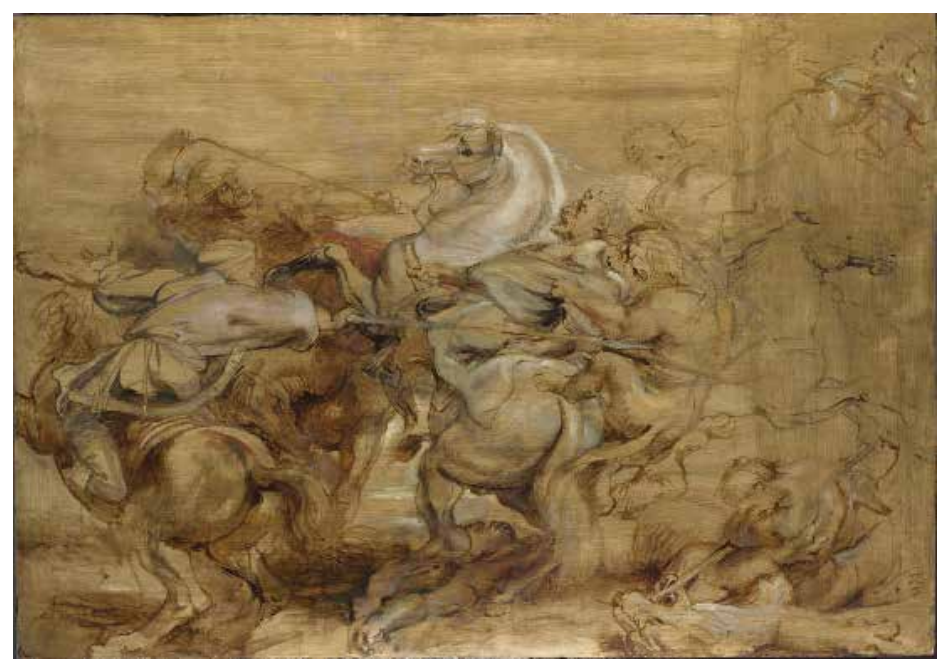

Fig. 13 Peter Paul Rubens, A Lion Hunt, ca. 1614-1615, oil on panel, $73.6 \times 105.4 \mathrm{~cm}$. The National Gallery, London, bought 1871 (artwork in the public domain)

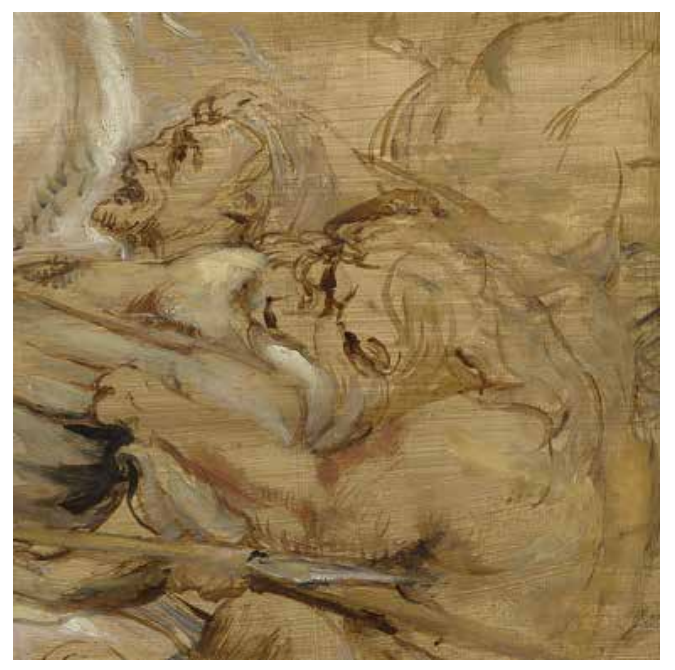

Fig. 14 Rubens, A Lion Hunt, detail of the brown brushwork Rubens used in his oil sketches and to sketch out the preliminary design of his paintings.

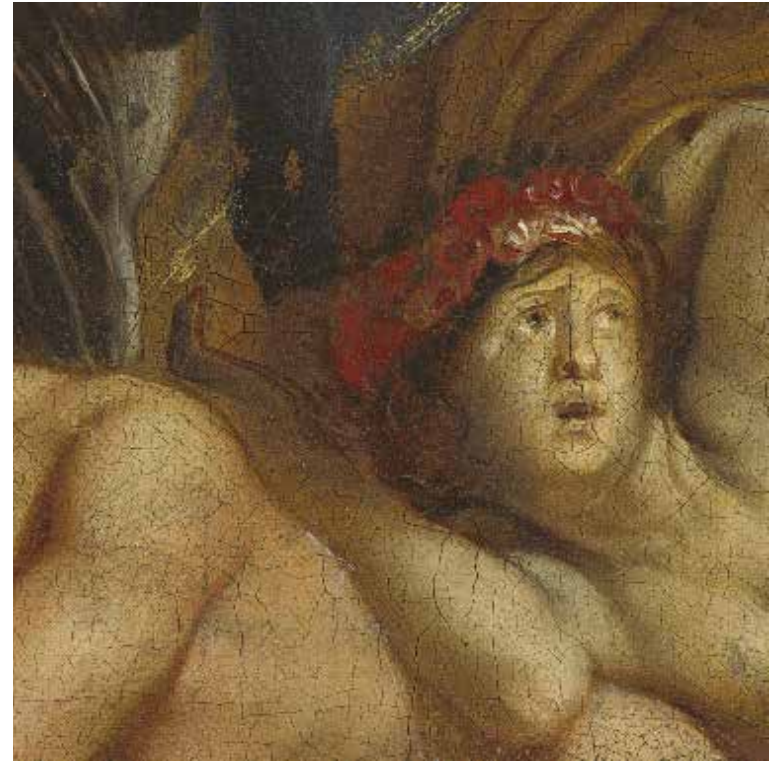

Fig. 15 The Fall of Phaeton, detail. Sketch-like paint creates an unfinished appearance in the hand. 
Throughout much of the composition Rubens allowed both the ground's yellow-tan color and the brown lines of his painted sketch to play a role in his intended image, both in features that he barely suggested and in more finished passages. The ground color serves as a dominant unifying tone, particularly in delicate details such as the flying hair of the Horae or translucent zones in their wings. And Rubens left some lines of his painted sketch uncovered to emphasize contours such as the torso of the rose-garlanded Hora (fig. 15). The visible presence of the painted sketch seems intentional. As he did routinely in his mature works, Rubens sometimes reiterated a contour or a shadow in the final paint layers using a color similar to the sketch. In passages such as this Hora's ochre-colored cloak or apparently unfinished hand, the contrast between the sketchlike quality of this brown paint and the more finished face beside it creates a sense of brilliant, painterly immediacy.

\section{The original composition}

When scholars have situated The Fall of Phaeton within Rubens's career-evaluating how the work of other artists may have impacted him or relating this painting to his other works - the handling of the figures and the formal qualities of the figure group have tended to dominate the discussion. This works well to fix the origin of this painting within the artist's career. The figures seen today are largely unchanged from the original composition that Rubens planned, and they are consistent with his works painted around 1604-1605 (such as the Transfiguration; see fig. 21), after his return from his diplomatic mission in Spain on Gonzaga's behalf. However, the setting in which the narrative takes place has undergone dramatic changes. These changes are particularly telling when considering how the artist's aesthetic concerns evolved through the early years of his career.

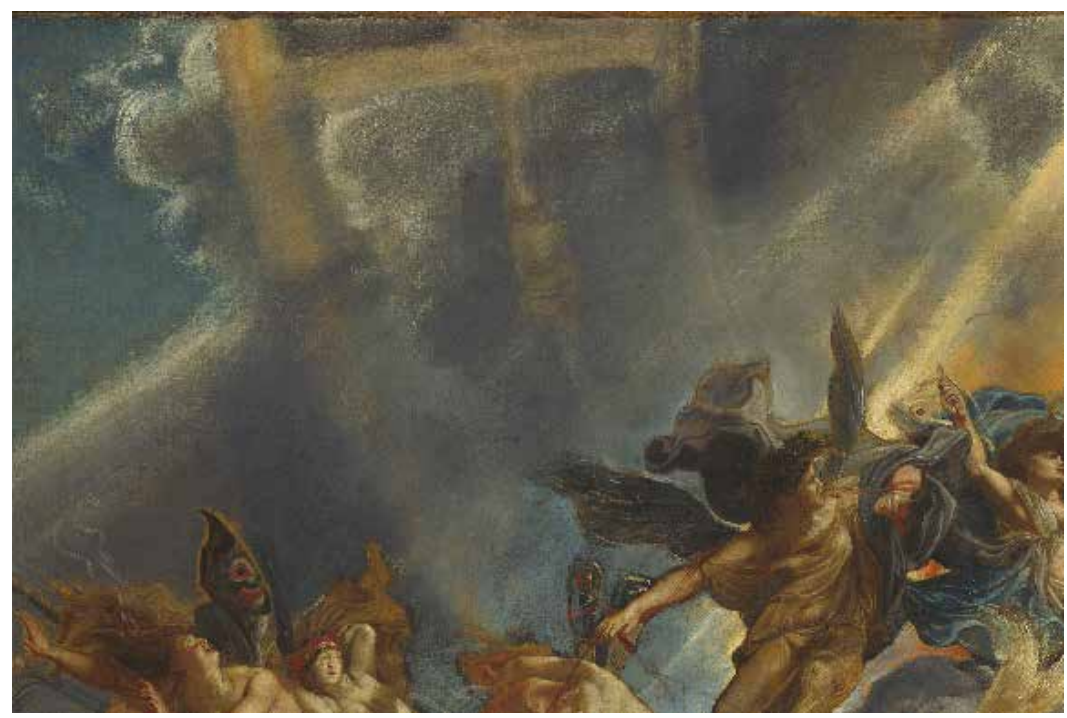

Fig. 16 The Fall of Phaeton, detail of the upper left, showing the original blue sky, white clouds, and tawny zodiac, which Rubens later muted with gray paint.

Technical study reveals that, by comparison with the present composition, in which Jupiter's wrath is expressed abstractly through light, the initial conception for The Fall of Phaeton was a much darker image than we see today. After Rubens laid out the figures with his painted sketch, he filled in the setting around them. In the upper left and lower right quadrants, he painted a pre-dawn sky, creating a concentrated tone with the blue pigment indigo mixed with white lead. ${ }^{30}$ In the opposite orientation - the upper right and lower left-he shaded to gray, loosely brushing 
the paint of the sky just short of the figures. In the space between the blue and gray sections of sky, Rubens painted the tawny-colored zodiac fringed with white clouds, then dragged a few thin streaks of light and a slender whiplash of lightning across the stormy gray. In a detail of the sky (fig. 16), traces of this original setting can still be seen peeking out from under the darker gray paint of subsequent revisions. At the left, the deep-blue sky painted with indigo is largely original, as are the white clouds and tawny zodiac where they show as bright fringes behind the later gray paint. One of the original, narrow rays of light still glimmers through smudges of gray.

In the figure group, however, surviving evidence of the original context is far more fleeting. The glimpse of red-and-orange flickering brushwork between the two Horae at the top of the group described above (see fig. 9) is the most obvious example of a detail that Rubens overlooked in concealing his original conception. Michael Jaffé rightly recognized these strokes as fire but suggested that only the Hora's cloak had burst into flames. ${ }^{31}$ However, deeper examination reveals evidence of flames throughout the figure group. As the eye becomes attuned, evidence emerges that Rubens's first composition was a horrifying conflagration. A closer look at the crouching Hora at the left shows evidence that flames originally swept up around her arm and reflected off her cheeks and blond hair (see fig. 5). In the upper right, flames are just visible in a narrow gap between the gray horse and the Horae who struggle to restrain it, but the secondary effects depicted are equally striking (fig. 17). The devastating force of the impact is implicit in the plume of smoke that streams away to the upper right, and the red glow of the fire reflects off that smoke and the underside of one Hora's ochre-colored cloak.

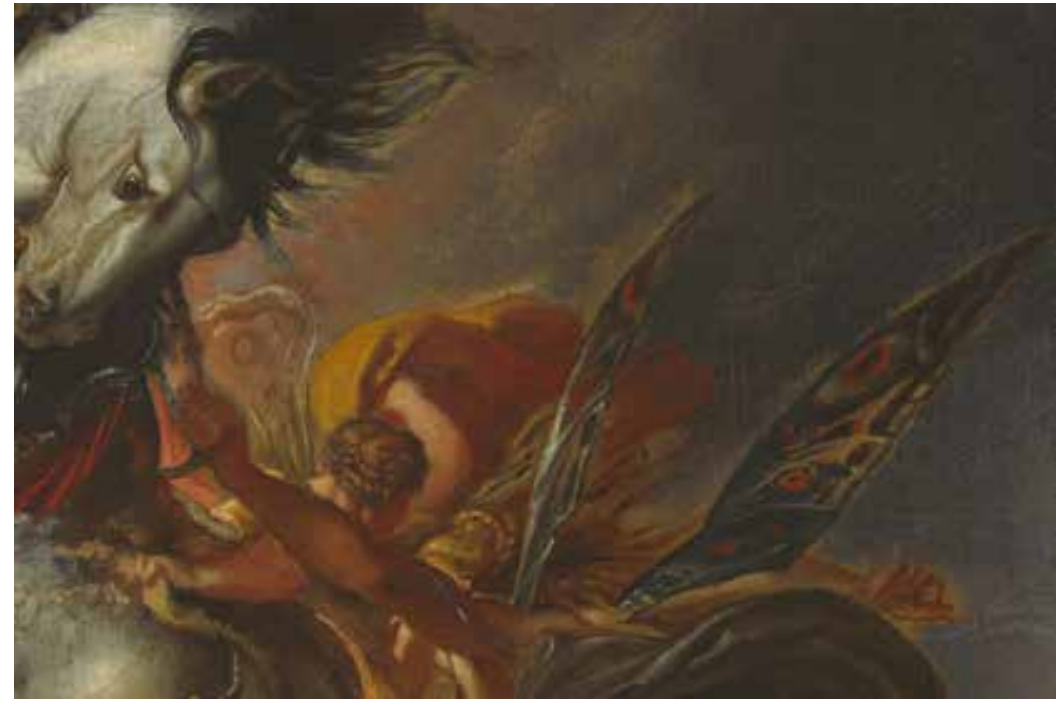

Fig. 17 The Fall of Phaeton, detail at the upper right, showing elements of Rubens's original composition (Stage 1): Horae and smoke illuminated by fire

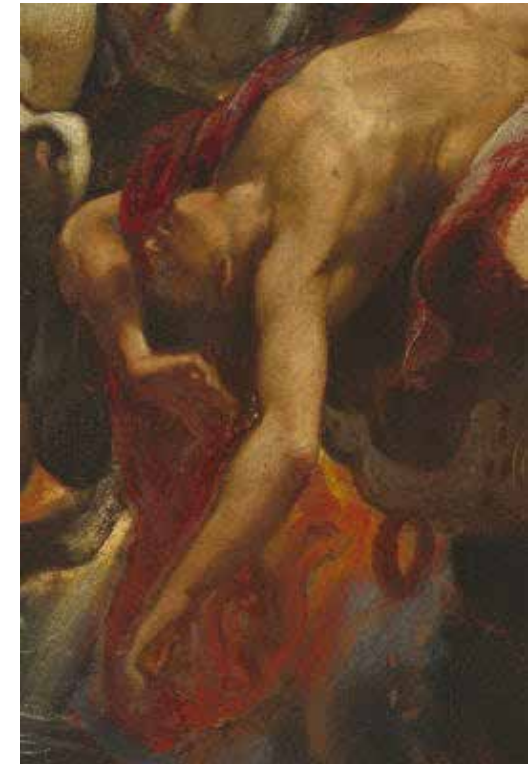

Fig. 18 The Fall of Phaeton, detail. Rubens transformed the flames behind Phaeton (Stage 1) into a red cloak.

20 Close looking also reveals that a form that seems simply to be Phaeton's red cloak below his falling body resolves into two parts, painted in two different red pigments: on the left, the crimson-toned red lake that Rubens used to depict the rest of the cloak; on the right, flickering strokes painted with the scarlet-red pigment vermilion (fig. 18). In the original composition, with flames widespread among the figures, it would have been clear that Phaeton's cloak itself was in flames. 
Later, Rubens relied on the viewer's eye, without that context, to perceive simply a red cloak. Throughout the figure group, when no signs of fire are present, there is evidence that the original background was virtually black, as the IRR described above suggests (see fig. 10c). This background is often still visible along the contours, where later paint left a narrow gap; the contrast would have made the flames even more vivid.

The Fall of Phaeton shows the impact of Tintoretto's light effects in these years. ${ }^{32}$ The central contrast of flames against a black background would have recalled the Venetian artist's rich colors seen against the dark brown - or even black - grounds he sometimes used on his canvases. ${ }^{33}$ The ragged brushwork Rubens used for the rays of light in this first version of The Fall of Phaeton is reminiscent of the drybrush handling of Tintoretto's rays and lightning seen against a dark sky in The Transportation of the Body of Saint Mark (see fig. 6). ${ }^{34}$ Such skipping lines of white paint are a signature of Tintoretto's paintings; he used them both for preliminary underdrawing and to sketch out further details, such as the ephemeral running figures in that work. ${ }^{35}$ Even in the years after he returned from Italy, as Rubens developed a more creamy, blended paint handling, he continued to use Tintoretto's vocabulary of nervous white lines in oil sketches such as All Saints (c. 1613-1614; figs. 19, 20). ${ }^{36}$

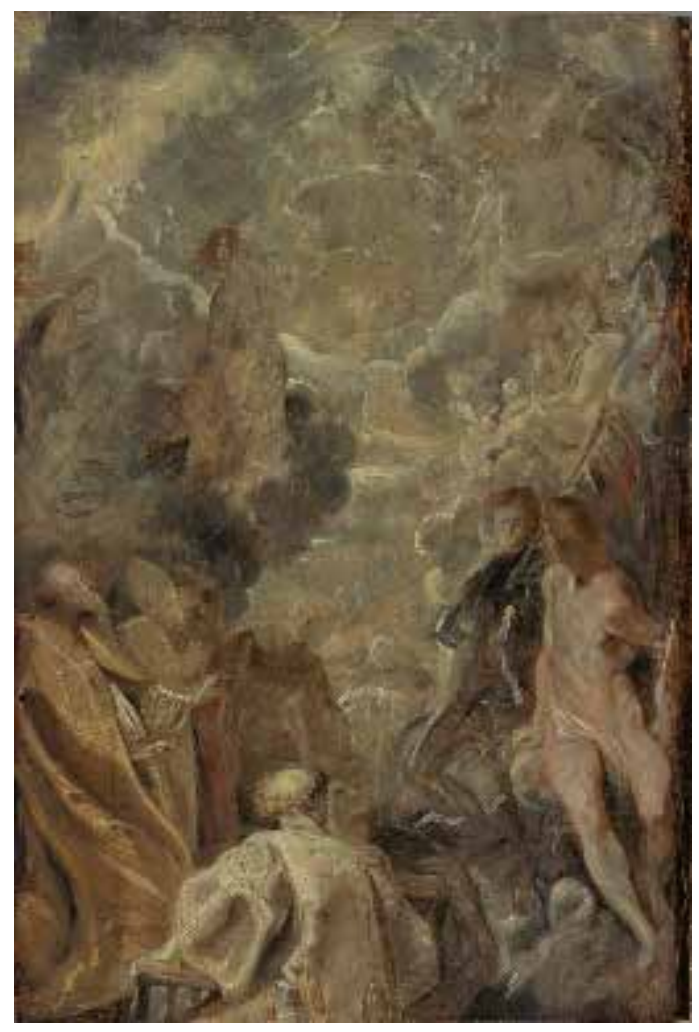

Fig. 19 Peter Paul Rubens, All Saints, ca. 1614, oil sketch on panel, $38 \times 58 \mathrm{~cm}$. Rotterdam, Boijmans van Beuningen Museum, Schenking / Donation: A. J. Lamme 1863, Studio Tromp, Rotterdam (artwork in the public domain) [comparison viewer]

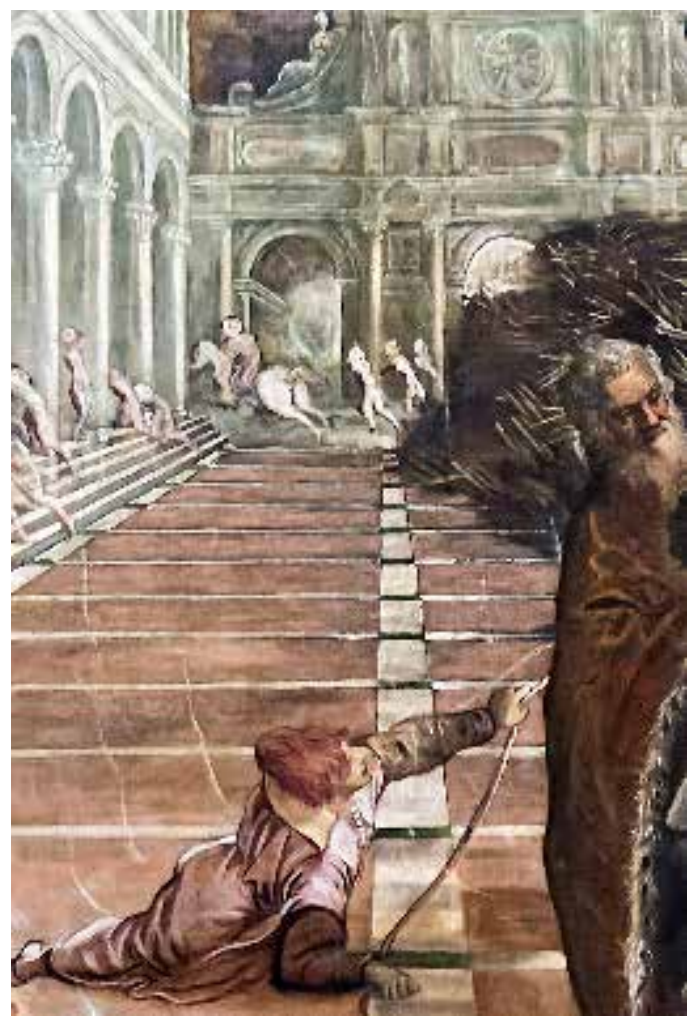

Fig. 20 Tintoretto, The Transportation of the Body of Saint Mark, detail of figures in fig. 6 [comparison viewer]

The physical evidence suggests that Rubens's composition was a truly horrific representation of the impact of Jupiter's lightning bolt. That image was more faithful to the classical texts than the 
painting we now see. In Ovid's telling, Phaeton fell from the heavens with flaming hair, ${ }^{37}$ and Rubens evoked this brutal image: Phaeton's cloak on fire and flames licking naked bodies, with the trajectory of their collective fall traced by the plume of ruddy smoke. That original composition also must have shared the vivid emotion and dramatic light effects that Rubens brought to the Gonzaga commissions of 1604-1605, such as the Transfiguration (fig. 21). As in that painting, Rubens represented divine light with just narrow rays, yet the figures are harshly illuminated by that light.

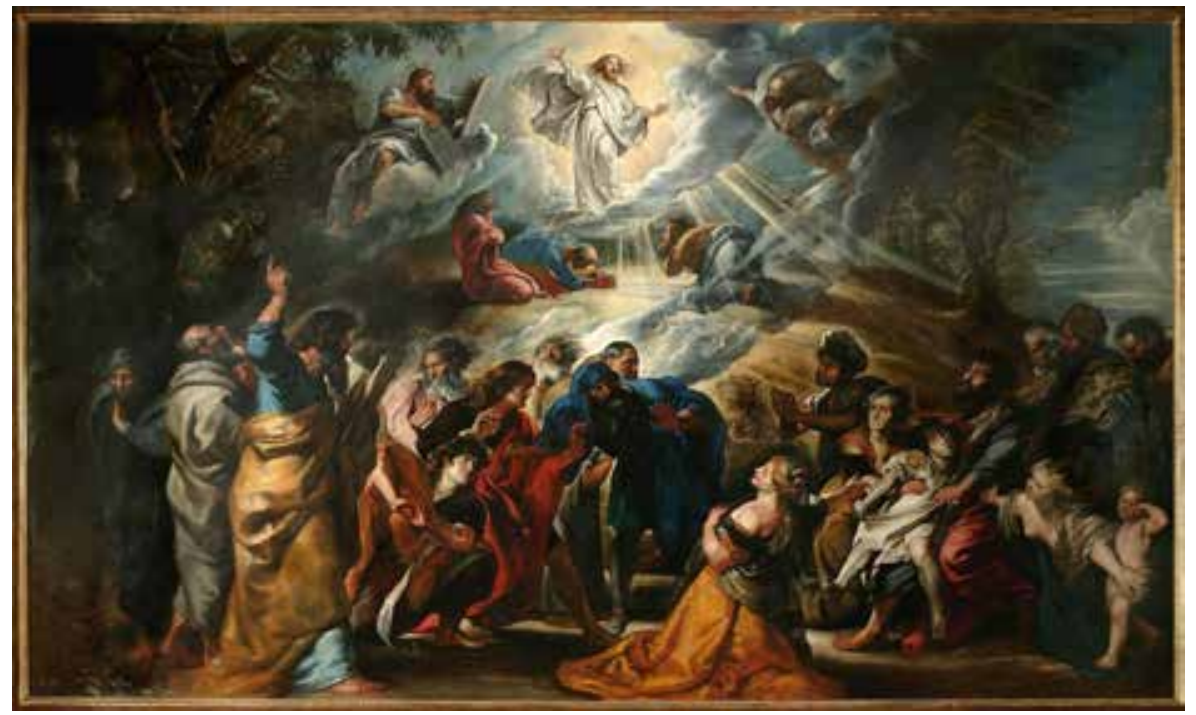

Fig. 21 Peter Paul Rubens, The Transfiguration, ca. 1604-1606, oil on canvas, 407 x 670 cm. Musée des Beaux-Arts de Nancy, Cliché P. Mignon, Inv. 71 (artwork in the public domain) [comparison viewer]

\section{Hero and Leander}

This evidence for the original appearance of The Fall of Phaeton sheds new light on another work with a classical theme that Rubens painted around 1605. Hero and Leander (Yale University Art Gallery) also depicts a tragic protagonist accompanied by nude, semi-divine companions: Nereids (water nymphs) accompany the body of Leander, who drowned while crossing the stormy Hellespont to reach his beloved Hero, in much the same way that Phaeton's companions, the Horae, accompany him on his fateful passage along the zodiac (figs. 22, 23).

24 In addition to the thematic parallels, striking material parallels between Hero and Leander and The Fall of Phaeton suggest that he undertook the two works within a short time, while he had access to the same supplies. Although he did not buy the two canvases as a pair-they did not come from the same bolt of fabric, and Leander is more coarsely woven ${ }^{38}$-he did choose similar grounds: both canvases were prepared with a single-layer ground in a dark yellow-tan. ${ }^{39}$ In both paintings, his paints include a white lead pigment whose largest particles have a distinctive, slightly translucent appearance. For both skies (as well as the sea in Hero and Leander) he seems to have used the dark-blue indigo, rather than the brighter blue pigments (ultramarine or smalt) that he used routinely after his return to Antwerp. ${ }^{40}$

25 The material similarities make it plausible that the two works originated in the same studio. 


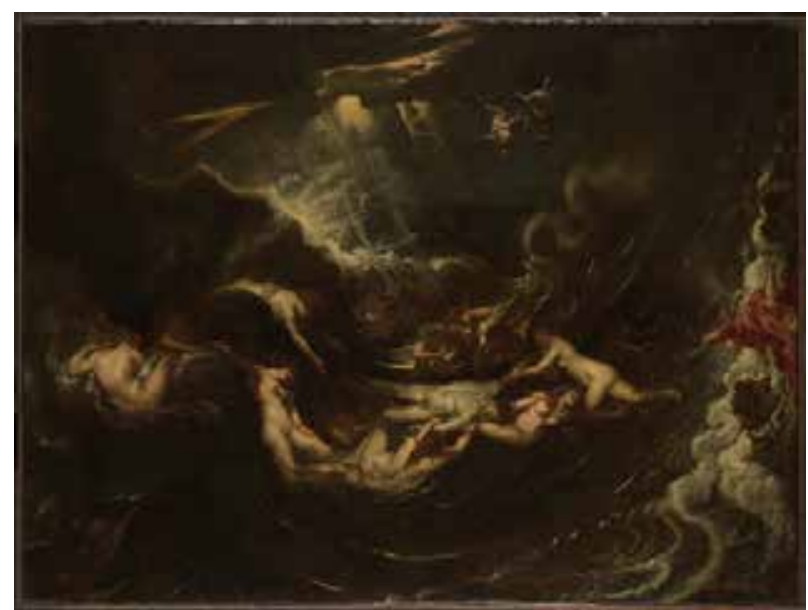

Fig. 22 Peter Paul Rubens, Hero and Leander, ca. 1605, oil on canvas, 95.9 x $128 \mathrm{~cm}$. New Haven, CT, Yale University Art Gallery (artwork in the public domain) [comparison viewer]

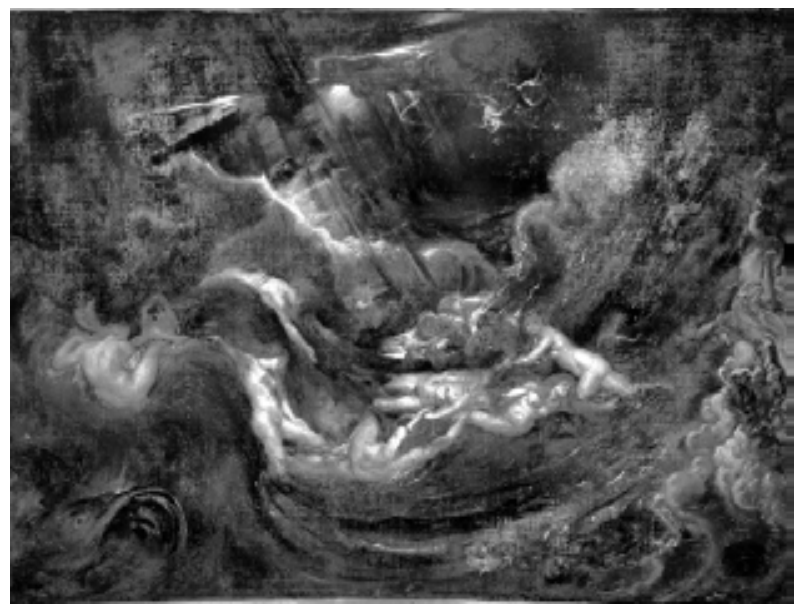

Fig. 24 Infrared reflectogram of Peter Paul Rubens, Hero and Leander (captured by Kelsey Wingel) [comparison viewer]

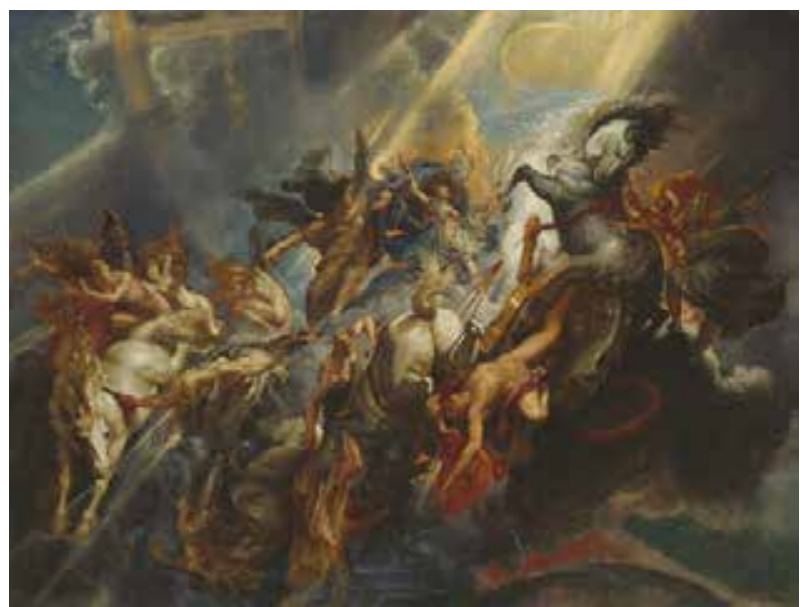

Fig. 23 The Fall of Phaeton as it appears today (Stage 3). The bright, clear colors are not consistent with the dark tonality of Hero and Leander. [comparison viewer]

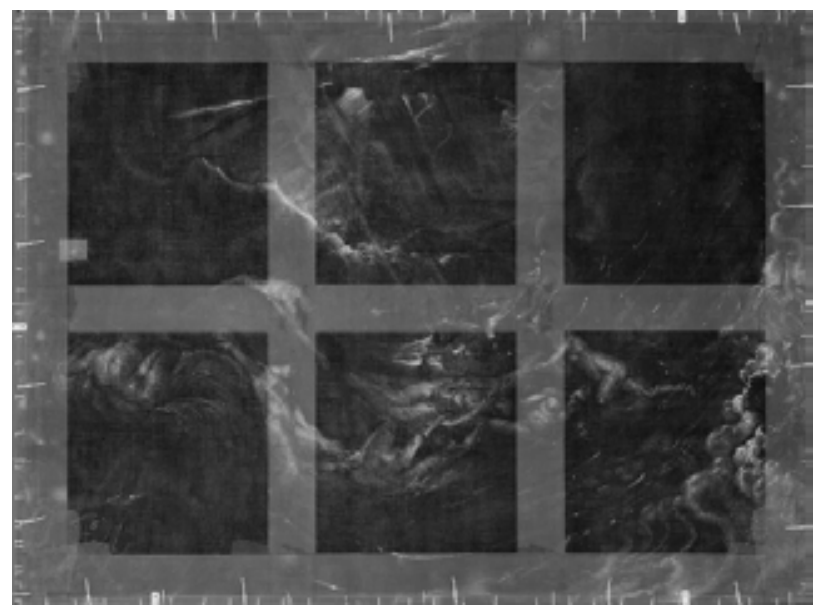

Fig. $25 \mathrm{X}$-radiograph of Peter Paul Rubens, Hero and Leander [comparison viewer]

Moreover, the painting sequence and the handling of paint revealed in IRR and x-radiography (figs. 24, 25) and surface examination-personal features that can reflect an artist's individual working habits - are also remarkably similar in these paintings. In both paintings, Rubens laid out the composition in the same way: first sketching the figure group with brownish paint and then selectively reinforcing some forms with lines of blackish paint. He also used this blackish paint to sketch selected details of the setting; in both skies, straight lines visible in IRR that anticipate rays of light underscore the importance he gave this compositional feature. ${ }^{41}$

In both works, Rubens painted the nudes (figs. 26, 27) by laying in a grayish underlying flesh tone that serves as cool shadow in contrast to warmer highlights. In both, he sometimes emphasized rounded forms with ruddy final contours. More often, he left a gap between figure and setting, revealing lower layers - the painted sketch or the ground itself-to serve as warm, brownish contours; in both $\mathrm{x}$-radiographs these characteristic gaps appear as dark halos outlining the forms 
(figs. 28, 29). When depicting the settings, Rubens brushed the paint of the sky and sea with a rapid, streaky touch that allowed the yellow-tan ground to glimmer through. In each sky, he brushed lightning with quick impasto streaks, his paint strokes weaving strands of almost unmixed white lead, lead-tin yellow, and ochre.

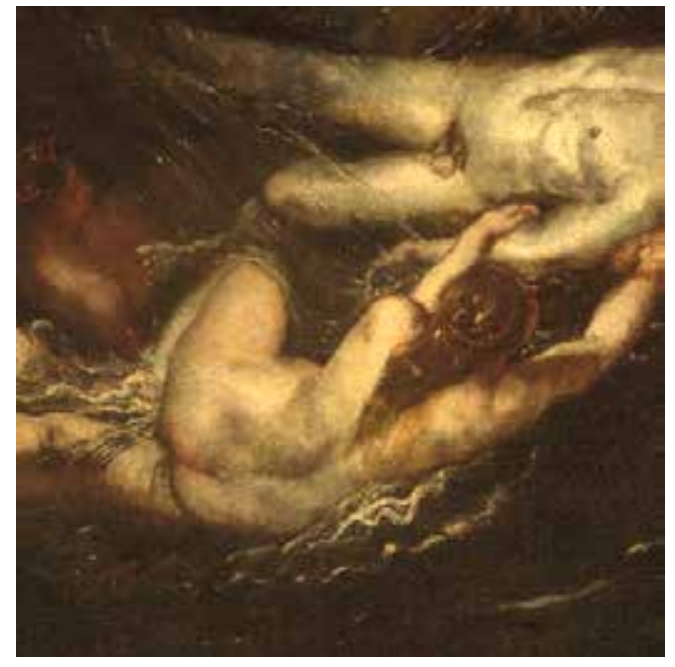

Fig. 26 Hero and Leander, detail of a Nereid [comparison viewer]

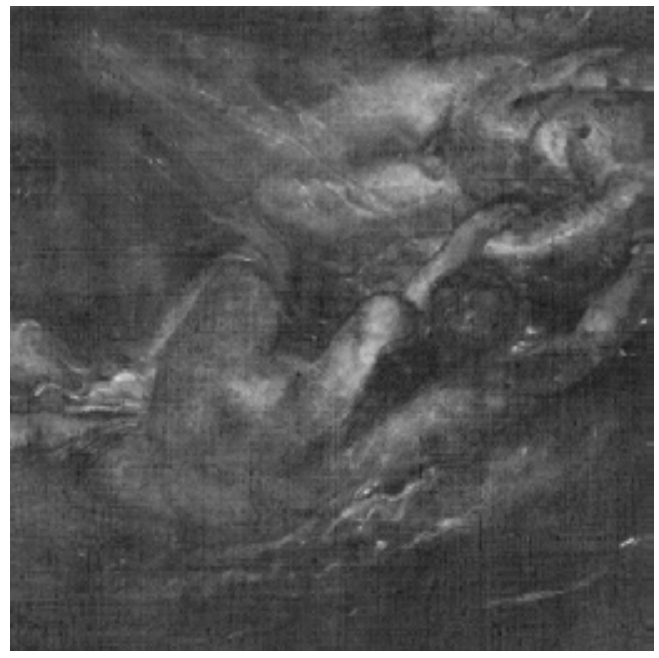

Fig. $28 \mathrm{X}$-radiograph of Rubens, Hero and Leander, detail, area of fig. 26 [comparison viewer]

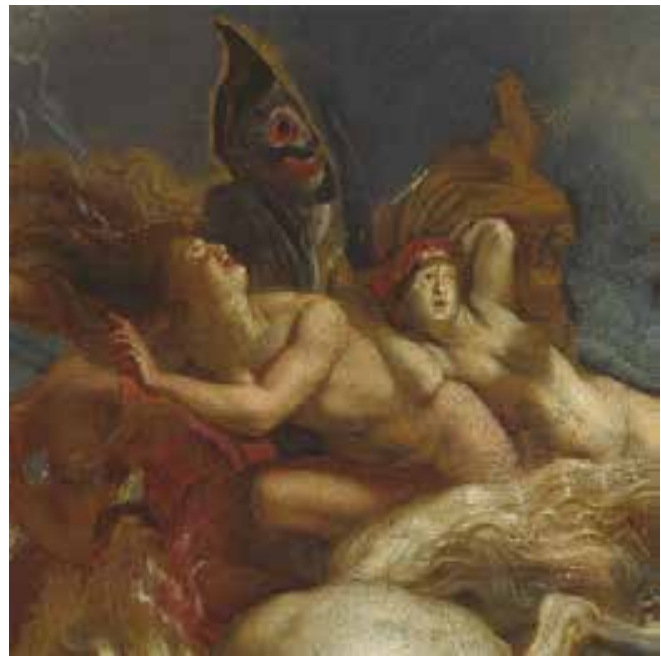

Fig. 27 The Fall of Phaeton, detail of Horae on left. Rubens often left a gap between figure and setting, revealing lower layers - the painted sketch or the ground itself — to serve as warm, brownish contours. [comparison viewer]

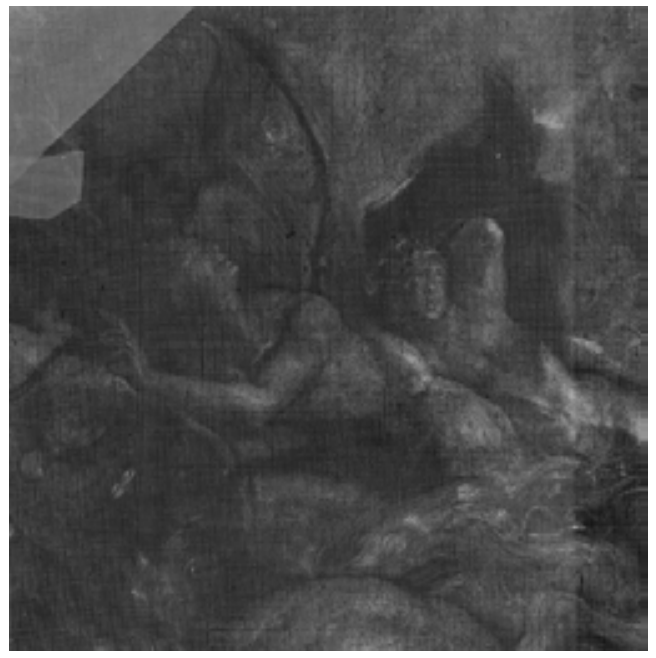

Fig. 29 X-radiograph of The Fall of Phaeton, detail, area of fig. 27. In both $\mathrm{x}$-radiographs, gaps between the figures and the setting appear as dark halos outlining the forms. [comparison viewer]

27 The present technical study has uncovered extensive similarities of materials and working practices. However, any comparison of the two paintings is necessarily affected by their disparate early restoration histories. The Fall of Phaeton is in excellent condition, even preserving in exposed areas Rubens's quick strokes of brown sketch paint (seen in the flying hair in fig. 12), which have proven to be susceptible to the strong cleaning methods used in the past. By contrast, the surface of Hero and Leander is muted by discolored varnish, and, more important, the worn paint in many areas has lost much detail. Illuminated flesh tones seem patchy, and brown sketch paint is 
missing; some shadowed faces and blowing hair have effectively disappeared. The resulting differences in appearance could influence scholarly reception of the two paintings. In his forthcoming catalogue entry on Hero and Leander for the Corpus Rubenianum Ludwig Burchard, ${ }^{42}$ Gregory Martin does not exclude Rubens's authorship of the Yale painting, but he suggests that it might be a studio replica of a lost original that, he proposes, could have had more dramatic drive than the versions that survive today. ${ }^{43}$ Rubens may have produced some such works speculatively, to assess interest among Italian collectors for mythological easel paintings. ${ }^{44} \mathrm{~A}$ different classical scene that Rubens painted in Mantua may be another example: The Battle of the Amazons (c. 1598-1600; private collection) was also painted on canvas and is generally of the same scale. ${ }^{45}$ However, the formats of The Fall of Phaeton and Hero and Leander are much closer, ${ }^{46}$ so much so that they have been proposed as possible pendants more than once. ${ }^{47}$ Rubens is not known to have produced pendants, ${ }^{48}$ yet the compositions also share a suggestive formal symmetry that might imply a pairing. The streams of light that play an important role in each painting, although far brighter in The Fall of Phaeton, descend from above at the same angle but in opposite orientations. Similarly, the sweep of the wave that mounts to the upper right of Hero and Leander is mirrored by the tawny curve of the zodiac in the upper left of Phaeton. ${ }^{49}$

The similarities of subject, format, and composition may simply reflect Rubens's repeated experimentation in producing mythological easel paintings for the Italian market. However, one intriguing physical detail invites speculation that the association might have been closer. At the angle of the jagged line of lightning in Hero and Leander, Rubens's brush deposited an errant touch of blue-white along with his yellow paint. This blue is much lighter than the sky in this painting, but it is close in value to the mid-blue sky in Phaeton. This is circumstantial evidence, but it conjures up a tantalizing image of the artist working on the two canvases side by side, his brush moving back and forth between the two skies to establish a balance of lightning and streaks of light. ${ }^{5}$

As the paintings appear today, they are not satisfying pendants (see figs. 22, 23). In the recent exhibition Rubens: A Master in the Making, ${ }^{51}$ the dark sky and threatening sea of Hero and Leander conflicted with the blue sky and blinding wash of light in the final composition of Phaeton, and the forceful diagonal composition of Phaeton seemed at odds with the lyrical wreath of nude figures in Hero and Leander. While it is true that the paintings' history explains some of the disparity-Hero and Leander has been muted by the passage of time-technical examination of these two paintings brings out another important reason that their appearance today is so different. Hero and Leander has almost no evidence of any changes by the artist, and, even in its worn condition, it conveys Rubens's original plan for this composition. By contrast, The Fall of Phaeton has undergone such extensive revisions that the present appearance obscures much of the original composition. To compare the paintings as Rubens originally envisioned them, we must imagine The Fall of Phaeton not as it appears today but in Rubens's original conception.

One part of this study has been to visualize the findings of technical research in schematic representations that approximate features of earlier stages in the evolution of The Fall of Phaeton. In comparison to the present painting, the mock-up of Stage 1 makes a far more intriguing complement to Hero and Leander (figs. 30, 31). The two images now share dark settings (the stormy night and the celestial twilight before dawn) broken by thin lines of light and streaks of lightning. The varied forms of lightning in the storm that doomed Leander, not only a jagged bolt but also 


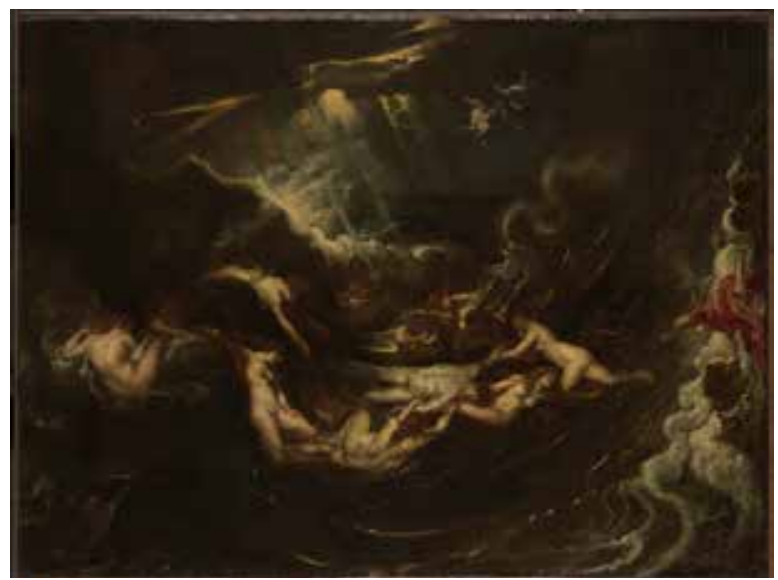

Fig. 30 Peter Paul Rubens, Hero and Leander, ca. 1605, oil on canvas, 95.9 x $128 \mathrm{~cm}$. New Haven, CT, Yale University Art Gallery (artwork in the public domain) [comparison viewer]

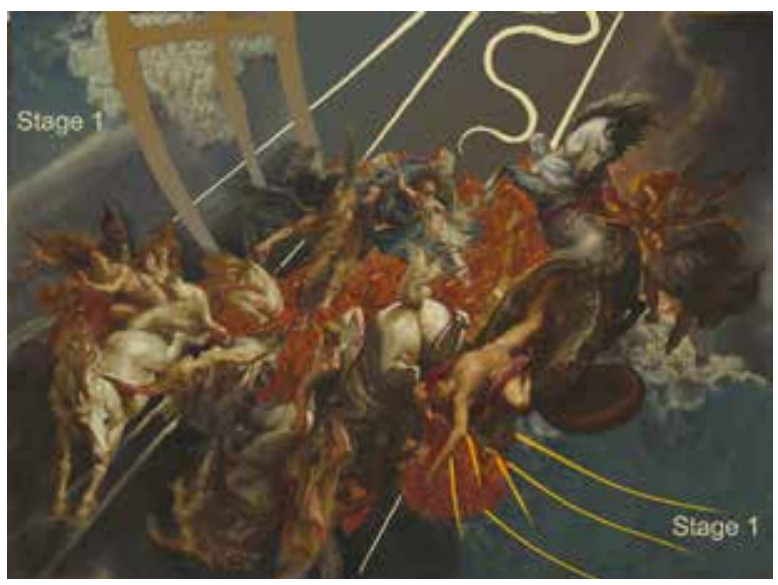

Fig. 31 Mock-up of the original composition (Stage 1) of The Fall of Phaeton shows a dark tonality that seems more consistent with Hero and Leander. [comparison viewer]

a curving whiplash, confirms that the large whiplash form that originally dominated the upper part of The Fall of Phaeton was a direct allusion to Jupiter's bolt of lightning in the first composition. ${ }^{52}$ This sinuous bolt, the same form that appears in Tintoretto's stormy sky in The Transportation of the Body of Saint Mark (figs. 32, 33), is an important design element that weaves through both compositions: echoed in the curling white forms of the clouds in Phaeton, the waves that break below Hero's plunging form, the snaking wisp of seafoam blown beyond the Nereids, and the smoke blown past the Horae. The figure groups of the two compositions would also have had more in common. Allowing for the twelfth Hora, which Rubens later painted out of the lower right of Phaeton,,$^{53}$ the group of Horae, Phaeton, and horses would have had a more horizontal emphasis, with a rising and falling rhythm that echoed the garland of Nereids woven around the dead Leander.

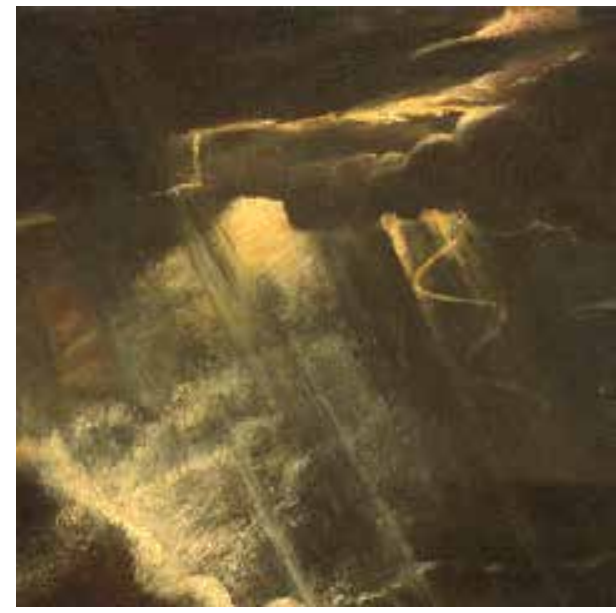

Fig. 32 Rubens, Hero and Leander, detail of the lightning, is reminiscent of Tintoretto's work. [comparison viewer]

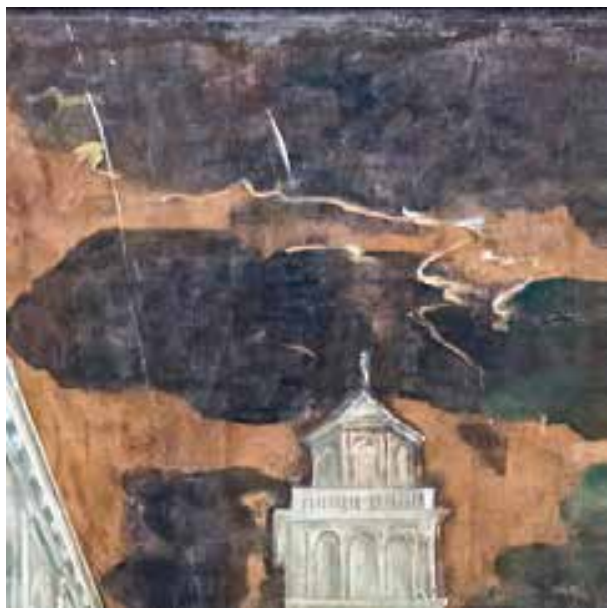

Fig. 33 Tintoretto, The Transportation of the Body of Saint Mark, detail of lightning in fig. 6 [comparison viewer]

31 This new understanding of Rubens's original composition for The Fall of Phaeton also suggests a thematic balance. The catalogue for A Master in the Making proposed that, as the two stories take place in water and air, the original plan might have called for two additional mythological paint- 
ings to represent fire and earth, thus forming a suite of the four elements. ${ }^{54}$ The recognition that Rubens might originally have planned a pair of paintings in which the figures were engulfed by either fire or the sea now points to the possibility that such pendants would have shared a symmetry based on two opposed elements: water (cold and wet) and fire (hot and dry). ${ }^{5}$

32 It seems likely that both The Fall of Phaeton and Hero and Leander were among the considerable number of his own paintings that Rubens shipped north on his hasty return to Antwerp late in 1608. In Antwerp, such works would have formed the nucleus of the artistic stock he kept for sales without commission. There he continued to work on some of his Italian pictures and put others to new uses. He seems to have rolled and shipped home the large painting that was his first (rejected) version of the altarpiece for the Chiesa Nuova in Rome, reusing it in 1610 when he established a memorial to his mother in the Abbey of St. Michael, in Antwerp. ${ }^{56}$ He must also have brought the unfinished St. Sebastian Succored by Angels (c. 1601-1602; Palazzo Corsini, Rome), which he completed in Antwerp. ${ }^{57}$ Likewise, Saint George (1606-1608; Prado, Madrid), which he kept until his death, served as a source of inspiration for the complex hunting scenes he painted some years after his return. ${ }^{58}$

Whether or not Rubens originally conceived of the two mythological paintings as a pendant pair, the ways in which their subsequent histories diverged suggest he came to regard them differently. Hero and Leander made a strong impression on connoisseurs from the outset. Giambattista Marino was inspired to compose a poem for his volume La Galeria on Rubens's poignant image, which he must have seen while he served as court poet to Vincenzo Gonzaga from 1606 to 1608 . $^{59}$ Apparently Rubens deemed Hero and Leander, a composition he never felt the need to revise, worthy of wider distribution: he had a studio variant of Hero and Leander made in Antwerp shortly after his return, ${ }^{60}$ and in 1619 he described his plan to have Lucas Vorsterman make an engraving after this composition. ${ }^{61}$ Later, he must have sold the Yale version of Hero and Leander as an individual work. ${ }^{62}$ The fact that he did not plan to reproduce The Fall of Phaeton, together with the history of his extensive revisions to the composition, suggests that he assigned this painting a different, more experimental role.

\section{Stage 2: Revisions in Italy}

When Rubens undertook the first set of revisions to The Fall of Phaeton, not long after he had completed the original, his motivation could have been to harmonize the emotional impact of the two compositions; possibly the horror he had first depicted seemed at odds with the elegiac quality of Hero and Leander. In any event, his revisions shifted the tenor of the scene from the feverish tumult that The Fall of Phaeton shares with The Transfiguration (see fig. 21) toward the lightness he brought to his later works. ${ }^{63}$

In this first reworking of the composition (Stage 2), Rubens made few changes to the Horae and horses and instead revised the setting in ways that altered the protagonists' experience of the narrative. He eliminated or suppressed the most vivid aspects of the gruesome scene: Jupiter's lightning and the inferno it ignited. Now, rather than focusing on Jupiter's weapon, a specific bolt of lightning, he reconfigured this part of the painting into a more abstract representation of the god's anger. In the original composition the whiplash form had been silhouetted against 
a gray sky (see fig. 31); in Stage 2 he incorporated the lightning into a broad burst of radiance that fans out from the upper right. Close examination of the upper part of the sky shows that in Stage 2 he filled the space around the lightning, covering the dark sky with cool yellowish paint (figs. 34, 35). A narrow margin of gray sky is still visible along the edges of the lightning bolt and in glimpses through the thin brushwork of added yellow. Though he also retraced the whiplash form while painting this generalized wash of light, evidence of the original lightning bolt can still be seen-most clearly at the left edge, where a brownish wisp of ochre-yellow extends out from under the Stage 2 paint. $^{64}$

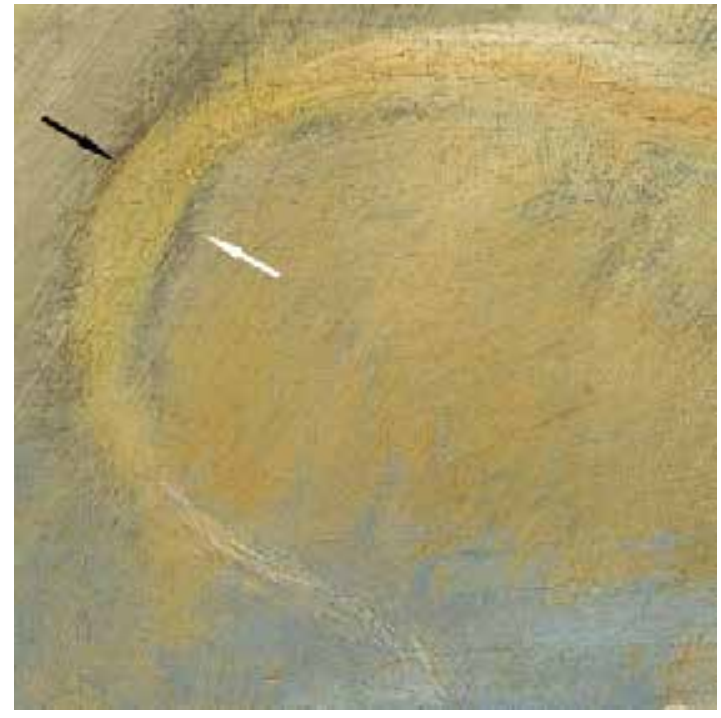

Fig. 34 The Fall of Phaeton, detail. In his Stage 2 revisions, Rubens used yellowish paint (indicated with a white arrow) to fill in the space around the original whiplash lightning bolt, leaving fringes of the original gray sky. A black arrow indicates a wisp of the Stage 1 lightning, still visible below the later paint. [IIIF curtain and comparison viewer]

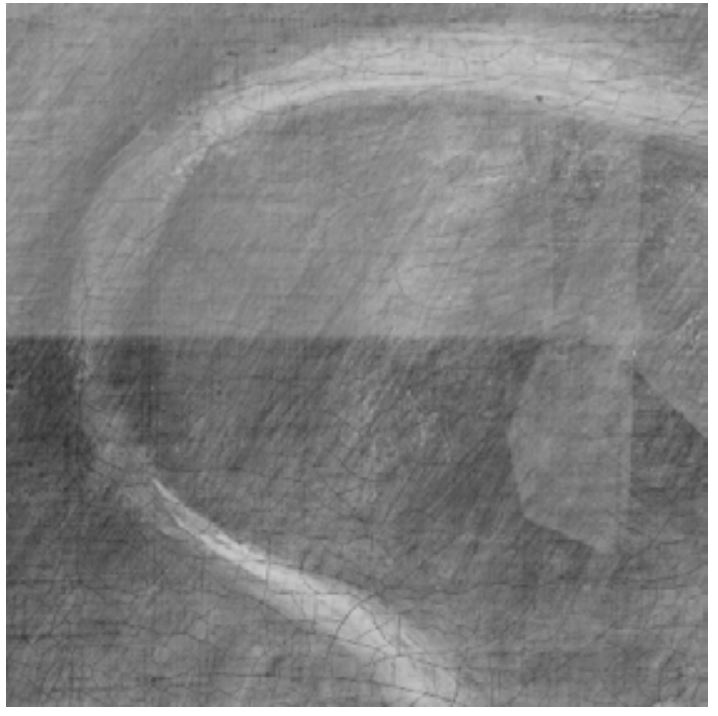

Fig. 35 X-radiograph of The Fall of Phaeton, detail of the area in fig. 34. The dense yellow paint Rubens brushed close to the lightning bolt in Stage 2 appears light-colored, while evidence of the original gray sky can be seen in a narrow, dark-colored zone around the lightning. [IIIF curtain and comparison viewer]

Throughout the complex mass of figures, Rubens simplified the composition in the process of painting out the flames. He filled the spaces with white and gray clouds, leaving only narrow borders of blackish sky around the figures, and he extended the wash of radiance with broad yellow streaks of light that he wove through the group. He opened the space between three Horae by painting a diagonal yellow-white beam of light over their interlocking legs (figs. 36, 37). The $\mathrm{x}$-radiograph shows an extended leg in Stage 1, now partially covered by the light added in Stage 2 , and where the lower Hora originally had braced her foot against her companion, only the toes remain visible.

37 When compared to the mock-up of Stage 1, a schematic approximation of the Stage 2 composition presents a markedly different impression (figs. 38, 39). With these changes the painting's tonality became brighter, and the formal rhythm of the composition shifted. In the original composition, the rays of light and lightning bolt on the right would have balanced the curve of the zodiac on the left. The new emphasis on the dominant diagonal stream of light realigned the composition along this axis. Rubens's only narrative changes also reinforced the formal realignment. Against a blue-gray sky in the lower right of the original composition, he had first 


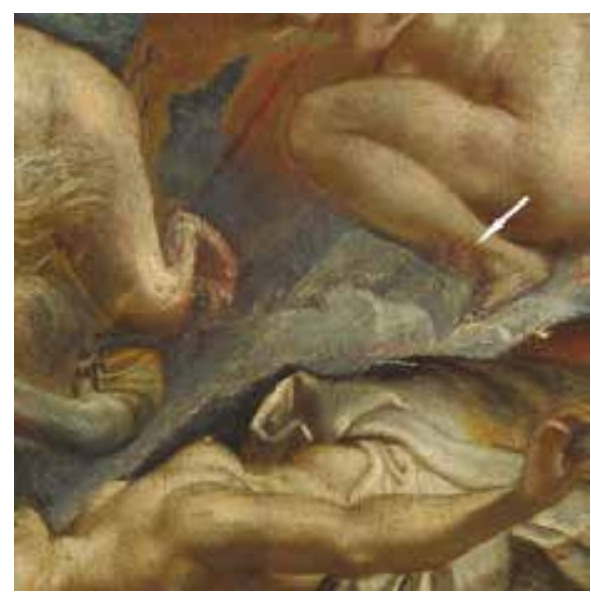

Fig. 36 The Fall of Phaeton, detail of the space between the Horae at left. An arrow indicates toes still visible after another leg was painted out. [IIIF curtain and comparison viewer]

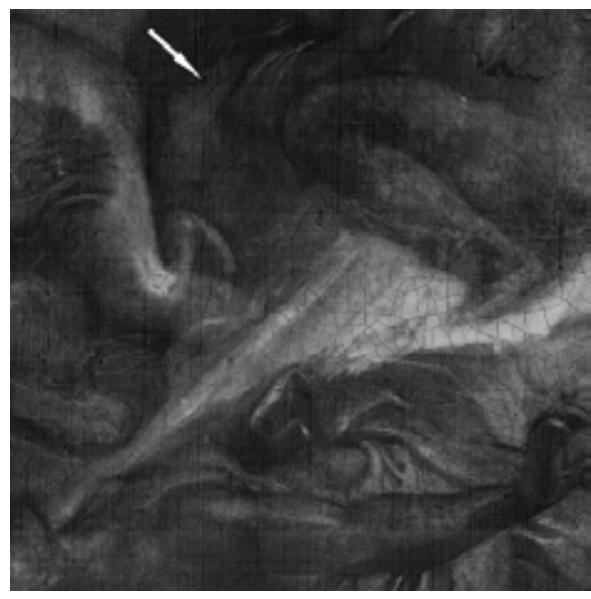

Fig. 37 X-radiograph of The Fall of Phaeton, area shown in fig. 36. An arrow indicates a leg hidden when Rubens later added a diagonal beam. [IIIF curtain and comparison viewer]

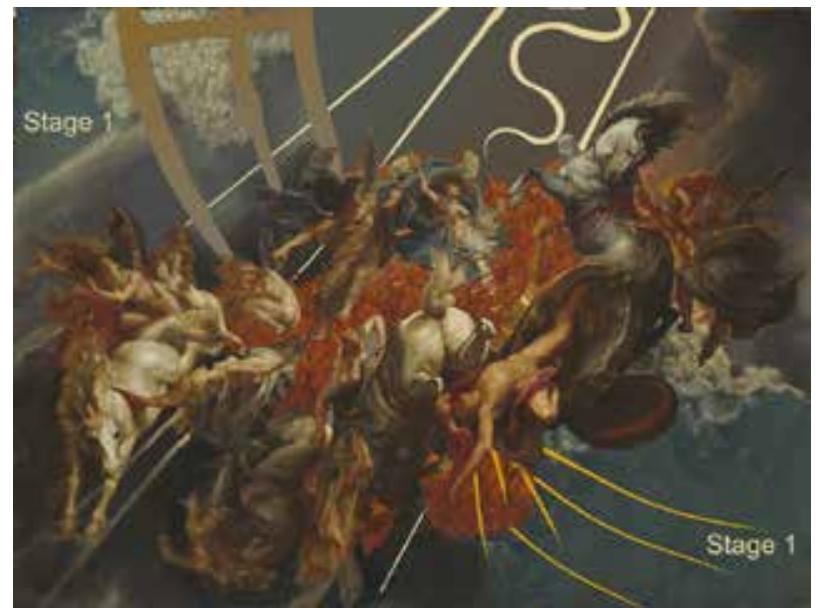

Fig. 38 Mock-up of the original composition (Stage 1) of The Fall of Phaeton

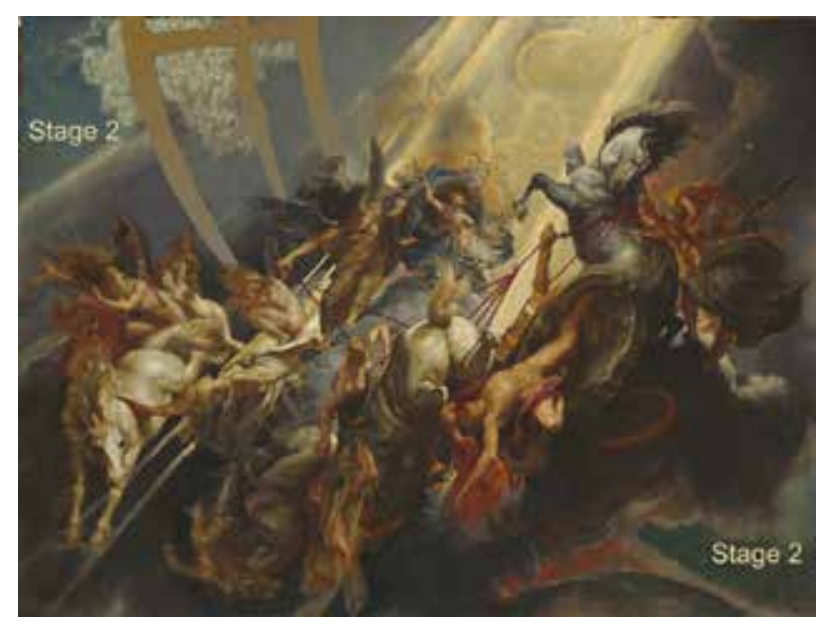

Fig. 39 Mock-up of Stage 2 (the first revision) of The Fall of Phaeton. Rubens covered over the flames with gray clouds and expanded the lightning bolt into a diagonal wash of golden light.

depicted lines of yellow light jetting outward from the impact and a twelfth Hora thrown free of the tangled figures. After his revisions had covered all these details with an undifferentiated mass of black clouds, and he had added a cursory rendition of the burning Earth below, ${ }^{65}$ the emphasis was redirected to the figure group. The figures, which had formed a horizontal garland, now took on a diagonal emphasis aligned with the wash of light. Yet at this unresolved stage-after he had painted out one of the expected twelve Horae without introducing a replacement-Rubens set this work aside.

If Rubens had once intended a relationship between The Fall of Phaeton and Hero and Leander, his Stage 2 changes only increased the tension between the paintings. His revisions, however, were not simply formal adjustments. When he converted the tangible lightning bolt into a wash of light and replaced the flames that overwhelmed the figures with cool gray clouds, he transformed a literal transcription of the Phaeton narrative into a conceptual rendering of divine wrath. Under- 
taking such extensive revisions must reflect his dissatisfaction with the first composition. But the fact that he did not complete the painting at this time suggests that his search for a new approach continued. He had yet to resolve the relationship between the newly abstract wash of divine light and the tangle of falling figures.

\section{Stage 3: Revisions in Antwerp}

39 Rubens's final revisions, which created the painting we see today (Stage 3), further abstracted the force of Jupiter's attack, narrowing and focusing the yellow radiance by muting the outer parts with thin gray paint that bracketed the light with darker gray on either side. Throughout the composition, his changes have an improvisatory character that sets them apart from the earlier stages of his work. The hasty brushwork that he painted into spaces between the figures forms a striking contrast to the care with which he had painted the figures themselves. When he revised the blackish sky around the crouching Hora (fig. 40), he covered it with blue paint that he scrubbed on with a broad brush, using looping strokes that stopped well short of her flying hair. He made no effort to preserve the taut network of reins and traces above her, a narrative detail that originally had communicated the Horae's desperate attempts to restrain the terrified horses; these now disappear without explanation beneath the blue sky. And when he filled in the space below her with empty blue sky, he haphazardly reintroduced the leg he had covered in the earlier revision, painting an ungainly flipper-like form in its place (see at the left in fig. 36).

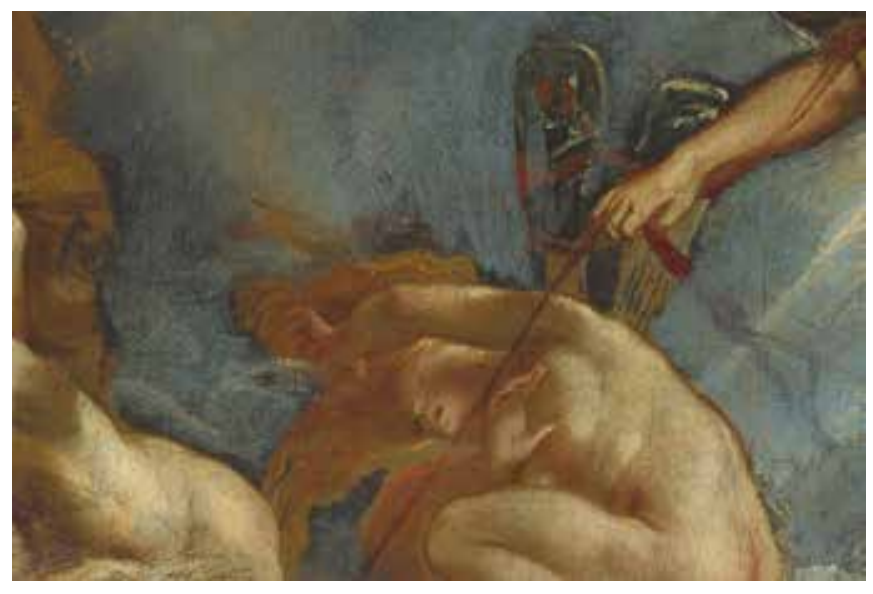

Fig. 40 The Fall of Phaeton, detail. In Stage 3 Rubens rapidly painted blue sky around the figure, covering the original blackish sky.

The last, and most transformative, of Rubens's many changes to The Fall of Phaeton was his addition of the brilliant white horse (fig. 41), although this made a team of five, rather than the four that Ovid described. He first brushed thin, sky-blue paint within the golden radiance to further suppress the lightning bolt. Then with just a few strokes in a single tone of white paint, he conjured up the rearing horse and flying white mane. The false-color IRR shows how rapidly he brushed around the adjacent gray horse, skirting one foreleg and truncating the other, selectively painting over parts of the elaborate red harness (fig. 42). The freedom of his brushwork in the white horse is a striking departure from his detailed depiction of the gray, but he integrated the two by brightening the original gray horse with the same white paint, economically adding just a few highlights and stipples that transformed it into a dapple-gray. The result is a compelling image: two rearing forms curved tightly against one another, the weighty dark gray silhouetted against the luminous white horse. 


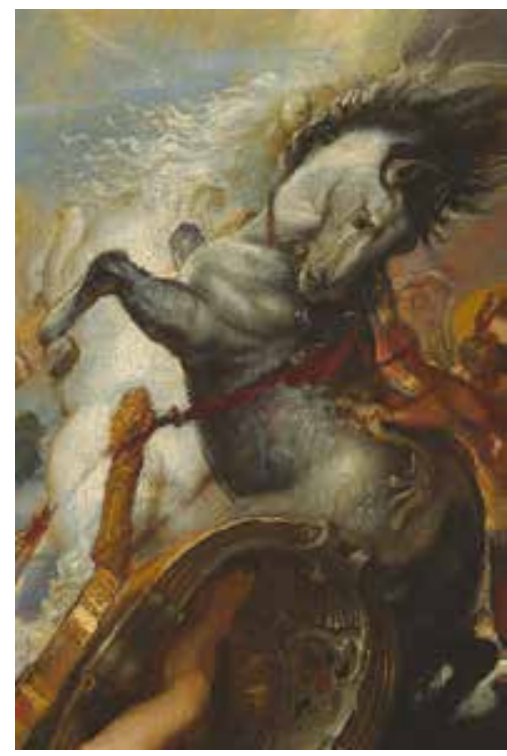

Fig. 41 The Fall of Phaeton, detail of rearing horses

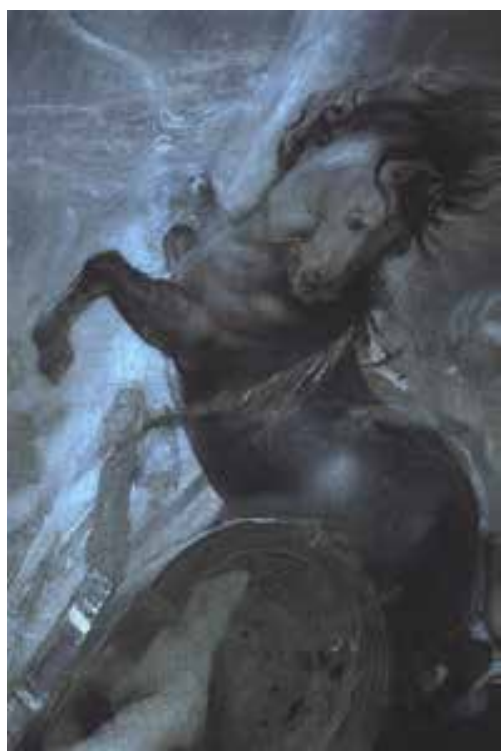

Fig. 42 False-color infrared reflectogram of The Fall of Phaeton, detail. The added white horse covered a complex tangle of harness and traces.

41 With these revisions, Rubens transformed the central group from a wreath of figures suspended in the heavens to a pyramid. The dramatic pair of rearing horses at the pinnacle binds the figures to the stream of light (figs. 43, 44). There is no doubt that Rubens himself made these revisions; although the messy handling of the sky might give pause, Rubens's brilliantly painted white horse lies over the blue paint. His apparent unconcern with the improbable sets of eleven Horae and five horses and the nonchalance of his paint handling speaks to an experimental approach. In this final revision, his attention would not have been focused on realizing a finished, coherent narrative. Instead he was testing dynamic forces within the composition, establishing the convergence of protagonists and divine light.

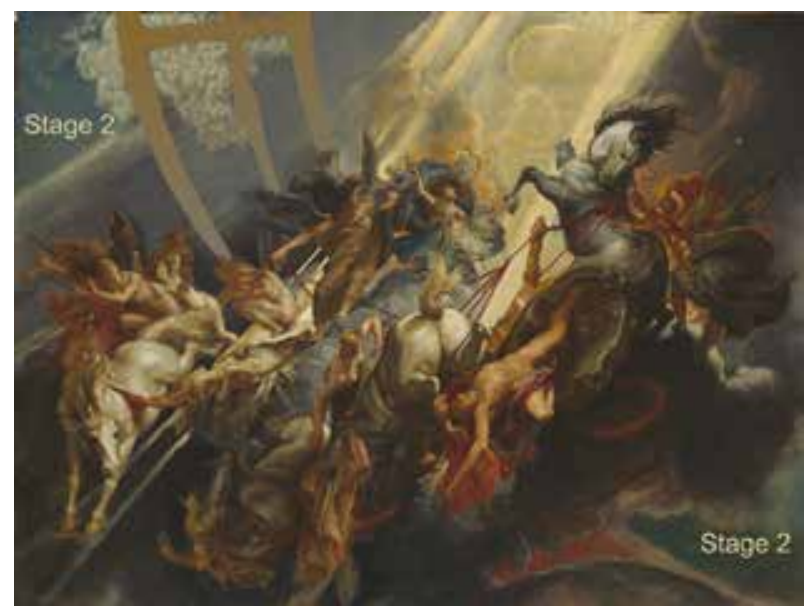

Fig. 43 Mock-up of the first revision (Stage 2) of The Fall of Phaeton

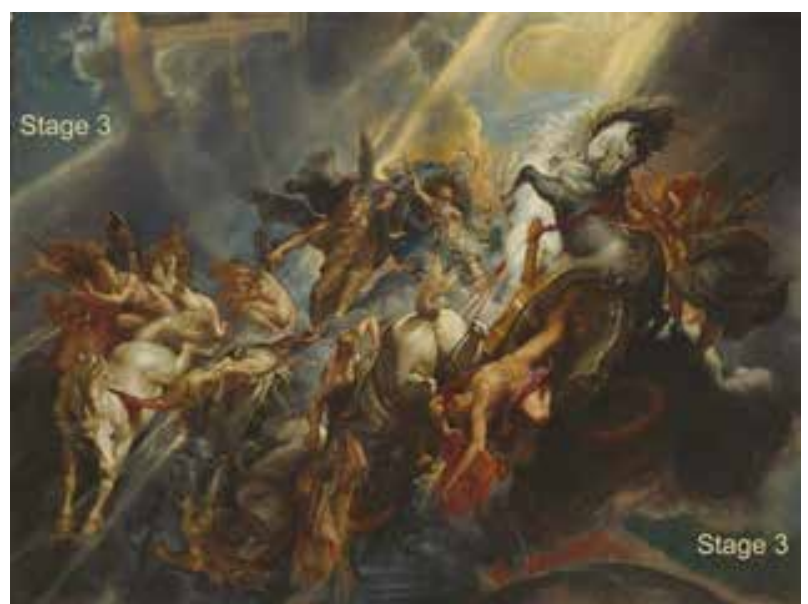

Fig. 44 The Fall of Phaeton (Stage 3). In his final, experimental revisions, Rubens rapidly painted blue sky around some figures and introduced the rearing white horse that crowns the composition. 


\section{Evidence for the passage of time}

42 After characterizing three stages of the composition-Rubens's original composition with its dark, chaotic depiction of Phaeton's violent death; his first revisions with the bright, diagonal wash of light that reoriented the composition; and the clarity of the final composition culminating in the pair of rearing horses-it is intriguing to consider when the changes came about. Were all his changes made in Italy, or did Rubens continue to work on The Fall of Phaeton after his return to Antwerp? Both sets of revisions have a provisional, experimental feel. The final changes, however, were executed with a freedom and directness that call to mind an utterly confident painter. Previously, scholars have noted compositional relationships between The Fall of Phaeton and works Rubens painted soon after his return to Antwerp, and one in particular will be explored below. The sequence of such relationships is often the basis for proposed dating, but the present technical study has yielded physical evidence that offers new insight into the timing of Rubens's revisions.

A minute lacuna in the shoulder of the white horse, where paint had flaked off in the past, offered the opportunity to take a paint sample documenting all three compositional stages (fig. 45). The lowest layer of the cross section is a fragment of the yellow-tan ground. Above this, two mixed tan layers correspond to smoke rising from the flames of the Stage 1 composition: charcoal black particles confirm the evidence of the IRR, that the original composition was comparatively dark in this part of the sky, and the addition of a small amount of red lake suggests that the flames cast a ruddy glow. In the middle, two yellow paint layers belong to the wash of light in the Stage 2 composition; these include white lead and lead-tin yellow, which create the dense appearance in the x-radiograph. At the top of the sample (below a layer of modern restoration paint that hid the paint loss at this location) are two layers from Stage 3: a pale layer of white lead with large particles of ultramarine blue (the blue sky) and a layer of pure white lead corresponding to the white horse. The four lowest layers, which correspond to the first two versions, are well adhered and were probably applied within a short period of time. ${ }^{66}$ There is no evidence of a continuous varnish layer to suggest that Rubens considered the painting completed and ready for varnishing after his Stage 2 revisions. However, a slight separation above the first four layers-between the last layer of Stage 2 and the first layer of Stage 3-suggests that the earlier layers had thoroughly

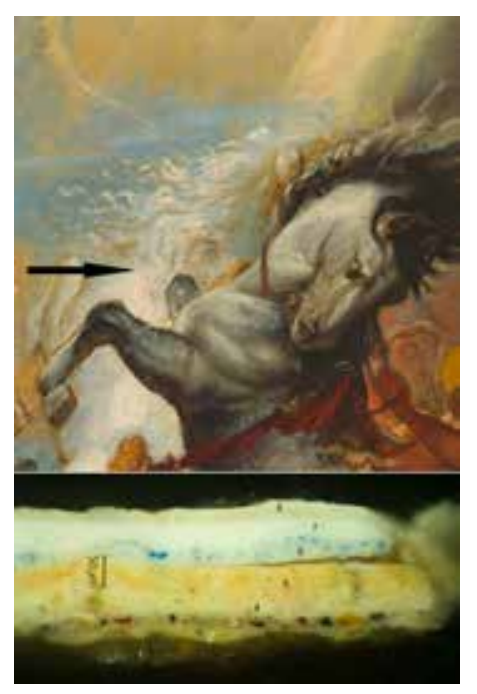

JHNA 11:2 (Summer 2019)
Fig. 45 The Fall of Phaeton, detail of the added white horse, with an arrow indicating the location where a microscopic sample was taken from the edge of an existing loss. The paint cross section includes layers from all three stages of the composition. Layer 1: yellow-tan ground; layers 2 and 3: smoke in Stage 1; layers 4 and 5: golden light in Stage 2; layers 6 and 7: blue sky and white horse in Stage 3 (layer 8 is later restoration). 
cured before the final paints were applied, circumstantial evidence of a time delay long enough to indicate that Rubens had almost certainly returned to Antwerp before doing so. ${ }^{67}$

44 There are also notable differences among the pigments Rubens chose at different points in the painting's history. The most obvious variation is his choice of blue pigment. For his original painting, as well as for Hero and Leander, Rubens used indigo for the skies and sea; however, he changed to high-quality ultramarine blue for the broadly brushed blue sky of Stage 3. Either blue pigment would have been available in both Italy and Antwerp, but the difference is unlikely to be random. Rubens usually used ultramarine in his mature paintings in Antwerp; he could by then afford this costliest of blue pigments, made from the semiprecious mineral lapis lazuli. Although the low cost of indigo may have been a factor (even in Antwerp indigo sometimes replaced ultramarine in workshop replicas) ${ }^{68}$ aesthetic concerns were also essential to Rubens's choice of blue pigments. The pronounced visual differences between the two blues are still apparent in The Fall of Phaeton. The blue of the indigo he used in Stage 1 has a subtly gray-green undertone that is appropriate to the dark, pre-dawn sky of the original (still seen in the upper left) and is also consistent with the tonality of the dramatic sky in The Transfiguration (see fig. 21), painted around the same time. By contrast, the revised sky throughout the figure group is based on ultramarine, giving a pure blue that accords with the clear skies Rubens painted in Antwerp in the 1610s.

Most of Rubens's pigments appear in all three stages of the painting, but for two other pigments, there is material evidence that, while he used one source in Stages 1 and 2, he had changed to another supply of the same pigment by the time he painted Stage 3. Artists who change to a new supplier for any of their standard painting materials may be motivated by price or aesthetic concerns, but frequently such a change is evidence that they had moved to a new locale where they had to find new sources for their accustomed materials. White lead particles are very small, but the hand-ground white lead pigment artists used in the seventeenth century includes larger agglomerates of pure, undispersed pigment that can be seen easily with only moderate magnification. In Stages 1 and 2 of The Fall of Phaeton, and also in Hero and Leander, these larger lumps have a slightly translucent quality; by contrast, the lumps of white lead in Stage 3 are recognizably more opaque. ${ }^{69}$ There also seem to be two different sources for the lead-tin yellow pigment that appears in all three stages. During the aging process this pigment often develops lead soaps, seen as translucent globules in the paint layer. ${ }^{70}$ Only a few of these inclusions can be seen in the yellows of the first two stages, but in magnified examination of the paint surface, the lead-tin yellow paints of Stage 3 are thick with such inclusions.

46 The likelihood that Rubens continued working on Phaeton after he returned from Italy-suggested by material evidence of both a time delay and pigment differences between the early and late stages of The Fall of Phaeton-adds a new perspective to the ongoing discussion of this work's role in his development. Research on Rubens often has sought to establish the chronology of his works by identifying shared motifs and tracing their evolution. Technical investigations expand the possibilities of this approach. The present project compared compositional elements in all three stages of The Fall of Phaeton to a range of other works. In addition to the shared motifs that are still visible today, technical images (x-radiography and IRR) and microscopic examination uncovered motifs found only in Rubens's earlier experiments hidden below the surfaces of other works. With this approach, the goal for establishing relationships between paintings shifts. Rather 
than organizing works into a linear chronology, it may be more helpful to visualize a web of relationships: a painting by Rubens as we know it today may share elements with one group of works, but its earlier stages may be linked to other works. And those may themselves have elements that weave through the equally complex evolution of still other works.

\section{Paintings in Antwerp c. 1610-1612}

The moment at which Rubens returned to Antwerp did not mark an abrupt boundary in his artistic development; he continued to test new ways of depicting subjects he had explored earlier in Italy. In these explorations, he drew freely on his own work as well as on the art of his predecessors, with motifs reappearing and being transformed over the course of years. While many motifs would have been recorded in his notebooks as individual figures, to be later recombined in possible compositions, he also seems to have kept access to some of his paintings and used these to build on his earlier ideas.

A challenge Rubens undertook repeatedly throughout his career, both in Italy and in Antwerp, was to articulate compositions of tightly interwoven figures and animals. Julius Held outlined the complicated relationships among works with subjects depicting tangled masses of men and falling horses that he dated to 1610-12, shortly after Rubens had returned from Italy. ${ }^{71}$ As in The Fall of Phaeton, each narrative called for dense groupings of struggling figures and horses, and in each a stricken protagonist was illuminated by beams of light manifesting the intervention of divine force into human concerns.

Rubens had already painted a Conversion of Saint Paul at least ten years before, depicting the moment that the future apostle, then known as Saul, was struck from his horse by a blinding light, to the terror and confusion of his followers (fig. 46). ${ }^{72}$ That early Conversion was either among the paintings that Rubens left in his mother's house during his time away ${ }^{73}$ or one of those he shipped north from Italy for his own use; by 1640, at least, it was recorded in Antwerp in the estate inventory of Nicolas Rockox. ${ }^{74}$ In that early work, Rubens staged dramatically posed figures with heavenly light serving more as a theatrical backdrop than an active force. Compositional echoes show that, after his return to Antwerp, this painting served as a stimulus for his ongoing exploration of the Conversion theme.

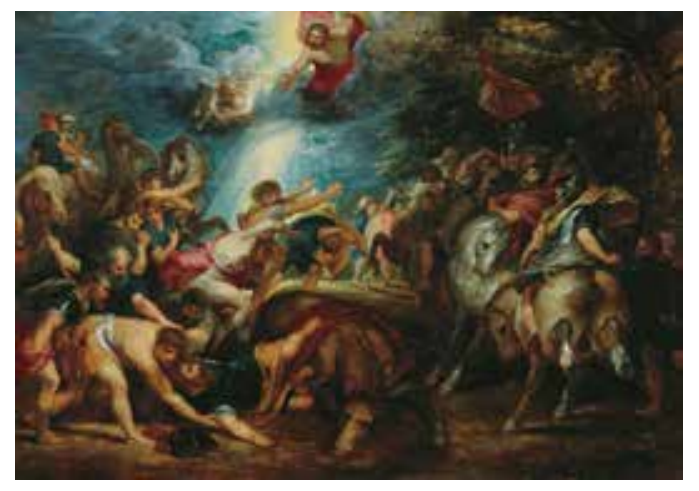

Fig. 46 Peter Paul Rubens, The Conversion of Saint Paul, ca. 1599-1601, oil on panel, $72 \times 103 \mathrm{~cm}$. (C) Liechtenstein, The Princely Collections, Vaduz-Vienna (Scala, Florence / Art Resource, NY) (artwork in the public domain)

50 The findings of the current research suggest that The Fall of Phaeton served even more forcefully as a spur to open new lines of thinking when Rubens wrestled with complex compositions in the 
years 1610-12. Rubens returned to the theme of Paul's conversion in a series of works now at the Courtauld Gallery: two preparatory works—an oil sketch and a compositional drawing-and the finished painting. ${ }^{75}$ In the course of the present research, it was possible to examine all three works off the wall for comparison with The Fall of Phaeton. ${ }^{76}$ More recently, Clare Richardson and Kate Stonor have carried out new research at the Courtauld Institute, and their findings on the complex evolution of The Conversion of Saint Paul will be presented in full in an upcoming issue of the Journal of Historians of Netherlandish Art. ${ }^{77}$ The present article traces a single motif-the pair of rearing horses that also appears in Phaeton - through these related works. Close comparison of The Fall of Phaeton to the several stages of The Conversion of Saint Paul clarifies Rubens's experimental creative process. This motif shows that Phaeton was one of several antecedents in the genealogy of Rubens's Conversion compositions. The Fall of Phaeton was the incubator in which Rubens developed the compositional solution to a conundrum posed by the Conversion.

\section{The Conversion of Saint Paul: Oil Sketch}

51 In the oil sketch (fig. 47), the scene is structured as an open circle focused on the fallen saint, who sprawls across the foreground while his horse breaks free, kicking his hind legs as he escapes to the right. The rapid, summary technique reveals an experimental compositional process.

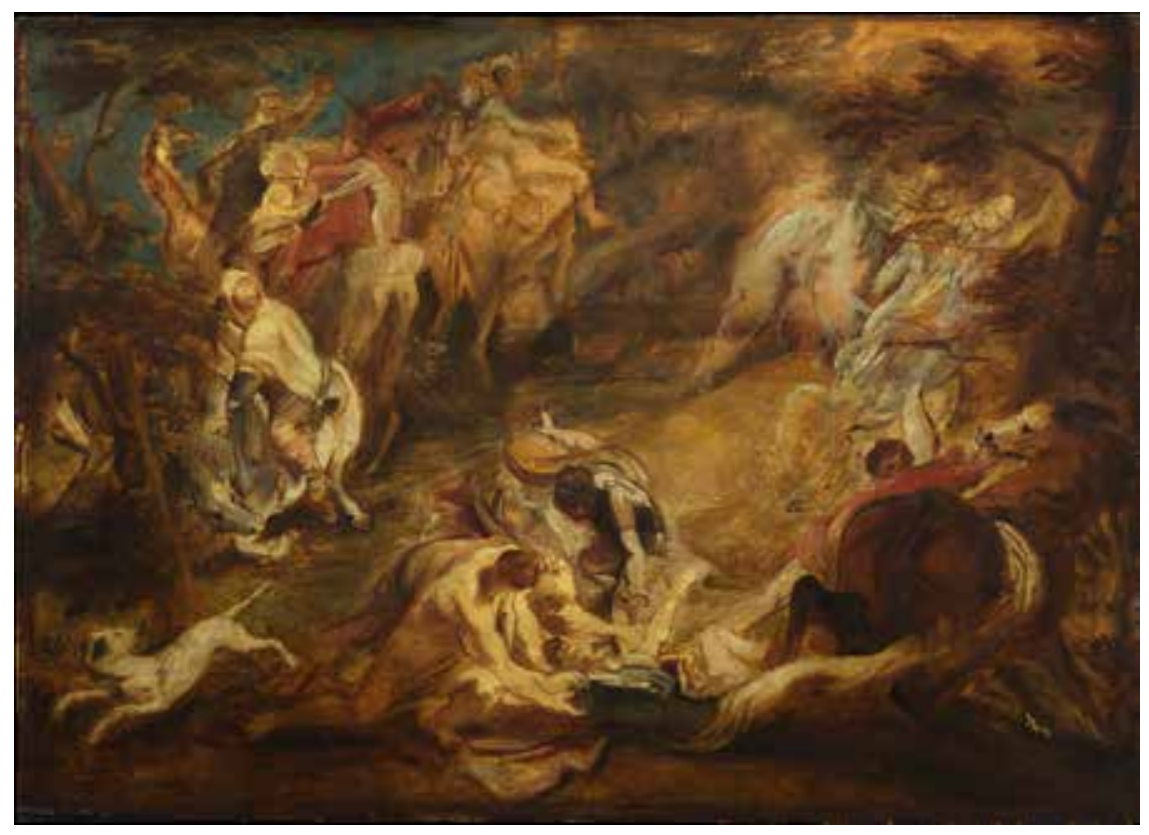

Fig. 47 Peter Paul Rubens, The Conversion of Saint Paul (oil sketch), ca. $1610-1612$, oil on panel, $57.4 \times 78.1 \mathrm{~cm}$. London, The Courtauld Gallery, Bequest of Antoine (Count) Seilern (artwork in the public domain)

52 Though the forms are not always easy to read, some changes can be deciphered. In the rider at the left, whose horse falls forward as its legs buckle, Rubens adjusted certain details with summary notations. Such details would appear careless in a finished work, but as he worked out this compositional challenge, each would have served as an aide memoire, recording the solution to a piece of the puzzle. The free brushwork is reminiscent of Rubens's Stage 3 revisions to The Fall of Phaeton. The rapid brushwork with which he revised the horse blanket from a reddish fabric to blue recalls the blue sky added between figures in Phaeton (figs. 48, 49, 50). Black strokes that reshaped the horse's hind foot into a curious pointed hoof are as hasty as the flipper-shaped leg of a Hora (see figs. 48, 36). The fact that Rubens used the same informal process in both situations 


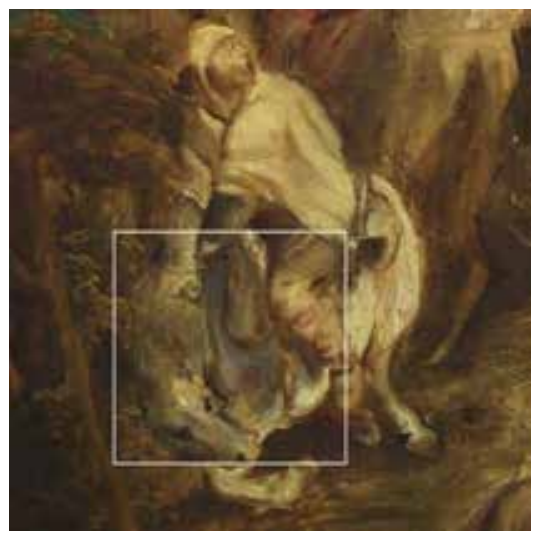

Fig. 48 Rubens, The Conversion of Saint Paul (oil sketch), detail of fig. 47 showing hasty brushwork reminiscent of the final revisions to The Fall of Phaeton. A white box marks the area shown in fig. 49.

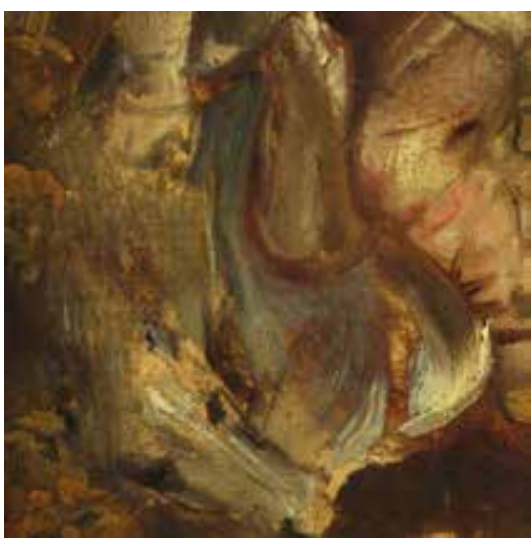

Fig. 49 Rubens, The Conversion of Saint Paul (oil sketch), close detail of area shown in white box in fig. 48

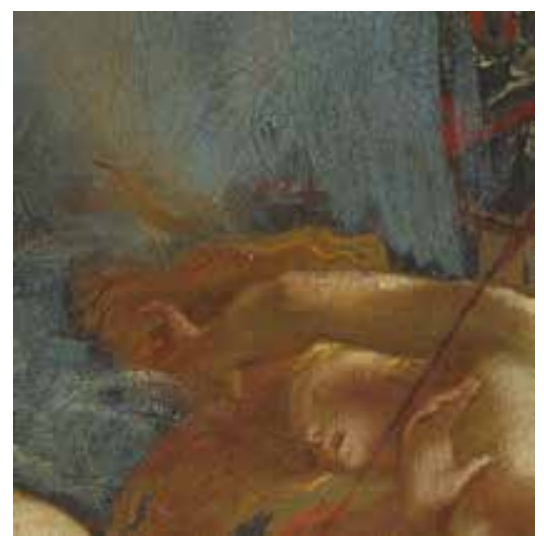

Fig. 50 The Fall of Phaeton, detail of blue sky added with rapid brushwork in Stage 3

reinforces our understanding that Stage 3 in Phaeton, like this experimental sketch, was an active thinking process. ${ }^{78}$ Rubens's goal was never the tidy completion of an unfinished painting.

\section{The Conversion of Saint Paul: Drawing}

Held argued convincingly that the oil sketch of the Conversion was Rubens's first effort at a new rendering of the subject. ${ }^{79}$ However, faced with what seemed an insoluble compositional dilemma, he set aside the oil sketch and reevaluated these issues in an improvisatory drawing (fig. 51). ${ }^{80}$ He must have begun by drawing across facing pages in a notebook; then he cut out the pages and reassembled them, adding scraps of paper at the right to accommodate alternative compositional ideas. ${ }^{81}$ Because it was a notebook opening, the drawing's format is more horizontal than either the sketch or the finished painting, and Rubens was able to test out a broader setting with more figures than could be accommodated in the final work. He carried over some details from the oil sketch - the saint still sprawls parallel to the picture plane-but he drew Paul's horse balking with braced forelegs instead of running off. With three decisive strokes in the sky, he drew rays of light, a detail that in the oil sketch he had barely indicated with final streaks of white paint.

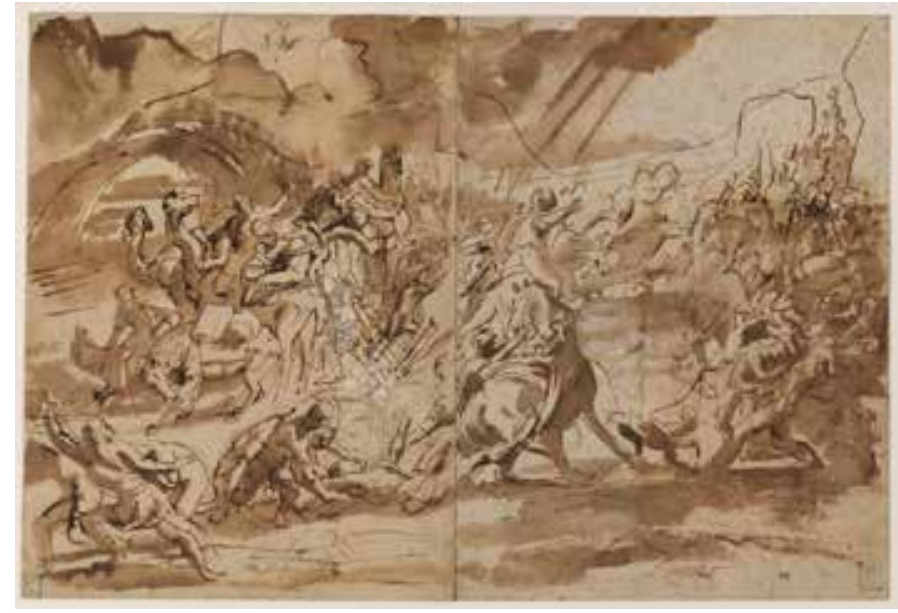

Fig. 51 Peter Paul Rubens, The Conversion of Saint Paul (preparatory drawing), ca. 16101612, pen and brown ink with wash and white bodycolor on paper, $32.9 \times 22.2 \mathrm{~cm}$. London, The Courtauld Gallery, Bequest of Antoine (Count) Seilern (artwork in the public domain) 
Some aspects of the graphic handling in the drawing are reminiscent of Rubens's approach as he planned his paintings in the preliminary design stage (the painted sketch) of The Fall of Phaeton and Hero and Leander. Two types of pen work, the fine lines with which he jotted first thoughts and the heavier lines that reinforced the forms, function like the sequence in those paintings of the brown painted sketch with which he began his compositions and the black sketch that he used to reinforce forms.

Further, the diagonal strokes in the sky recall the blackish lines in the painted sketches of both Phaeton and Leander that anticipated the rays of light (figs. 52, 53). Other penwork mirrors the final adjustments he made in the Conversion oil sketch and in Stage 3 of Phaeton. The horse at the left of the oil sketch that fell to its knees, looking back at the fallen saint, is now riderless. Rubens emphasized its firmly planted hooves with quick, heavy strokes of the pen, reminiscent of the black revision to that horse's foot in the oil sketch; in each medium, the same gesture gave the hoof the same pointed shape.

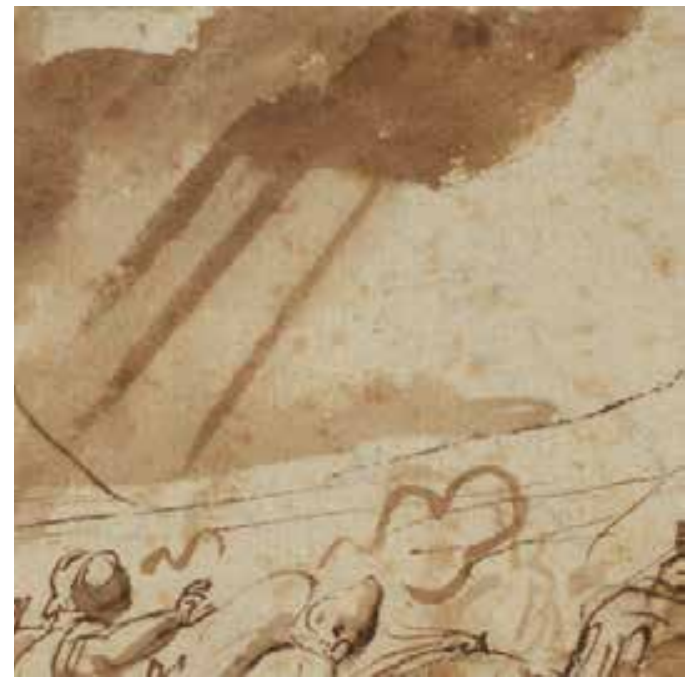

Fig. 52 Rubens, The Conversion of Saint Paul (preparatory drawing), detail of light rays in fig. 51

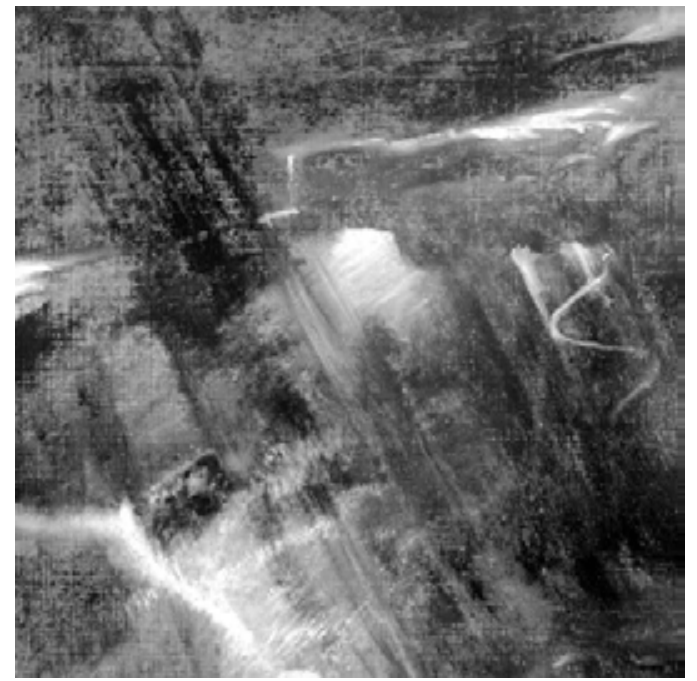

Fig. 53 Infrared reflectogram of Rubens, Hero and Leander, detail of fig. 22 , showing similar light rays that Rubens indicated in his painted sketch.

\section{The Conversion of Saint Paul: Painting}

56 In the finished painting Rubens further opened the space (fig. 54). Rays of light flood from the heavens, as in the drawing, but he now depicted the source: Christ looking down through an opening in brilliantly backlit clouds. He retained the position of Paul's horse in the drawing, legs braced, but he turned the fallen saint, who now almost spills out of the picture plane, and he pushed back the accompanying men and horses to form a dense frieze of violent reactions. The saint, his attendants, and his horse form a compact pyramid, and above them rises a pair of rearing horses reminiscent of the pair in The Fall of Phaeton. As in that painting, the lighter horse is on the left, its thrown-back head aligned with the rays of light, and it serves as a visual connection between the saint and the heavens. Technical examination has established that Rubens reworked this painting as well, and the changes made to the pair of rearing horses are particularly 


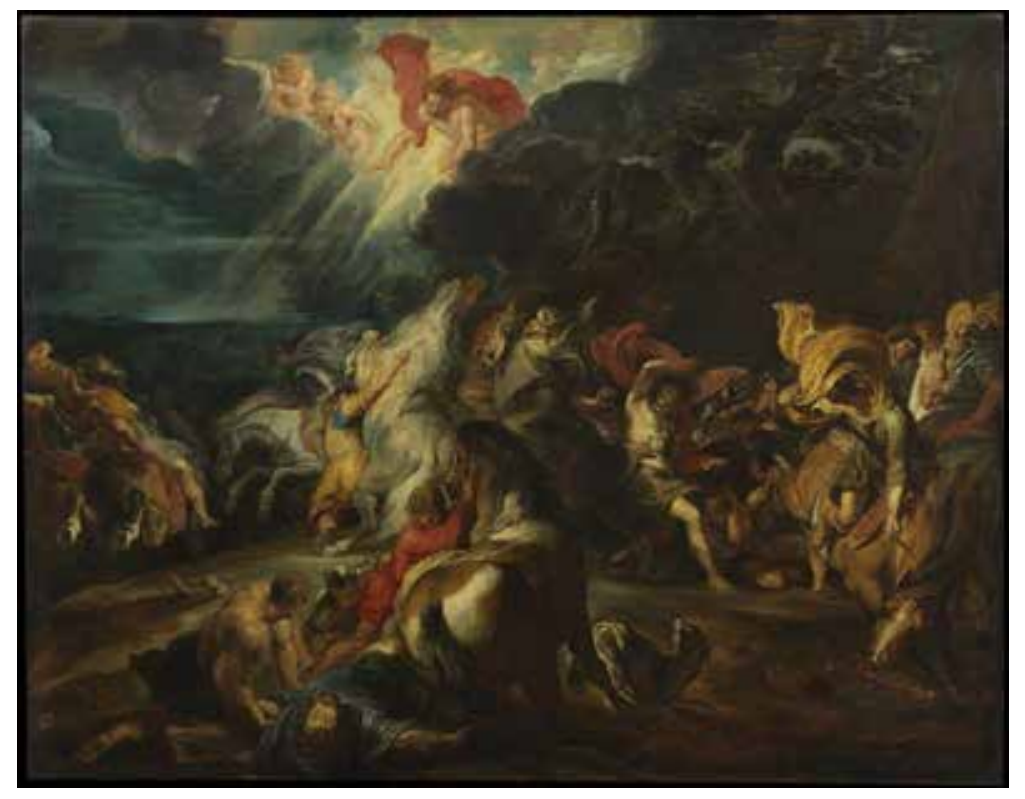

Fig. 54 Peter Paul Rubens, The Conversion of Saint Paul, ca. 1610-1612, oil on panel, $95.2 \times 120.7 \mathrm{~cm}$. London, The Courtauld Gallery, Bequest of Antoine (Count) Seilern (artwork in the public domain)

important for understanding the role that The Fall of Phaeton played in the development of the Conversion. Microscopic surface examination, IRR, and x-radiographs reveal that, in Rubens's first conception, the horses were even closer to Stage 3 of Phaeton than they now appear (figs. 55, 56, 57). The stance of the brown horse on the right echoes the gray in Phaeton. The hind legs were changed from a leaping position to a rearing pose (a pentimento has left both legs visible), and its foreleg was thrown across the back of the other horse, a variant of the Phaeton gray's rearing forelegs silhouetted in front of the white horse.

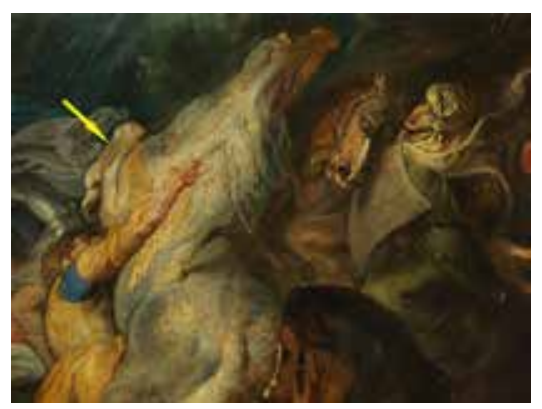

Fig. 55 Rubens, The Conversion of Saint Paul (painting), detail. In the final version of the painting, the horse on the right was painted brown. The horse on the left was repainted dapple-gray, but the unrevised foreleg (indicated by a yellow arrow) is still white.

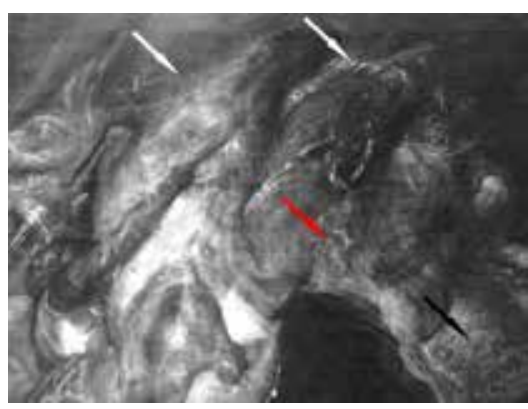

Fig. 56 X-radiograph of Rubens' The Conversion of Saint Paul (painting). A detail of the area in fig. 55 shows that originally the horses were like those in The Fall of Phaeton. The black arrow indicates stippled handling that suggests the horse on the right was originally dappled. The white arrows indicate white highlights in this horse's mane and a flying white mane on the left-hand horse. The red arrow indicates evidence that the right-hand horse had a long, curling mane.

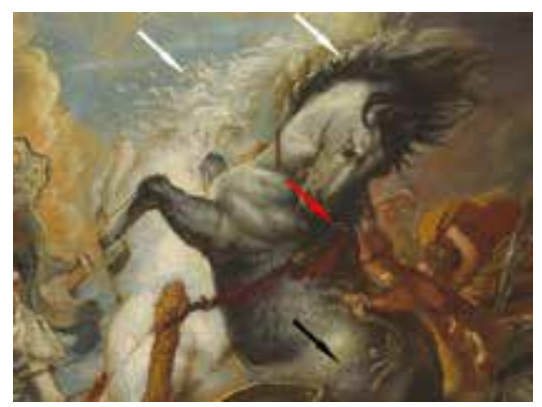

Fig. 57 The Fall of Phaeton, detail. Arrows correspond to features appearing in the original depiction in The Conversion of Saint Paul (see fig. 56)

The present-day colors of the two horses reflect a later revision, ${ }^{82}$ but originally they were closely based on the horses Rubens developed in his final experiments with The Fall of Phaeton: a white 
horse with flying mane on the left, a dappled horse on the right (fig. 57). Although in The Conversion the right-hand horse is now brown, it was originally a much lighter color: the x-radiograph (fig. 56) shows white highlights in the waving mane along its neck (like the highlights Rubens added to the right-hand horse in Stage 3), and curling white highlights across the shoulder also recall the long mane that fell around the neck of Phaeton's gray horse. Possibly it was even a dapple-gray; the x-radiograph shows a stippled application of paint. By contrast, the left horse in The Conversion, which today is dapple-gray, was originally white, and its curling mane flew out to the left, as in the white horse Rubens added to The Fall of Phaeton. In the body of this horse, the $\mathrm{x}$-radiograph shows dense white where the gray paint of the revision overlapped the white original; however, Rubens's repaint did not cover the tightly folded foreleg (identical to the leg in Phaeton), and this leg discloses the horse's original creamy white color.

Rubens's experimentation in the Conversion series-as he reworked his oil sketch, started again with a new compositional drawing that he cut and modified further, and then reworked the final painting still more-underscores his persistence in seeking to balance narrative clarity with a formally and thematically satisfying composition. The sudden appearance of a pair of rearing horses in the Conversion painting-one white, one perhaps dappled-was an element that had not figured in either sketch or drawing. This pair of rearing horses clearly owes a debt to his final conception in The Fall of Phaeton. ${ }^{83}$ The material evidence that he undertook final revisions to Phaeton not in Italy, but after he had returned to Antwerp, suggests he could have worked on both paintings around the same time. It seems plausible that, in the face of repeated frustration, he turned to the still-unfinished Fall of Phaeton, which offered fertile ground for experimentation. There he made the compositional discovery that opened new possibilities in other works: the realization that the intertwined forms of two rearing horses rising above a tangled crowd could draw out new alignments where previously he had seen unresolved disorder.

\section{The Death of Hippolytus}

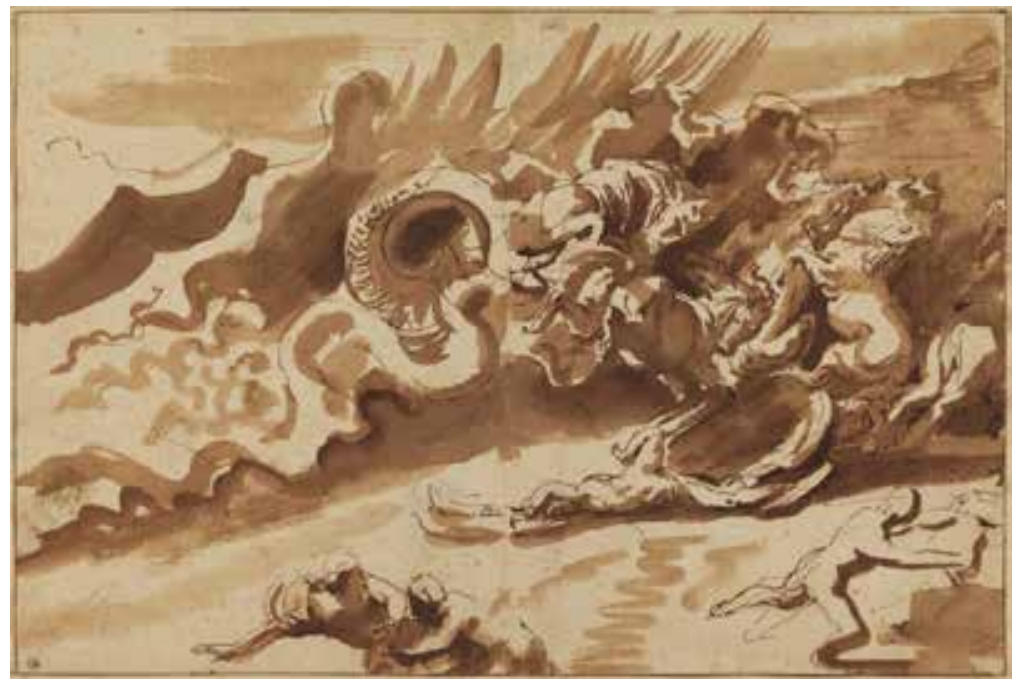

Fig. 58 Peter Paul Rubens, The Death of Hippolytus, ca. 1610-1612, pen and ink with wash on paper, 220 x $321 \mathrm{~mm}$. Bayonne, Musée Bonnat. Illustration from Held, Selected Drawings, 1986, fig. 58, cat. 60 (see Bibliography).

Once Rubens had found the rearing horses to be the solution to the challenges posed by the Conversion, he soon used them again in rendering the story of Hippolytus. This subject required fewer interlocking pieces than either The Fall of Phaeton or The Conversion of Saint Paul-a sea monster, 
four terrified horses, and an overturned chariot dragging the titular youth to his death-but the pair of rearing horses again served as the composition's structural anchor. Rubens depicted The Death of Hippolytus three times in these years: a preliminary drawing now in Bayonne (fig. 58), a panel painting in the collection of the Courtauld Institute Gallery of Art (fig. 59) (which was examined for this study), ${ }^{85}$ and a somewhat later painting on a copper panel, now in Cambridge (fig. 60) ${ }^{86}$ All three include the two rearing horses: in the Courtauld panel we see the now-familiar formulation of white and dapple-gray based on the pair in the final composition of Phaeton and in the Conversion painting (before the horses' coats were repainted), and by the time Rubens painted the Cambridge painting on copper, the contrast between the white horse and dapple-gray had become an established decorative formula, with parallel rows of dots along the gray horse's neck.

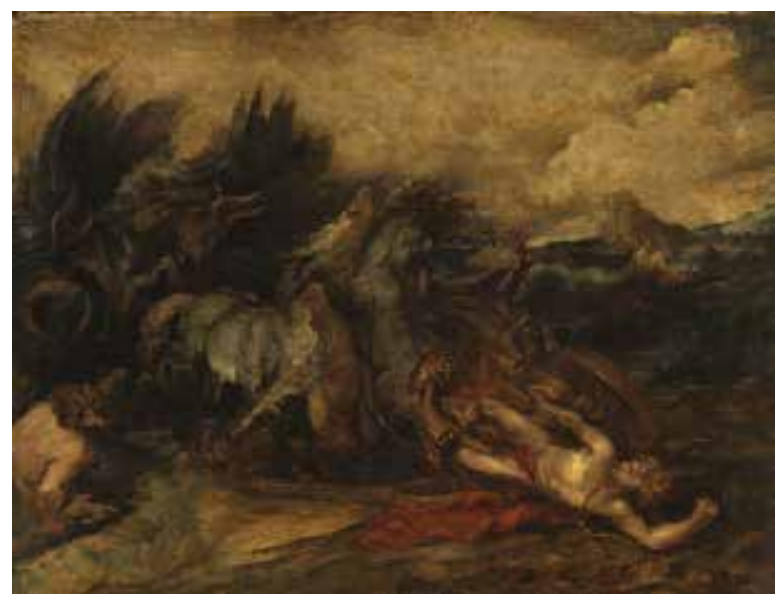

Fig. 59 Peter Paul Rubens, The Death of Hippolytus, ca. 1610-1612, oil on panel, $51 \times 65.1 \mathrm{~cm}$. London, The Courtauld Gallery, Bequest of Antoine (Count) Seilern (artwork in the public domain)

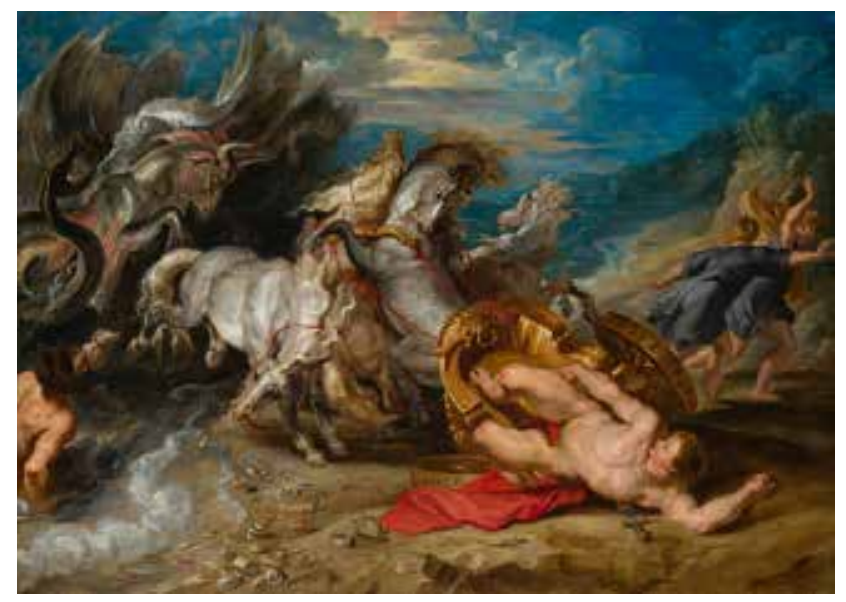

Fig. 60 Peter Paul Rubens, The Death of Hippolytus, ca. 1610-1612, oil on copper, $50.2 \times 70.8 \mathrm{~cm}$. ( The Fitzwilliam Museum, Cambridge (Accepted by H.M. Government in Lieu of Inheritance Tax and allocated to the Fitzwilliam Museum, 1979) (artwork in the public domain)

60 Details below the paint surface show that Rubens must have painted the rearing horses in the Hippolytus compositions after The Conversion of Saint Paul (figs. 61, 62). In the Courtauld and Cambridge paintings as they appear today, the white horse's muzzle turns away from its chariot mate, a change from those in Phaeton and the Conversion, where the horses' muzzles are almost parallel. But the muzzles are perfectly aligned in the drawing in Bayonne and in the first stage of the Courtauld panel (the preparatory underdrawing seen in IRR) (figs. 63, 64). Most important for the sequence of these works, the stance of the right-hand horse seems to derive from a variation Rubens introduced in the Conversion. In Hippolytus, the right-hand horse almost embraces its teammate, a stance like that in the Conversion, where Rubens changed a bent foreleg to a leg pushed against the left-hand horse's shoulder.

At some point in the years 1610-1612, there must have been a short period of intense activity when Rubens, in quick succession, made his final revisions to The Fall of Phaeton, initiated the finished painting for The Conversion of Saint Paul, and painted the Courtauld Death of Hippolytus. The pair of rearing horses that appears in each not only establishes that Rubens used his compositional innovation in all three works; close examination of this detail in the three also clarifies the sequence in which he worked on them. The interrelationships between these three different 


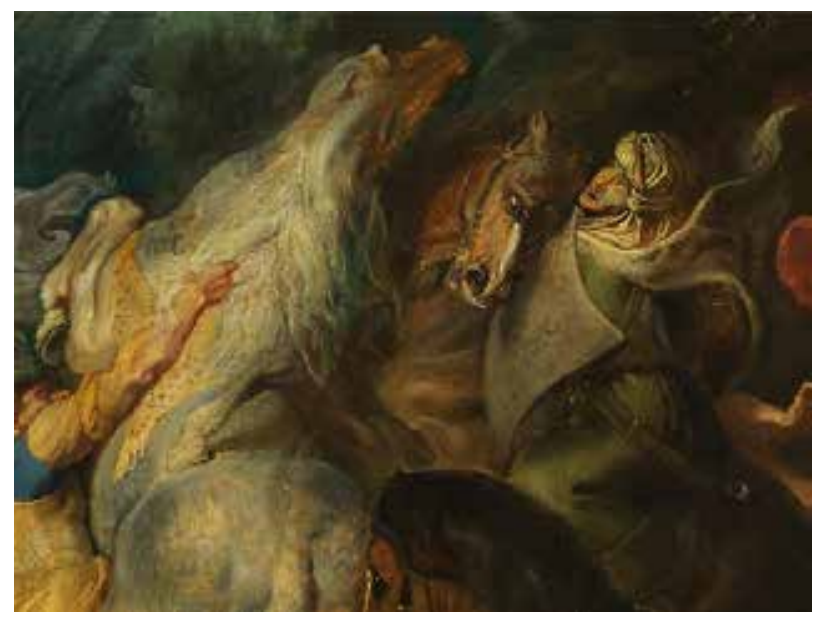

Fig. 61 Rubens, The Conversion of Saint Paul (painting), detail of fig. 54. As in The Fall of Phaeton, the horses' muzzles are aligned.

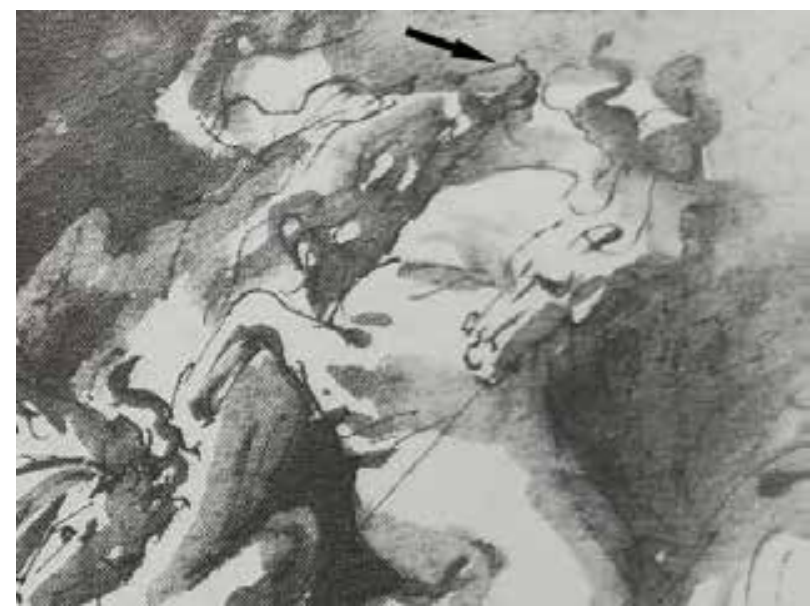

Fig. 63 Rubens, The Death of Hippolytus (drawing), detail of fig. 58. However, in the preparatory drawing Rubens planned to depict the horses with their muzzles aligned.

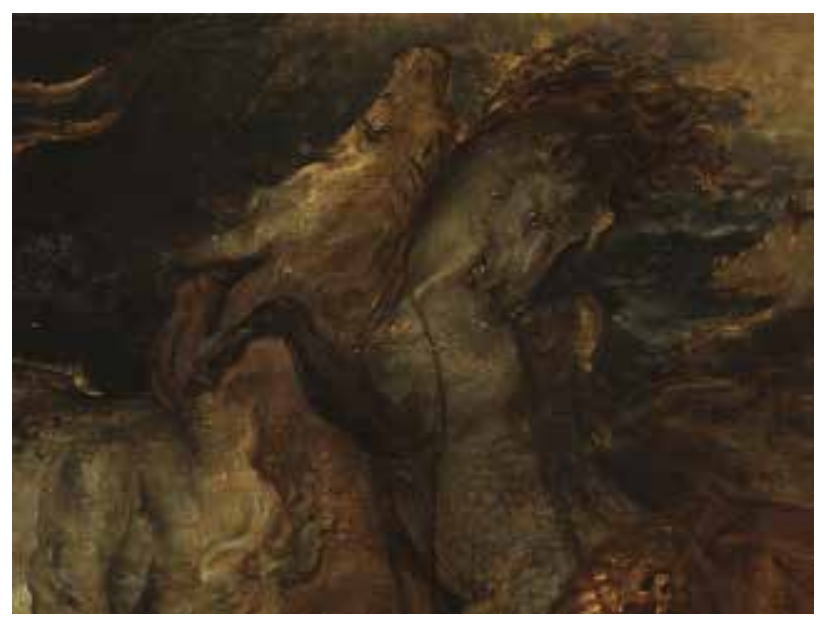

Fig. 62 Rubens, The Death of Hippolytus (Courtauld version), detail of fig. 59. In this painting Rubens varied the position of the horses slightly: the muzzle of the white horse here turns away from the gray.

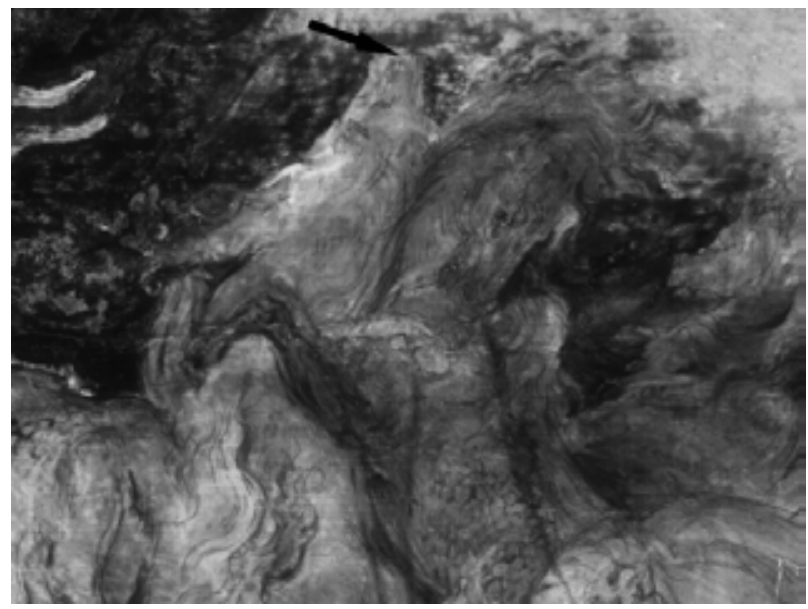

Fig. 64 Infrared reflectogram of Rubens, The Death of Hippolytus (Courtauld version), detail. The white arrow indicates underdrawing lines showing that when Rubens planned this painting, he still intended the white horse's muzzle to be aligned with the other horse.

subjects show that he did not develop each composition in isolation, moving from preliminary studies to finished painting in an orderly, linear sequence. His insights as he developed one scene of interlocking figures and animals must often have served as inspiration for another, sparking new lines of exploration. Technical study of the paintings allows a more precise estimation of how he jumped from one work to another as he experimented with design solutions.

\section{Conclusion}

62 The Fall of Phaeton offers a fascinating glimpse into Rubens's fertile mind. Early in his career he undertook a number of paintings whose narratives each posed a similar challenge: he sought to structure a crowded composition to depict chaotic events with both drama and clarity. But as he sought to clarify the relationship between intertwined figures and divine light, each new attempt 
seems to have left him dissatisfied.

63 Technical study of The Fall of Phaeton has revealed new complexities in the web of relationships among these paintings and has uncovered the sequence of Rubens's ideas. Around 1604-1605, he conceived of two paintings showing scenes from mythology: Hero and Leander and The Fall of Phaeton. In his first version of the Phaeton tale (Stage 1), he depicted a horrific, fiery scene, perhaps in counterpoint to the watery scene of mourning for Leander. Soon after, while still in Italy, he seems to have rethought The Fall of Phaeton, revising it into a brighter composition (Stage 2), suppressing the flames, and abstracting Jupiter's lightning. When Rubens returned to Antwerp late in 1608 , he seems to have brought the still-unfinished painting with him.

64 In Antwerp between 1610 and 1612, Rubens wrestled with similarly complex scenes. He initiated The Conversion of Saint Paul, first in an oil sketch and then in a more expansive compositional drawing, but he did not yet complete it. At this crucial moment, Rubens set it aside, and in a brief detour he again revised The Fall of Phaeton, which had posed similar problems some five years earlier. Using his earlier painting as a foundation for free improvisation (Stage 3), he quickly brushed blue sky between figures, focused the wash of light, and introduced a rearing white horse, pairing it with the original rearing dapple-gray. This was the solution he had sought: clarifying the relationship between a complex group of figures and divine intervention expressed as light. Rubens immediately put this crucial innovation to use; a pair of rearing horses soon appeared at the pinnacle of the figure group in the painting of The Conversion of Saint Paul (originally, like the Phaeton horses, showing a brilliantly lit white horse on the left and a dappled horse on the right). Shortly after this, he incorporated the same innovation as he painted The Death of Hippolytus, anchoring that composition, as well, with white and gray rearing horses based on Phaeton and the Conversion.

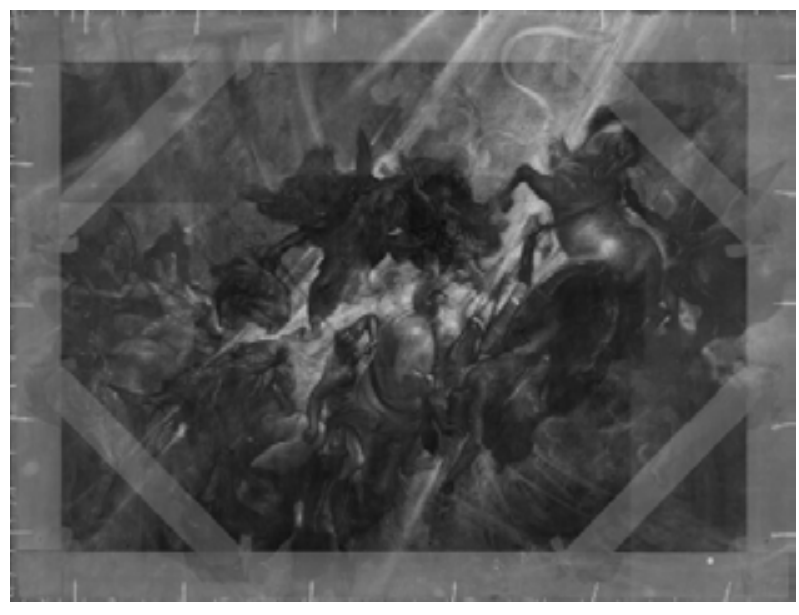

Fig. 65 X-radiograph, The Fall of Phaeton (captured by Douglas Lachance)

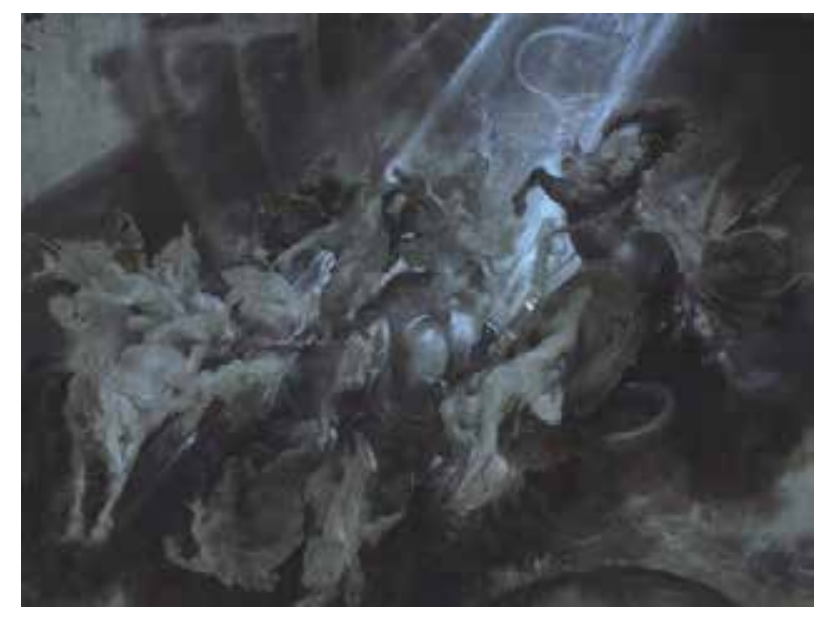

Fig. 66 False-color infrared reflectogram, The Fall of Phaeton (captured by John Delaney and Kate Dooley)

When Rubens set aside The Fall of Phaeton for the third and final time, he may still have regarded it more as improvisation than finished work. The brilliant painting we see today captures a moment of inspired experimentation. Technical study of this work-close study of the surface, images such as X-radiographs and IRR (figs. 65, 66) and analysis of microscopic paint samples- 
has offered new insights into the way that Rubens used the discoveries from one compositional puzzle to illuminate others. As often noted, Rubens frequently quoted his own works, but when such elements appear in multiple paintings, we should not picture a working practice in which he simply consulted his notebooks and then rearranged stock components. ${ }^{87}$ Rubens's creative process seems to have thrived at the intersection of different lines of inquiry. We can imagine the artist turning from one painting to another, and turning back again to earlier works, in a fluid, iterative process of invention. The interlocking figures of these compositions offer a metaphor for the interlocking chains of ideas that span his inventive career.

\section{Interactive Timeline}

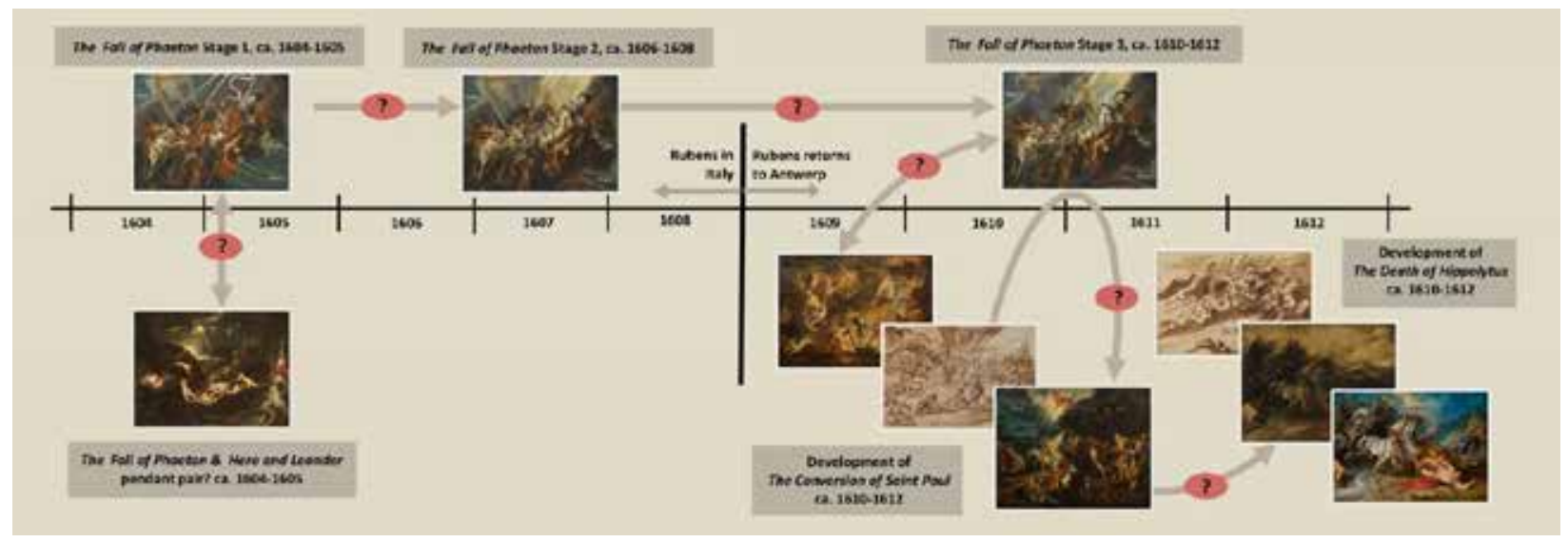

Fig. e Timeline of Peter Paul Rubens, The Fall of Phaeton, begun ca. 1604-1605, completed ca. 1610-1612 (Stage 3), oil on canvas, $98.4 \times 131.2 \mathrm{~cm}$. The National Gallery of Art, Washington, DC (timeline created by E. Melanie Gifford) This graphic lays out the relationship between The Fall of Phaeton and several other works by Rubens between 1604 and 1612. Click to open the image viewer, then hover over marked hot spots for annotations summarizing some of the material evidence discussed in this article. For further exploration, please visit "Exploration and Resources."

\section{Acknowledgements}

This interactive article is indebted to the imaginative skill of Jennifer Henel, Digital Humanities Developer, the expertise of programmer Morgan Schwartz, and the support of the Samuel H. Kress Foundation. The remarkable images were prepared by National Gallery of Art colleagues Kate Dooley, John Delaney, Douglas Lachance and Greg Williams. John Gordy, NGA web designer, taught me much about digital tools. Colleagues at institutions where I examined other works were most generous: Laurence Kanter, Ian McClure and Ashley Wingel at the Yale University Art Gallery; at the Courtauld Institute, Aviva Burnstock, Graeme Barraclough, Ketty Gottardo, Clare Richardson and Kate Stonor. I am grateful for the observations of Fiona Healy and Gregory Martin, contributors to forthcoming volumes of the Corpus Rubenianum Ludwig Burchard XI. 
Early results of this research appeared in Arthur K. Wheelock Jr's systematic catalogue of Flemish paintings at the NGA and were presented at a study day during the exhibition A Master in the Making (London, 2005). I have benefited from the keen insights of colleagues who read earlier drafts of this article: Alexandra Libby, Alison Kettering, Fiona Healy and peer reviewers. Finally, I am deeply grateful for the years I studied with Julius Held. My renewed immersion in the central focus of his scholarship - Peter Paul Rubens's inventive mind-has been an unalloyed pleasure.

Melanie Gifford is Research Conservator for Painting Technology at the National Gallery of Art. Her work focuses on the artistic decision-making process among Dutch and Flemish painters, using microscopic analysis of painting materials to address art historical questions. Before joining the NGA's Scientific Research Department, she worked for 15 years as a painting conservator at the Walters Art Museum in Baltimore. Her PhD in art history traced the development of naturalistic Dutch landscape paintings through the innovative painting practices of artists working at the start of the 17th century. Recent publications include studies of individual paintings by Van Eyck and Dürer as well as monographic studies of Lievens, Metsu and, with colleagues in Washington and Houston, the still life painter Willem van Aelst. Her recent research with Lisha Glinsman documents seventeenth-century evaluations of artistic style through technical study of artistic interactions among Dutch genre painters working 1650-1675.

Melanie Gifford

National Gallery of Art, Washington DC

Mailing address

2000-B South Club Drive, Landover MD 20785

m-gifford@nga.gov

\section{List of Illustrations}

Fig. 1 Peter Paul Rubens, The Fall of Phaeton, begun ca. 1604-1605, completed ca. 1610-1612 (Stage 3), oil on canvas, 98.4 x $131.2 \mathrm{~cm}$. The National Gallery of Art, Washington, DC (photo: Greg Williams) (artwork in the public domain) [IIIF multi-mode viewer]

Fig. 2 Leonardo da Vinci, A Rearing Horse, ca. 1503-1504, red chalk, pen, and ink on paper, 15.3 x $14.2 \mathrm{~cm}$. London, The Royal Collection Trust, RCIN 912336 (artwork in the public domain). Formerly in the collection of Pompeo Leoni [side-by-side viewer]

Fig. 3 The Fall of Phaeton, detail of rearing horses [side-by-side viewer]

Fig. 4 Roman, Aphrodite or “Crouching Venus," second century AD, marble, 125 x 53 x 65 cm. London, The Royal Collection Trust, RCIN 69746 (artwork in the public domain). Formerly in the Gonzaga Collection, Mantua [side-by-side viewer]

Fig. 5 The Fall of Phaeton, detail of crouching Hora [side-by-side viewer] 
Fig. 6 Jacopo Tintoretto, The Transportation of the Body of Saint Mark, ca. 1562-1566, oil on canvas, 398 x $315 \mathrm{~cm}$. Galleria dell'Accademia, Venice (artwork in the public domain) [side-by-side viewer]

Fig. 7 The Fall of Phaeton, detail showing overpainted reins and traces [IIIF multi-mode viewer]

Fig. 8 The Fall of Phaeton, detail of the lower right, in visible light and x-radiograph. An arrow indicates the foot of a Hora that Rubens painted over. [IIIF multi-mode viewer]

Fig. 9 The Fall of Phaeton, detail of upper Horae. Flickering red and orange brushstrokes between the figures are inconsistent with the golden light behind them. [IIIF multi-mode viewer]

Fig. 10 Left to Right: 10a-The Fall of Phaeton, detail from the center of fig. 9; 10b - X-radiograph of The Fall of Phaeton, the area shown in fig. 10a reveals flickering brushwork below the surface; 10c-False-color infrared reflectogram (IRR) of The Fall of Phaeton, detail of the area shown in fig. 10a reveals black sky hidden by later paint [IIIF multi-mode viewer]

Fig. 11 The Fall of Phaeton, detail of sky beside the central Horae, with an arrow indicating the location where a microscopic sample was taken from the edge of an existing loss. Layer 1: yellow-tan ground; Layers 2 and 3: black sky in Stage 1; Layer 4: yellow-white streak of light (Stage 2?); Layer 5: blue sky (Stage 3); Layer 6 is later restoration. [IIIF multi-mode viewer]

Fig. 12 The Fall of Phaeton, detail of Horae on left [IIIF multi-mode viewer]

Fig. 13 Peter Paul Rubens, A Lion Hunt, ca. 1614-1615, oil on panel, 73.6 x $105.4 \mathrm{~cm}$. The National Gallery, London, bought 1871 (artwork in the public domain) [side-by-side viewer]

Fig. 14 Rubens, A Lion Hunt, detail of the brown brushwork Rubens used in his oil sketches and to sketch out the preliminary design of his paintings. [side-by-side viewer]

Fig. 15 The Fall of Phaeton, detail. Sketch-like paint creates an unfinished appearance in the hand. [side-by-side viewer]

Fig. 16 The Fall of Phaeton, detail of the upper left, showing the original blue sky, white clouds, and tawny zodiac, which Rubens later muted with gray paint. [IIIF multi-mode viewer]

Fig. 17 The Fall of Phaeton, detail at the upper right, showing elements of Rubens's original composition (Stage 1): Horae and smoke illuminated by fire [IIIF multi-mode viewer]

Fig. 18 The Fall of Phaeton, detail. Rubens transformed the flames behind Phaeton (Stage 1) into a red cloak. [IIIF multi-mode viewer]

Fig. 19 Peter Paul Rubens, All Saints, ca. 1614, oil sketch on panel, 38 x 58 cm. Rotterdam, Boijmans van Beuningen Museum, Schenking / Donation: A. J. Lamme 1863, Studio Tromp, Rotter- 
dam (artwork in the public domain) [side-by-side viewer]

Fig. 20 Tintoretto, The Transportation of the Body of Saint Mark, detail of figures in fig. 6 [side-byside viewer]

Fig. 21 Peter Paul Rubens, The Transfiguration, ca. 1604-1606, oil on canvas, 407 x $670 \mathrm{~cm}$. Musée des Beaux-Arts de Nancy, Cliché P. Mignon, Inv. 71 (artwork in the public domain) [side-by-side viewer]

Fig. 22 Peter Paul Rubens, Hero and Leander, ca. 1605, oil on canvas, 95.9 x $128 \mathrm{~cm}$. New Haven, CT, Yale University Art Gallery (artwork in the public domain) [side-by-side viewer]

Fig. 23 The Fall of Phaeton as it appears today (Stage 3). The bright, clear colors are not consistent with the dark tonality of Hero and Leander. [IIIF multi-mode viewer]

Fig. 24 Infrared reflectogram of Peter Paul Rubens, Hero and Leander (captured by Kelsey Wingel) [side-by-side viewer]

Fig. 25 X-radiograph of Peter Paul Rubens, Hero and Leander [side-by-side viewer]

Fig. 26 Hero and Leander, detail of a Nereid [side-by-side viewer]

Fig. 27 The Fall of Phaeton, detail of Horae on left. Rubens often left a gap between figure and setting, revealing lower layers - the painted sketch or the ground itself-to serve as warm, brownish contours. [side-by-side viewer]

Fig. 28 X-radiograph of Rubens, Hero and Leander, detail, area of fig. 26 [side-by-side viewer]

Fig. 29 X-radiograph of The Fall of Phaeton, detail, area of fig. 27. In both x-radiographs, gaps between the figures and the setting appear as dark halos outlining the forms. [side-by-side viewer]

Fig. 30 Peter Paul Rubens, Hero and Leander, ca. 1605, oil on canvas, 95.9 x $128 \mathrm{~cm}$. New Haven, CT, Yale University Art Gallery (artwork in the public domain) [side-by-side viewer]

Fig. 31 Mock-up of the original composition (Stage 1) of The Fall of Phaeton shows a dark tonality that seems more consistent with Hero and Leander (mock-up created by E. Melanie Gifford) [IIIF multi-mode viewer]

Fig. 32 Rubens, Hero and Leander, detail of the lightning, is reminiscent of Tintoretto's work. [side-by-side viewer]

Fig. 33 Tintoretto, The Transportation of the Body of Saint Mark, detail of lightning in fig. 6 [sideby-side viewer]

Fig. 34 The Fall of Phaeton, detail. In his Stage 2 revisions, Rubens used yellowish paint (indicated 
with a white arrow) to fill in the space around the original whiplash lightning bolt, leaving fringes of the original gray sky. A black arrow indicates a wisp of the Stage 1 lightning, still visible below the later paint. [IIIF multi-mode viewer]

Fig. 35 X-radiograph of The Fall of Phaeton, detail of the area in fig. 34. The dense yellow paint Rubens brushed close to the lightning bolt in Stage 2 appears light-colored, while evidence of the original gray sky can be seen in a narrow, dark-colored zone around the lightning. [IIIF multimode viewer]

Fig. 36 The Fall of Phaeton, detail of the space between the Horae at left. An arrow indicates toes still visible after another leg was painted out. [IIIF multi-mode viewer]

Fig. 37 X-radiograph of The Fall of Phaeton, area shown in fig. 36. An arrow indicates a leg hidden when Rubens later added a diagonal beam. [IIIF multi-mode viewer]

Fig. 38 Mock-up of the original composition (Stage 1) of The Fall of Phaeton (mock-up created by E. Melanie Gifford) [IIIF multi-mode viewer]

Fig. 39 Mock-up of Stage 2 (the first revision) of The Fall of Phaeton (mock-up created by E. Melanie Gifford). Rubens covered over the flames with gray clouds and expanded the lightning bolt into a diagonal wash of golden light. [IIIF multi-mode viewer]

Fig. 40 The Fall of Phaeton, detail. In Stage 3 Rubens rapidly painted blue sky around the figure, covering the original blackish sky. [IIIF multi-mode viewer]

Fig. 41 The Fall of Phaeton, detail of rearing horses [IIIF multi-mode viewer]

Fig. 42 False-color infrared reflectogram of The Fall of Phaeton, detail. The added white horse covered a complex tangle of harness and traces. [IIIF multi-mode viewer]

Fig. 43 Mock-up of the first revision (Stage 2) of The Fall of Phaeton (mock-up created by E. Melanie Gifford) [IIIF multi-mode viewer]

Fig. 44 The Fall of Phaeton (Stage 3). In his final, experimental revisions, Rubens rapidly painted blue sky around some figures and introduced the rearing white horse that crowns the composition. [IIIF multi-mode viewer]

Fig. 45 The Fall of Phaeton, detail of the added white horse, with an arrow indicating the location where a microscopic sample was taken from the edge of an existing loss. The paint cross section includes layers from all three stages of the composition. Layer 1: yellow-tan ground; layers 2 and 3: smoke in Stage 1; layers 4 and 5: golden light in Stage 2; layers 6 and 7: blue sky and white horse in Stage 3 (layer 8 is later restoration). [IIIF multi-mode viewer]

Fig. 46 Peter Paul Rubens, The Conversion of Saint Paul, ca. 1599-1601, oil on panel, 72 x $103 \mathrm{~cm}$. (C) Liechtenstein, The Princely Collections, Vaduz-Vienna (Scala, Florence / Art Resource, NY) 
(artwork in the public domain) [side-by-side viewer]

Fig. 47 Peter Paul Rubens, The Conversion of Saint Paul (oil sketch), ca. 1610-1612, oil on panel, 57.4 x $78.1 \mathrm{~cm}$. London, The Courtauld Gallery, Bequest of Antoine (Count) Seilern (artwork in the public domain) [side-by-side viewer]

Fig. 48 Rubens, The Conversion of Saint Paul (oil sketch), detail of fig. 47 showing hasty brushwork reminiscent of the final revisions to The Fall of Phaeton. A white box marks the area shown in fig. 49. [side-by-side viewer]

Fig. 49 Rubens, The Conversion of Saint Paul (oil sketch), close detail of area shown in white box in fig. 48 [side-by-side viewer]

Fig. 50 The Fall of Phaeton, detail of blue sky added with rapid brushwork in Stage 3 [side-by-side viewer]

Fig. 51 Peter Paul Rubens, The Conversion of Saint Paul (preparatory drawing), ca. 1610-1612, pen and brown ink with wash and white bodycolor on paper, 32.9 x $22.2 \mathrm{~cm}$. London, The Courtauld Gallery, Bequest of Antoine (Count) Seilern (artwork in the public domain) [side-by-side viewer]

Fig. 52 Rubens, The Conversion of Saint Paul (preparatory drawing), detail of light rays in fig. 51 [side-by-side viewer]

Fig. 53 Infrared reflectogram of Rubens, Hero and Leander, detail of fig. 22, showing similar light rays that Rubens indicated in his painted sketch. [side-by-side viewer]

Fig. 54 Peter Paul Rubens, The Conversion of Saint Paul, ca. 1610-1612, oil on panel, $95.2 \times 120.7$ $\mathrm{cm}$. London, The Courtauld Gallery, Bequest of Antoine (Count) Seilern (artwork in the public domain) [side-by-side viewer]

Fig. 55 Rubens, The Conversion of Saint Paul (painting), detail. In the final version of the painting, the horse on the right was painted brown. The horse on the left was repainted dapple-gray, but the unrevised foreleg (indicated by a yellow arrow) is still white. [side-by-side viewer]

Fig. 56 X-radiograph of Rubens' The Conversion of Saint Paul (painting). A detail of the area in fig. 55 shows that originally the horses were like those in The Fall of Phaeton. The black arrow indicates stippled handling that suggests the horse on the right was originally dappled. The white arrows indicate white highlights in this horse's mane and a flying white mane on the left-hand horse. The red arrow indicates evidence that the right-hand horse had a long, curling mane. [sideby-side viewer]

Fig. 57 The Fall of Phaeton, detail. Arrows correspond to features appearing in the original depiction in The Conversion of Saint Paul (see fig. 56) [side-by-side viewer]

Fig. 58 Peter Paul Rubens, The Death of Hippolytus, ca. 1610-1612, pen and ink with wash on 
beige laid paper, 218 x 327 mm. Bayonne, Musée Bonnat-Helleu (ㄷ Bayonne, Musée Bonnat-Helleu/ photograph A. Vaquero; artwork in the public domain) [side-by-side viewer]

Fig. 59 Peter Paul Rubens, The Death of Hippolytus, ca. 1610-1612, oil on panel, 51 x $65.1 \mathrm{~cm}$. London, The Courtauld Gallery, Bequest of Antoine (Count) Seilern (artwork in the public domain) [side-by-side viewer]

Fig. 60 Peter Paul Rubens, The Death of Hippolytus, ca. 1610-1612, oil on copper, 50.2 x $70.8 \mathrm{~cm}$. (c) The Fitzwilliam Museum, Cambridge (Accepted by H.M. Government in Lieu of Inheritance Tax and allocated to the Fitzwilliam Museum, 1979, http://data.fitzmuseum.cam.ac.uk/id/object/1865 (artwork in the public domain) [side-by-side viewer]

Fig. 61 Rubens, The Conversion of Saint Paul (painting), detail of fig. 54. As in The Fall of Phaeton, the horses' muzzles are aligned. [side-by-side viewer]

Fig. 62 Rubens, The Death of Hippolytus (Courtauld version), detail of fig. 59. In this painting Rubens varied the position of the horses slightly: the muzzle of the white horse here turns away from the gray. [side-by-side viewer]

Fig. 63 Rubens, The Death of Hippolytus (drawing), detail of fig. 58. However, in the preparatory drawing Rubens planned to depict the horses with their muzzles aligned. [side-by-side viewer]

Fig. 64 Infrared reflectogram of Rubens, The Death of Hippolytus (Courtauld version), detail. The white arrow indicates underdrawing lines showing that when Rubens planned this painting, he still intended the white horse's muzzle to be aligned with the other horse. [side-by-side viewer]

Fig. 65 X-radiograph, The Fall of Phaeton (captured by Douglas Lachance) [IIIF multi-mode viewer]

Fig. 66 False-color infrared reflectogram, The Fall of Phaeton (captured by John Delaney and Kate Dooley) [IIIF multi-mode viewer]

Fig. e Timeline of Peter Paul Rubens, The Fall of Phaeton, begun ca. 1604-1605, completed ca. 1610-1612 (Stage 3), oil on canvas, $98.4 \times 131.2 \mathrm{~cm}$. The National Gallery of Art, Washington, DC (timeline created by E. Melanie Gifford) This graphic lays out the relationship between The Fall of Phaeton and several other works by Rubens between 1604 and 1612. Click to open the image viewer, then hover over marked hot spots for annotations summarizing some of the material evidence discussed in this article. For further exploration, please visit "EXPLORATION AND RESOURCES." [side-by-side viewer]

\section{Bibliography}

Ainsworth, Maryan Wynn, Egbert Haverkamp-Begemann, John Brealey, Pieter Meyers. Art and 
Autoradiography: Insights into the Genesis of Paintings by Rembrandt, Van Dyck and Vermeer. New York: The Metropolitan Museum of Art, 1982.

Andrews, Keith. Catalogue of Netherlandish Drawings in the National Gallery of Scotland. Edinburgh: National Gallery of Scotland, 1985.

D’Arco, Carlo. Delle arti e degli artefici di Mantova. Mantua: D. Agazzi, 1857.

Bauman, Guy, and Walter A. Liedtke. Flemish Paintings in America: A Survey of Early Netherlandish and Flemish paintings in the Public Collections of North America. Antwerp: Fonds Mercator, 1992.

Beal, Mary Rose Sylvia. "A Study of Richard Symonds: His Italian Notebooks and their Relevance to Seventeenth-Century Painting Techniques.” PhD diss., Courtauld Institute of Art, 1978.

Belkin, Kristin Lohse. "Rubens's Latin Inscriptions in his Copies after Holbein's Dance of Death." Journal of the Warburg and Courtauld Institutes 52 (1989): 245-50.

Bergeon, Ségolène. Science et patience, ou la restauration des peintures. Paris: Editions de la Réunion des musées nationaux, 1990.

Berrie, Barbara, and Louisa Matthew. "Lead White from Venice: A Whiter Shade of Pale?" In Studying Old Master Paintings, Technology and Practice, edited by Marika Spring, 295-301. London: Archetype Publications, 2011.

Christensen, Carol, Michael Palmer, and Michael Swicklick. "Van Dyck's Painting Technique, His Writings, and Three Paintings in the National Gallery of Art." In Anthony van Dyck, edited by Arthur K. Wheelock Jr., Susan J. Barnes, and Julius S. Held, 45-52. Exh. cat. Washington, DC: National Gallery of Art, 1990.

Conover, Damon M., John K. Delaney, and Murray H. Loew. "Automatic Registration and Mosaicking of Technical Images of Old Master Paintings.” Applied Physics A 119 (2015): 1567-75.

Doherty, Tiarna, Mark Leonard, and Jørgen Wadum. "Brueghel and Rubens at Work: Technique and the Practice of Collaboration." In Rubens \& Brueghel: A Working Friendship, edited by Anne T. Woollett and Ariane van Suchtelen, 215-251. Exh. cat. Los Angeles: J. Paul Getty Museum and The Hague, The Mauritshuis, 2006.

Durante, Stephanie-Suzanne. “The Conversion of Saint Paul." In Peter Paul Rubens: A Touch of Brilliance: Oil Sketches and Related Works from The State Hermitage Museum and the Courtauld Institute Gallery, 66-73. Exh. cat. London: Courtauld Institute of Art, 2003.

Eastaugh, Nicholas, Valentine Walsh, Tracey Chaplin, and Ruth Siddall. The Pigment Compendium: Optical Microscopy of Historical Pigments. Oxford, UK: Elsevier Butterworth Heinemann, 2004. 
Freedberg, David. Rubens: The Life of Christ After the Passion. Corpus Rubenianum VII. London: Harvey Miller Ltd, 1984.

Génard, Pierre. P. P. Rubens: Aanteekeningen over den grooten Meester en zijne bloedverwanten. Antwerp: Boekhandel van P. Kockx, 1877.

Gifford, E. Melanie. "Style and Technique in the Evolution of Naturalism: North Netherlandish Landscape Painting in the Early Seventeenth Century." PhD diss., University of Maryland, College Park, 1997.

Golahny, Amy. "Rubens' Hero and Leander and its Poetic Progeny." Yale University Art Gallery Bulletin (1990): 20-37.

Healy, Fiona. "Losing Control of the Senses: The Fifth Horse in Rubens's Fall of Phaeton." In Von Kunst und Temperament: Festschrift für Eberhard König, edited by Caroline Zöhl and Mara Hofmann with contributions by Marion Kaminski, Stephanie Buck, and Maximilian Benke, 10518. Ars nova. Turnhout: Brepols, 2007.

Held, Julius S. The Oil Sketches of Peter Paul Rubens: A Critical Catalogue. Kress Foundation Studies in the History of European Art. Princeton, NJ: Princeton University Press, 1980.

- . Rubens: Selected Drawings. 2nd ed. Oxford: Phaidon Press, 1986.

Higgitt, Catherine, Marika Spring, and David Saunders. "Pigment-medium Interactions in Oil Paint Films containing Red Lead or Lead-Tin Yellow." National Gallery Technical Bulletin 24 (2003): 75-95.

Van Hout, Nico. "Meaning and Development of the Ground Layer in Seventeenth-Century Painting." In Looking through Paintings: The Study of Painting Techniques and Materials in Support of Art Historical Research, edited by Erma Hermens, Annemiek Ouwerkerk, and Nicola Costaras. Leids hunsthistorisch jaarboek 11 (1998): 199-225.

Van Hout, Nico, and Arnout Balis. Rubens Unveiled: Notes on the Master's Painting Technique. Exh. cat. Antwerp: Koninklijk Museum voor Schone Kunsten, 2012.

Jaffé, David, Elizabeth McGrath, Amanda Bradley, Ulrich Heinen, Veronika Kopecky, and Delfina Bergamaschi. Rubens: A Master in the Making. Exh. cat. London: National Gallery, 2005.

Jaffé, Michael. "Samson Destroying the Temple of Dagon: A Rediscovered Rubens." Apollo 139 (December 1993): 377-82.

- . Rubens and Italy. Ithaca: Cornell University Press, 1977.

- . "Rubens in Italy: Rediscovered Works," The Burlington Magazine 100, no. 669 (December 
1958): 411-422, 426.

Johnson, Don H., C. Richard Johnson, and Robert G. Erdmann, "Weave Analysis of Paintings on Canvas from Radiographs." Signal Processing 93 (2013): 527-40.

Kamba, Nobuyuki. "Scientific Examination of the Ground, Pigments and Painting Techniques Used in Three Versions of The Flight of Lot and His Family from Sodom." In Rubens and His Workshop: "The Flight of Lot and His Family from Sodom," edited by Toshiharu Nakamura, 69-94. Exh. cat. Tokyo: The National Museum of Western Art, 1994.

Kirby, Jo. “The Painter's Trade in the Seventeenth Century: Theory and Practice." National Gallery Technical Bulletin 20 (1999): 5-49.

Lammertse, Friso and Alejandro Vergara. Rubens: Painter of Sketches. Exh. cat. Madrid: Museo del Prado and Rotterdam: Museum Boijmans Van Beuningen, 2018.

Lindberg, David C. The Beginnings of Western Science: The European Scientific Tradition in Philosophical, Religious, and Institutional Context, Prehistory to a.d. 1450. 2nd ed. Chicago: University of Chicago Press, 2007. The Letters of Peter Paul Rubens, translated and edited by Ruth Saunders Magurn. Cambridge, MA: Harvard University Press, 1955.

Martin, Gregory. The Flemish School: Circa 1600-Circa 1900. London: National Gallery, 1970.

- . "Hero and Leander." In Rubens: Mythological Subjects 2. Corpus Rubenianum Ludwig Burchard XI. London and Turnhout: Harvey Miller Publishers/Brepols, forthcoming.

McGrath, Elizabeth. "Rubens and Classical Myth: An Introduction.” In McGrath, Martin, Healy, Schepers, Van de Velde, and De Clippel, Mythological Subjects 1.

McGrath, Elizabeth, Gregory Martin, Fiona Healy, Bert Schepers, Carl van de Velde, and Karolien de Clippel. Rubens: Mythological Subjects 1: Achilles to the Graces. Corpus Rubenianum Ludwig Burchard XI. London and Turnhout: Harvey Miller Publishers/Brepols, 2016.

Müller-Hofstede, Justus. "An Early Rubens Conversion of Saint Paul: The Beginning of his Preoccupation with Leonardo's Battle of Anghiari.” The Burlington Magazine 106, no. 732 (1964): 94-103, 105-106.

Muller, Jeffrey M. Rubens: The Artist as Collector. Princeton, NJ: Princeton University Press, 1989.

Noble, Petria, Jaap J. Boon, and Jørgen Wadum. "Dissolution, Aggregation and Protrusion: Lead Soap Formation in 17th-Century Grounds and Paint Layers." ArtMatters: Netherlands Technical Studies in Art 1 (2002): 46-61. Ovid. Metamorphoses. Translated by Brookes Moore. The Theoi Classical Texts Library, https://www.theoi.com/Text/OvidMetamorphoses2.html.

De Piles, Roger. Abrégé de la Vie des Peintres, Avec des réflexions sur leurs Ouvrages, Et un Traité 
du Peintre ... Paris: Chez Charles de Sercy, 1699.

Peter Paul Rubens, 1577-1640. Exh. cat. Cologne: Museen der Stadt Köln, 1977.

Plesters, Joyce. “Tintoretto's Paintings in the National Gallery: Part I." National Gallery Technical Bulletin 3 (1979): 3-24.

- . “Tintoretto's Paintings in the National Gallery: Part II.” National Gallery Technical Bulletin 4 (1980): 32-48.

Plesters, Joyce, and Lorenzo Lazzarini. "Preliminary Observations on the Technique and Materials of Tintoretto." Conservation of Paintings and the Graphic Arts: Preprints of Contributions to The Lisbon Congres 1972, 153-70. London: The International Institute for Conservation of Historic and Artistic Works, 1972.

Scott-Elliot, A. H. "Statues from Mantua in the Collection of King Charles I." The Burlington Magazine 101, no. 675 (1959): 218-27.

Seilern, Antoine. Corrigenda \& Addenda to the Catalogue of Paintings \& Drawings at 56 Princes Gate, London SW7. London: Shenval Press, 1971.

- . Flemish Paintings \& Drawings at 56 Princes Gate, London SW7. London: Shenval Press, 1955.

Von Sonnenburg, Hubert. "Rubens' Bildaufbau und Technik, I: Bildträger, Gruniereung un Vorskizzierung." Mahltecknik Restauro 85, no. 2 (1979): 77-100.

- . "Rubens' Bildaufbau und Technik, II: Farbe und Auftragstechnik," Mahltecknik Restauro 85, no. 3 (1979): 181-203.

Stols-Witlox, Maartje. “From Reading to Painting': Authors and Audiences of Dutch Recipes for Preparatory Layers for Oil Painting." Early Modern Low Countries 1 (2017): 71-134.

Stols-Witlox, Maartje, Tiarna Doherty, and Barbara Schoonhoven. "Reconstructing Seventeenth-century Streaky Imprimatura Layers Used on Panel Paintings." In Preparation for Painting: The Artist's Choice and its Consequences, edited by Joyce H. Townsend, Tiarna Doherty, Gunnar Heydenreich, and Jacqueline Ridge, 79-91. London: Archetype Publications, 2008.

Vlieghe, Hans. Saints. Corpus Rubenianum Ludwig Burchard VIII. London and New York: Phaidon, 1973.

Wheelock, Arthur K., Jr. Flemish Paintings of the Seventeenth Century. Washington, DC: National Gallery of Art, 2005.

Wood, Jeremy. “Damaged by Time and Rubens': Rubens's Restorations and Retouchings," Apollo (1995): 16-23. 
${ }^{1}$ National Gallery of Art, Washington, DC, inv. no. 1990.1.1.

${ }^{2}$ Fiona Healy notes that in addition to Ovid's telling of the tale, Rubens would also have known versions by Nonnos and Philstratus the Elder (Fiona Healy, "Losing Control of the Senses: The Fifth Horse in Rubens's Fall of Phaeton," in Von Kunst und Temperament: Festschrift für Eberhard König, ed. Caroline Zöhl and Mara Hofmann [Turnhout: Brepols, 2007], 86).

${ }^{3}$ Healy suggests that Rubens might have derived the unusual detail of the twelve Horae from Nonnos. Healy, "Losing Control of the Senses," 86.

${ }^{4}$ Michael Jaffé, Rubens and Italy (Ithaca: Cornell University Press, 1977), 30, 71, 79-80; Arthur K. Wheelock Jr., Flemish Paintings of the Seventeenth Century (Washington, DC: National Gallery of Art, 2005), 149-50.

${ }^{5}$ Leonardo's drawing illustrated here (Royal Collection Trust inv. no. 912336) must have been among the drawings showing Leonardo's mastery of the anatomy of horses that Rubens described studying in that collection. Roger de Piles, Abrégé de la vie des Peintres, avec des réflexions sur leurs ouvrages, Et un Traité du Peintre . . (Paris: Chez Charles de Sercy, 1699), 168; for drawing's provenance, "Leonardo da Vinci - A Rearing Horse," Royal Collection Trust, accessed June 21, 2019, HTTPS://WWW.RCT.UK/COLLECTION/912336/A-REARING-HORSE.

${ }^{6}$ In Mantua Rubens would have known the version of the Crouching Venus illustrated here (Royal Collection Trust inv. no. 69746), which was recorded in the 1627 inventory of the Gonzaga collection. Carlo d'Arco, Delle arti e degli artefici di Mantova (Mantua: D. Agazzi, 1857), 2:169; A. H. Scott-Elliot, "Statues from Mantua in the Collection of King Charles I," The Burlington Magazine 101, no. 675 (1959): 220.

${ }^{7}$ Musée des beaux-arts de Nancy, inv. no. 71.

${ }^{8}$ Venice, Gallerie dell'Accademia, cat. no. 831. Michael Jaffé, "Rubens in Italy: Rediscovered Works," The Burlington Magazine 100, no. 669 (December 1958): 416, 419; Jaffé, Rubens and Italy, 36.

9 Jaffé, "Rediscovered Works," 415-19.

${ }^{10}$ Jaffé, "Rediscovered Works," 416; Jaffé, Rubens and Italy, 71; Wheelock, Flemish Paintings, 146, 151.

${ }^{11}$ Wheelock, Flemish Paintings, 151.

${ }^{12}$ Julius S. Held, Rubens Selected Drawings (Oxford: Phaidon Press, 1986), 93-94; Julius S. Held, The Oil Sketches of Peter Paul Rubens: A Critical Catalogue (Princeton, NJ: Princeton University Press, 1980), 333-34, 578-80.

${ }^{13}$ Wheelock, Flemish Paintings, 146, 151, 152 n. 2, 153 n. 23.

${ }^{14}$ Jaffé, "Rediscovered Works," 146; Wheelock, Flemish Paintings, 151.

${ }^{15}$ The original research was briefly summarized in the systematic catalogue of Flemish paintings at the National Gallery (Wheelock, Flemish Paintings). At the start of that project, Adam Greenhalgh, then a summer intern at the National Gallery, joined some initial examination sessions of The Fall of Phaeton and drafted interesting thoughts on the possible evolution of the painting.

${ }^{16}$ In addition to the colleagues thanked in the Acknowledgments, Clare Richardson and Kate Stonor have kindly discussed their new technical research on the Conversion of Saint Paul series at the Courtauld. Their findings are forthcoming in an future article in the Journal of Historians of Netherlandish Art (hereafter Richardson and Stonor, forthcoming).

${ }^{17}$ Yale University Art Gallery, inv. no. 1962.25.

${ }^{18}$ The Courtauld Gallery, Bequest of Antoine (Count) Seilern (inv. no. P.1978.PG.358).

${ }^{19}$ The Courtauld Gallery, Bequest of Antoine (Count) Seilern (oil sketch: inv. no. P.1978.PG.356; 
drawing: inv. no. D.1978.PG.57; painting: inv. no. P.1978.PG.357).

${ }^{20}$ Jeremy Wood, “Damaged by Time and Rubens': Rubens's Restorations and Retouchings," Apollo (1995): 16-23.

${ }^{21}$ The painting's surface was examined by the author using a stereomicroscope at up to $50 \mathrm{x}$ magnification. Digital x-radiography was carried out by Douglas Lachance using a Comet XRP75MXR-75HP unit (at $35 \mathrm{kev}, 8 \mathrm{~mA}$ and 30-second exposures) with Carestream Industrex Blue digital imaging plates. Kate Dooley mosaicked the fifteen plates by registering (i.e. spatially aligning) the sub images to a high-resolution color image using custom registration software (Damon M. Conover, John K. Delaney, and Murray H. Loew, "Automatic Registration and Mosaicking of Technical Images of Old Master Paintings.” Applied Physics A 119 (2015): 1567-75.Infrared reflectograms were captured by Kate Dooley and John Delaney using a custom IRR system consisting of a $55 \mathrm{~mm}$ EFL near infrared lens (Stingray Optics, Keene, NH) and an infrared camera (model IRC912, IRCameras, Santa Barbara, CA) that has a $1280 \times 1024$ pixel InSb focal plane array of detectors. An interference filter at the cold stop of the dewar limits the spectral sensitivity to 1000$2500 \mathrm{~nm}$. Three IR reflectograms were collected using IR interference bandpass filters that pass only portions of the IR spectral range (1100-1400 nm, 1500-1800 nm, and 2100-2400 nm). Kate Dooley mosaicked each IR reflectogram to a high-resolution color image as above, and combined these in a false-color IRR.The false-color IRR image was created by placing the three individual IR reflectograms into the red, green, and blue color channels of a digital RGB color image. This is a useful way to visually distinguish areas painted with different artists' materials. Because different materials have different reflectance in the three IR spectral bands, a "false-color" image results from overlaying the reflectograms.

${ }^{22}$ A small number of microscopic paint samples were analyzed by the author using a Leica DMRX polarizing light research microscope at up to 500x magnification. Dispersed samples, consisting of a few grains of pigment removed from the paint surface, were mounted in Cargille Meltmount $(n=1.66)$ for microscopic examination in transmitted light. Paint cross-section samples were mounted in polyester resin, then ground and polished to expose the sequence of paint and ground layers.

${ }^{23}$ The fine, plain-weave canvas measures 17.3 threads/cm in the warp direction and 14 threads/ $\mathrm{cm}$ in the weft direction. Automated thread counting analysis was carried out by Kelsey Wingel (Yale University Art Museum) with the assistance of Dr. Don H. Johnson (Thread Count Automation Project, Rice University) using the protocols and software developed by Dr. Don H. Johnson and Dr. C. Richard Johnson (Don H. Johnson, C. Richard Johnson, and Robert G. Erdmann, "Weave Analysis of Paintings on Canvas from Radiographs." Signal Processing 93 (2013): 52740. ). Kelsey Wingel, email message to the author, February 14, 2019. SEM-EDS analysis of the ground identified a translucent matrix of siliceous earths, calcite, and traces of dolomite, colored with small amounts of ochre and charcoal black.

${ }^{24}$ Although the literature on Rubens's painting materials and techniques is extensive (for comprehensive overviews, see Hubert von Sonnenburg, "Rubens' Bildaufbau und Technik, I: Bildträger, Gruniereung un Vorskizzierung," Mahltecknik Restauro 85, no. 2 [1979]: 77-100; Hubert von Sonnenburg, "Rubens' Bildaufbau und Technik, II: Farbe und Auftragstechnik," Mahltecknik Restauro 85, no. 3 [1979]: 181-203; Nico van Hout and Arnout Balis, Rubens Unveiled: Notes on the Master's Painting Technique, exh. cat. [Antwerp: Koninklijk Museum voor Schone Kunsten], 2012), technical studies focused on early works, including works from Rubens's years in Italy, are limited. Typically, oak panels in Antwerp were prepared with a white, chalk-based lower ground, 
lightly toned by an upper ground, or imprimatura. Kirby, "The Painter's Trade in the Seventeenth Century: Theory and Practice," National Gallery Technical Bulletin 20 (1999): 17-22, 27-28; Nico van Hout, "Meaning and Development of the Ground Layer in Seventeenth-Century Painting," in Looking through Paintings: The Study of Painting Techniques and Materials in Support of Art Historical Research, edited by Erma Hermens, Annemiek Ouwerkerk, and Nicola Costaras. Leids kunsthistorisch jaarboek 11 (1998): 199-225."; Von Sonnenburg, "Rubens' Bildaufbau und Technik, II," 77-83.

${ }^{25}$ The recognizable "streaky imprimatura" that Rubens left visible in most of his oil sketches is often thought of as characteristic of the artist's personal painting practices (Von Sonnenburg, "Rubens' Bildaufbau und Technik, I," 89-92). However, such preparations appear in works by many painters active in Antwerp in the first half of the seventeenth century (Van Hout and Balis, Rubens Unveiled, 42-45; Van Hout, "Meaning and Development of the Ground Layer," 205-10). This raises the possibility that artists could have purchased panels already prepared with a streaky imprimatura. The author has observed a case, Vista from a Grotto by David Teniers (early 1630s; National Gallery of Art, Washington, DC), in which an artist seems to have obscured a translucent, brownish imprimatura with a thick, opaque, gray preparation layer, completely changing the visual effect of the painting surface (E. Melanie Gifford, "Style and Technique in the Evolution of Naturalism: North Netherlandish Landscape Painting in the Early Seventeenth Century" [PhD diss., University of Maryland, College Park, 1997], 86; Wheelock, Flemish Paintings, 232). It seems possible that this sequence is evidence of an artist modifying a commercially prepared panel. For an investigation into the materials and processes used for such preparations, see Maartje Stols-Witlox, Tiarna Doherty, and Barbara Schoonhoven, "Reconstructing Seventeenth-Century Streaky Imprimatura Layers Used on Panel Paintings," in Preparation for Painting: The Artist's Choice and its Consequences, ed. Joyce H. Townsend, Tiarna Doherty, Gunnar Heydenreich, and Jacqueline Ridge (London: Archetype Publications, 2008), 79-91.

${ }^{26}$ Richard Symonds, who traveled to Rome between 1649 and 1651, commented on the popularity of coarsely woven canvases in Italy, but finely woven canvases, some exported from Flanders, were also used (Mary Rose Sylvia Beal, "A Study of Richard Symonds: His Italian Notebooks and their Relevance to Seventeenth-Century Painting Techniques" [PhD diss., Courtauld Institute of Art, 1978), 85; Kirby, “The Painter's Trade," 25]. It is possible that in choosing a finely woven canvas Rubens continued to use Flemish canvas (either from a supply he had brought with him or purchased locally), but this ground seems typical of Italian practices. Symonds describes a ground for canvas paintings used by his mentor, Giovanni Angelo Canini, that is very similar to the ground of The Fall of Phaeton: based on earth pigments ("the earth that bricks are made from") and creta, which could indicate siliceous earths and clays as well as chalk (Beal, "Richard Symonds," 87, 218).

${ }^{27}$ Some fifteen years later, Anthony van Dyck also used finely woven linens during his time in Italy (Carol Christensen, Michael Palmer, and Michael Swicklick, "Van Dyck's Painting Technique, His Writings, and Three Paintings in the National Gallery of Art," in Anthony van Dyck, ed. Arthur K. Wheelock Jr., Susan J. Barnes, and Julius S. Held, exh. cat. [Washington, DC: National Gallery of Art, 1990], 47). The grounds of Rubens's Italian paintings are often described as darkred "bolus," but both his Italian grounds and Van Dyck's seem to have been more varied, suggesting perhaps that they used local suppliers as they traveled. For Hercules and Omphalec, 16021605; Louvre RF 1938-46), Rubens used an earth ground described as "red-orange" (Ségolène Bergeon, Science et patience, ou la restauration des peintures [Paris: Editions de la Réunion des 
musées nationaux, 1990], 233-35); for the Baptism of Christ (c. 1604-1605; Koninklijk Museum voor Schone Kunsten Antwerp, inv. no. 707), "ochre-brown" (Van Hout and Balis, Rubens Unveiled, 47); and for the Transfiguration (c. 1604-1606), now in Nancy, a double ground with a redbrown first layer and a gray upper ground (La Transfiguration de Rubens, exh. cat. (Nancy: Musée des beaux-arts, Nancy, 1990), 94, cited by Van Hout, "Meaning and Development of the Ground Layer," 224 n. 106). Van Dyck used a dark ground rich in umber for St. Rosalie Interceding for the Plague-stricken of Palermo, c. 1624; Maryan Wynn Ainsworth, Egbert Haverkamp-Begemann, John Brealey, Pieter Meyers. Art and Autoradiography: Insights into the Genesis of Paintings by Rembrandt, Van Dyck and Vermeer. New York: The Metropolitan Museum of Art, 1982, 12, plate 3, color plates $\mathrm{G}, \mathrm{H}$ ), but used lightly tinted whitish and gray grounds for two Genoese portraits, Elena Grimaldi and A Genoese Noblewoman and Her Son (1623 and c. 1626, respectively; National Gallery of Art, Washington, DC, 1942.9.92 and 1942.9.91; Christensen, Palmer, and Swicklick, "Van Dyck's Painting Technique," 47, 49: pls. 1, 3, and 4).

${ }^{28}$ National Gallery, London, inv. no. NG853.1.

${ }^{29}$ Dark lines reinforcing many of the contours were observed in figures Rubens contributed to The Battle of the Amazons, executed with Jan Brueghel c. 1598-1600, before Rubens left for Italy (Tiarna Doherty, Mark Leonard, and Jørgen Wadum, "Brueghel and Rubens at Work: Technique and the Practice of Collaboration," in Rubens \& Brueghel: A Working Friendship, ed. Anne T. Woollett and Ariane van Suchtelen, exh. cat. [Los Angeles: J. Paul Getty Museum and The Hague, The Mauritshuis, 2006], 223-4). Judging from images reproduced in that publication, these lines might have served not as an independent underdrawing but as a reinforcement to a brown painted sketch, similar to the selective reinforcement that a more confident Rubens used some years later in The Fall of Phaeton.

${ }^{30}$ The very fine particles of indigo were characterized through polarizing light microscopy by the author (see Nicholas Eastaugh, Valentine Walsh, Tracey Chaplin, and Ruth Siddall, The Pigment Compendium: Optical Microscopy of Historical Pigments [Oxford: Elsevier Butterworth Heinemann, 2004], 116-7) and confirmed by fiber optic reflectance spectroscopy (FORS) carried out by Kate Dooley. The pigment can be recognized in various areas across the painting's surface using a stereomicroscope: under high magnification it is seen as smears of dark blue in the paint matrix, rather than the individual particles typical of blue pigments such as ultramarine, azurite, or smalt. ${ }^{31}$ Jaffé, "Rediscovered Works," 416.

${ }^{32}$ Jaffé, Rubens and Italy, 36.

${ }^{33}$ Joyce Plesters has identified several types of dark grounds in paintings at the National Gallery, London: a charcoal black upper ground over a gesso lower ground (Christ Washing His Disciples' Feet, c. 1575-1580, NG 1130); a single-layer ground of ochre with mixed pigments, perhaps "palette scrapings" (The Origin of the Milky Way, c. 1575, NG 1313); and a double ground of dark palette scrapings over gesso (Portrait of Vincenzo Morosini, c. 1575-1580, NG 4004). Joyce Plesters, “Tintoretto's Paintings in the National Gallery: Part II," National Gallery Technical Bulletin 4 (1980): 36, 39, 41.

${ }^{34}$ Like a number of Tintoretto's works, this was painted on canvas prepared with a thin gesso (Joyce Plesters and Lorenzo Lazzarini, "Preliminary Observations on the Technique and Materials of Tintoretto," in Conservation of Paintings and the Graphic Arts: Preprints of Contributions to The Lisbon Congres 1972 [London: The International Institute for Conservation of Historic and Artistic Works, 1972], 155); in combination with the underlying canvas color, this would have been a mid-toned painting surface. 
${ }^{35}$ Plesters and Lazzarini, “Technique and Materials of Tintoretto," 156; Joyce Plesters, “Tintoretto’s Paintings in the National Gallery: Part I," National Gallery Technical Bulletin 3 (1979): 10-11, 1416; Plesters, "Tintoretto's Paintings in the National Gallery: Part II," 40, 43.

${ }^{36}$ Rotterdam, Museum Boijmans Van Beuningen, inv. no. 1738 (OK).

${ }^{37}$ Ovid, Metamorphoses, translated by Brookes Moore, The Theoi Classical Texts Library, HTTPS://WWW.THEOI.COM/TEXT/OVIDMETAMORPHOSES2.HTML, book 2, 319.

${ }^{38}$ Automated thread counting carried out Kelsey Wingel (as in n. 23) established that the plainweave canvas measures 9 threads $/ \mathrm{cm}$ in the warp direction and 9.4 threads/cm in the weft direction (personal communication, February 14, 2019).

${ }^{39}$ Because the ground of Hero and Leander has not been analyzed, it has not possible to establish whether the materials are identical to those analyzed in Phaeton. However, under high magnification with a stereomicroscope the appearance is comparable, suggesting that Rubens either purchased similar grounds or prepared both grounds himself. In Hero and Leander the ground has been described as "bolus," which would suggest the use of predominantly red earth, but the reddish tone seen in photographs of this painting is actually the combined color of the brown painted sketch and the lighter-colored ground below.

${ }^{40}$ Analysis of samples from The Fall of Phaeton (as in n. 30) confirms that the blue pigment is typical of indigo rather than ultramarine or smalt. Samples from Hero and Leander were not available for comparative analysis, but in magnified examination of the paint surface and in IRR the blue of Hero and Leander shows the same characteristics as the blue used for Stage 1 of The Fall of Phaeton.

${ }^{41}$ These lines are visible in IRR: in the upper center of Hero and Leander (above the angular lightning bolt and around the curved lightning) and above the far left figures in The Fall of Phaeton. ${ }^{42}$ Gregory Martin, "Hero and Leander," in Rubens: Mythological Subjects 2, Corpus Rubenianum Ludwig Burchard XI (London and Turnhout: Harvey Miller Publishers/Brepols, forthcoming). I am grateful to Gregory Martin for the opportunity to consult his draft before publication and for fruitful discussions of the issues raised by the present technical study.

${ }^{43}$ Two of these are discussed below (in n. 60 and n. 61).

${ }^{44}$ Elizabeth McGrath, "Rubens and Classical Myth: An Introduction," in Elizabeth McGrath, Gregory Martin, Fiona Healy, Bert Schepers, Carl van de Velde and Karolien de Clippel, Rubens: Mythological Subjects 1: Achilles to The Graces, Corpus Rubenianum Ludwig Burchard XI (London and Turnhout: Harvey Miller Publishers/Brepols, 2016), 43-44.

${ }^{45}$ Now in a French private collection, this work measures 89 x $135.5 \mathrm{~cm}$ (McGrath et al., Mythological Subjects 1, no. 7, 132-40).

${ }^{46}$ Both paintings have been relined with the tacking margins removed and are likely to have been slightly trimmed, which would account for small differences; The Fall of Phaeton now measures $98.4 \times 131.2 \mathrm{~cm}$ and Hero and Leander measures $95.9 \times 128 \mathrm{~cm}$.

${ }^{47}$ In first publishing the two paintings, Michael Jaffé described only their close compositional relationship (Jaffé, "Rediscovered Works," 416, 419), but in 1993 he also wrote that they were “almost certainly conceived as pendants c. 1605" (Jaffé, “Samson Destroying the Temple of Dagon: A Rediscovered Rubens," Apollo 139 [December 1993]: 382). Since then, the two paintings have been described as possible pendants by some (Wheelock, Flemish Paintings, 151; David Jaffé, Elizabeth McGrath, Amanda Bradley, Ulrich Heinen, Veronika Kopecky, and Delfina Bergamaschi, Rubens: A Master in the Making, exh. cat. [London: National Gallery, 2005], 72). Other scholars make no mention of a relationship (Held, Oil Sketches, 1:292, 589), and the two paintings 
frequently appear in adjacent discussions or catalogue entries without a relationship mentioned explicitly (for example, Peter Paul Rubens, 1577-1640, exh. cat. [Cologne: Museen der Stadt Köln, 1977], 145-6, 147-9; Guy Bauman and Walter A. Liedtke, Flemish Paintings in America: A Survey of Early Netherlandish and Flemish Paintings in the Public Collections of North America [Antwerp: Fonds Mercator, 1992], 172-4, 175-7).

${ }^{48}$ Fiona Healy and Gregory Martin each have generously discussed this point in personal communications, April 2019.

${ }^{49}$ A drawing recording Rubens's early ideas for Hero and Leander places even more emphasis on broad arcs defining the setting c. 1600-1603, National Gallery of Scotland, Edinburgh: inv. no 4936, recto; Keith Andrews, Catalogue of Netherlandish Drawings in the National Gallery of Scotland [Edinburgh: National Gallery of Scotland, 1985], 1:69-70, 2: fig. 464). Note that, based on the script used for the Latin inscription, Kristin Lohse Belkin dates this drawing to before Rubens left Antwerp, which would suggest that he developed this composition over an extended time, as he did other subjects, including The Conversion of Saint Paul, discussed below (Kristin Lohse Belkin, "Rubens's Latin Inscriptions in his Copies after Holbein's Dance of Death," Journal of the Warburg and Courtauld Institutes 52 [1989]: 246).

${ }^{50}$ The alternative explanation is that Rubens could have picked up the touch of light-blue paint from a detail on Leander, such as seafoam. However, in the only place near this stroke of lightning that he mixed wet paints, he pulled yellow paint (depicting a beam of light), and not white, through the dark-blue sky paint.

${ }^{51}$ National Gallery, London, 2005; Jaffé et al., A Master in the Making.

${ }^{52}$ The full form of this sinuous lightning bolt is now visible only in the x-radiograph. Wheelock described this as "the S-shaped curve indicating the wayward path of Phaeton's flight." Wheelock, Flemish Paintings, 153 n. 22.

${ }^{53}$ Since the evidence for the twelfth Hora is limited, no attempt was made to recreate this figure in the schematic representation of Stage 1.

${ }^{54}$ Jaffé et al., A Master in the Making, 72.

${ }^{55}$ In Aristotle's theory of the four elements, each was assigned two of four defining characteristics - hot, cold, wet, and dry. Water and fire are opposites, while in the alternative pair, air (hot, wet) is the complement of earth (cold, dry). David C. Lindberg, The Beginnings of Western Science: The European Scientific Tradition in Philosophical, Religious, and Institutional Context, Prehistory to

A.D. 1450, 2nd ed. (Chicago: University of Chicago Press, 2007), 52-56.

${ }^{56}$ Jaffé, Rubens and Italy, 97; on the Chiesa Nuova commission, see 85-99.

${ }^{57}$ Jaffé, “Samson," 378.

${ }^{58}$ Jaffé, “Rediscovered Works," 421; Hans Vlieghe, Saints, Corpus Rubenianum Ludwig Burchard VIII (London and New York: Phaidon, 1973), 2:35-38. This painting appeared in the inventory of his collections, the "Specification" (Jeffrey M. Muller, Rubens: The Artist as Collector [Princeton, NJ: Princeton University Press, 1989], 122).

${ }^{59}$ Amy Golahny, "Rubens' Hero and Leander and its Poetic Progeny," Yale University Art Gallery Bulletin (1990): 27-29. While Golahny has explored three different seventeenth-century poetic responses to Rubens's Hero and Leander composition, there is no equivalent literary record of the impression The Fall of Phaeton might have made on his contemporaries.

${ }^{60}$ Jaffé notes that this larger variant, now in Dresden (Gemäldegalerie Alte Meister, Gal.-Nr. 1002) was painted on a canvas prepared with a light-colored ground (more typical of northern practice), and not the earth ground typical of Italy. He dates the handling of the flesh tones in particular to 
around 1610 (Jaffé, "Rediscovered Works," 419-20).

${ }^{61}$ The plan for the engraving appears in a letter to Pieter van Veen, January 23, 1619 (see The Letters of Peter Paul Rubens, trans. and ed. Ruth Saunders Magurn [Cambridge, MA: Harvard University Press, 1955], 36-37). A drawing (Louvre, Inv. 20369) was presumably made in preparation for the engraving that was never executed. Based on the studio replica now in Dresden, the drawing follows numerous details that appear only in that version (Golhany, "Hero and Leander," 27 n. 18).

${ }^{62}$ In analyzing the provenance of the two versions of Hero and Leander, Jaffé lays out evidence that suggests that after Rubens used the smaller, Yale version as the model for the studio replica around 1610, it may have been among the paintings he sold to the Duke of Buckingham in 1627. A version was owned by the Duke's heirs in 1635, and measurements listed in a sale catalogue confirm that that smaller version was in England sometime later, as it appeared in the sale of Peter Lely's collection in 1682 (Jaffé, "Rediscovered Works," 420).

${ }^{63}$ See, for example, Ixion, King of the Lapiths, Deceived by Juno (c. 1611, Louvre RF2121).

${ }^{64}$ Examination at high magnification showed that, like the lightning in Hero and Leander, this original ochre paint was applied wet-in-wet with white lead paint.

${ }_{5}^{65}$ The crudely brushed green just above the Earth has yet to be deciphered, but it seems likely to have been introduced in this first revision.

${ }^{66}$ There also are no layers of surface dirt that could have documented an extended time lag between paint layers.

${ }^{67}$ Varnish has seeped from the paint loss (the void at the right edge of the sample) into the tiny gap. As this extends only a little way into the sample, it is not a complete varnish layer between the two stages, which would have been evidence that the painter considered the work completed (and ready to varnish) before the final paints were applied.

${ }^{68}$ In a comparison of three versions of The Flight of Lot and his Family from Sodom (Rubens and Studio, c. 1613-1615, The John and Mable Ringling Museum, Sarasota; Studio of Rubens, Bass Museum of Art, Miami Beach; Jacob Jordaens(?), National Museum of Western Art, Tokyo), also painted within a few years of Rubens's return to Antwerp, analysis found ultramarine used for a sky-blue sleeve in the autograph painting, but indigo was used for the comparable passage in two workshop compositions. For a darker, mauve-blue sleeve, all three used an alternative blue pigment, smalt (Nobuyuki Kamba, "Scientific Examination of the Ground, Pigments and Painting Techniques Used in Three Versions of The Flight of Lot and his Family from Sodom," in Rubens and His Workshop: "The Flight of Lot and His Family from Sodom," ed. Toshiharu Nakamura, exh. cat. [Tokyo: The National Museum of Western Art, 1994], 69-94).

${ }^{69}$ Without further sampling and analysis this difference cannot be characterized in more detail, but it is interesting to note that although white lead was manufactured by the same process in the north and the south, there is evidence that differences in purification methods made white lead produced in Venice different from the northern product (Barbara Berrie and Louisa Matthew, "Lead White from Venice: A Whiter Shade of Pale?" in Studying Old Master Paintings, Technology and Practice, ed. Marika Spring [London: Archetype Publications, 2011], 295-301; on the effects of various production methods for white lead, see Maartje Stols-Witlox, "From Reading to Painting': Authors and Audiences of Dutch Recipes for Preparatory Layers for Oil Painting, Early Modern Low Countries 1 [2017]: 201-10).

${ }^{70}$ Petria Noble, Jaap J. Boon, and Jørgen Wadum. "Dissolution, Aggregation and Protrusion: Lead Soap Formation in 17th-Century Grounds and Paint Layers," ArtMatters: Netherlands Technical 
Studies in Art 1 (2002): 46-61. On lead soaps in lead-tin yellow specifically, see Catherine Higgitt, Marika Spring, and David Saunders, "Pigment-medium Interactions in Oil Paint Films containing Red Lead or Lead-Tin Yellow." National Gallery Technical Bulletin 24 (2003): 75-95.

${ }^{71}$ As in n. 12.

${ }^{72}$ Liechtenstein, The Princely Collections, Vaduz-Vienna, inv. no. GE-40; Justus Müller Hofstede, "An Early Rubens Conversion of Saint Paul: The Beginning of his Preoccupation with Leonardo's Battle of Anghiari," The Burlington Magazine 106, no. 732 (1964): 94-103; 105-106. In 2000, Daniel Fabian presented results of his technical study of the Liechtenstein Conversion at a conference on Rubens's painting practices at the Rubenianum. The painting is on an oak panel, prepared with a white ground and an imprimatura of lead white toned with black and earth pigments (personal communication, February 25, 2019).

There is disagreement in the literature on both this Conversion and Rubens's early Judgment of Paris (National Gallery, London, 6379) as to whether he painted either work in Antwerp shortly before he left for Italy, or in Italy shortly after he arrived. He used oak panels for both, but as Gregory Martin noted, he also used oak for St. Helena (now in Grasse), which was commissioned in Italy in 1601 (Gregory Martin, The Flemish School: Circa 1600-Circa 1900 [London: National Gallery, 1970], 213-15). These oak panels, and in particular the light-colored double ground used for the Conversion, seem characteristic of painting supplies available in Antwerp. However, it is possible that Rubens brought a stock of materials with him when he traveled to Italy and used these for some of his earliest Italian paintings.

${ }^{73}$ Pierre Génard, P. P. Rubens: Aanteekeningen over den grooten Meester en zijne bloedverwanten (Antwerp: Boekhandel van P. Kockx, 1877), 373.

${ }^{74}$ Müller-Hofstede, "An Early Rubens," 97.

${ }^{75}$ As in $\mathrm{n} .19$.

${ }^{76}$ The author examined the oil sketch and painting in 2000 and in 2017 using a stereomicroscope, and by consulting $\mathrm{x}$-radiographs and IRR images on file. The drawing was examined in 2017 with an Eschenbach handheld microscope equipped with an auxiliary lens giving magnification up to $25 \mathrm{x}$; a transmitted-light IRR was available for comparison. X-radiography was carried out by Robert Bruce Gardner in 2007. Infrared reflectograms were captured by Clare Richardson and Kate Stonor using an Osiris camera (InGaAs detector array with a spectral sensitivity of 900-1700 $\mathrm{nm})$.

${ }^{77}$ Richardson and Stonor, forthcoming.

${ }^{78}$ The freedom of the revisions has also been noted in other examples of Rubens revising his own earlier paintings. In The Prodigal Son (1618; Koninklijk Museum voor Schone Kunsten Antwerp, inv. no. 781), Van Hout and Balis described the handling in revisions as "slapdash" and suggested this was more characteristic of works from his last decade (Van Hout and Balis, Rubens Unveiled, 77-79). However, the early examples described here suggest that throughout his career he used such free brushwork in moments of informal experimentation.

${ }^{79}$ Many authors propose that the drawing preceded the oil sketch: Held, Oil Sketches, 578-80; Antoine Seilern, Flemish Paintings \& Drawings at 56 Princes Gate, London SW7 (London: Shenval Press, 1955), 34-38; Seilern, Corrigenda \& Addenda to the Catalogue of Paintings \& Drawings at 56 Princes Gate, London SW7 (London: Shenval Press, 1971), 25; David Freedberg, Rubens: The Life of Christ After the Passion, Corpus Rubenianum VII. (London: Harvey Miller, 1984), 121-22; Friso Lammertse and Alejandro Vergara, Rubens: Painter of Sketches, exh. cat. (Madrid: Museo del Prado; Rotterdam: Museum Boijmans Van Beuningen, 2018), 80-81; and Jaffé et al., A Master 
in the Making, 152-54. Stephanie-Suzanne Durante described the conflicting opinions on the sequence of oil sketch and drawing and suggested that Rubens might have created still another preparatory work before the final painting. Stephanie-Suzanne Durante, "The Conversion of Saint Paul," in Peter Paul Rubens: A Touch of Brilliance: Oil Sketches and Related Works from The State Hermitage Museum and the Courtauld Institute Gallery, exh. cat. (London: Courtauld Institute of Art, 2003), 67.

${ }^{80}$ Held, Selected Drawings, 93-94: pl. 60; Freedberg, Life of Christ After the Passion, 118-20.

${ }^{81}$ Richardson and Stonor, forthcoming.

${ }^{82}$ Rubens also later revised the sky of The Conversion of Saint Paul, and this may have been when he repainted the horses with their present, darker colors. Held proposed that around 1620, as Rubens undertook a new version of the subject in the oil sketch now in Oxford, he made extensive revisions to the upper part of the painting and perhaps to some of the figures: Held, Oil Sketches, 1:580-82; Freedberg, Life of Christ After the Passion, 129-31. Richardson and Stonor consider this question more deeply (Richardson and Stonor, forthcoming).

${ }^{83}$ In another intriguing analogy, he seems to have narrowed the focus of the light emanating from the heavens by covering over rays at the left and right with dark paint, as he did in Phaeton.

${ }^{84}$ Musée Bonnat, Bayonne, inv. no. 1441; Held, Selected Drawings, 93, pl. 58.

${ }^{85}$ As in $\mathrm{n}$. 18. The author examined the painting in 2000 and 2017 using a stereomicroscope and consulting $\mathrm{x}$-radiograph and IRR images on file (x-radiography was carried out by Aviva Burnstock in 2016 at $20 \mathrm{kev}, 4.3 \mathrm{~mA}$ and 60 second exposures. Infrared reflectogram as in n. 76). There is disagreement in the literature on the function of the Courtauld painting: Held included it in his catalogue of the oil sketches but noted that the severely worn surface may contribute to its "sketchy" appearance: Held, Oil Sketches, 1:333-34, 2: pl. 245. To this observer, it seems more like a damaged painting than a sketch. The painting's heavily abraded surface suffered from old restorations. At some time in the past it was completely repainted, overpaint that was removed some time before 1955 (Seilern, Flemish Paintings \& Drawings, 32).

${ }^{86}$ Fitzwilliam Museum, inv. no. PD.8-1979.

${ }^{87}$ Von Sonnenburg, for example, emphasizes the efficiency of reusing motifs and established techniques in the context of a busy workshop ("Rubens' Bildaufbau und Technik, II", 187).

\section{Recommended Citation}

E. Melanie Gifford, "Rubens's Invention and Evolution: Material Evidence in The Fall of Phaeton," Journal of Historians of Netherlandish Art 11:2 (Summer 2019) D0l: 10.5092/jhna.2019.11.2.1 